\title{
THE IMPACT OF LIPID PERCENTAGE ON FIBROUS CAP STABILITY IN ATHEROSCLEROTIC LESIONS
}

\author{
A Thesis \\ Presented to \\ The Faculty of California Polytechnic State University, \\ San Luis Obispo
}

\begin{abstract}
In Partial Fulfillment
of the Requirements for the Degree

Master of Science in Engineering with a specialization in Biomedical

Engineering
\end{abstract}

by

Anita Lorraine Crompton

January 2009 
(C) 2009

Anita Lorraine Crompton

ALL RIGHTS RESERVED 


\section{COMMITTEE MEMBERSHIP}

TITLE: The Impact of Lipid Percentage on Fibrous Cap Stability in Atherosclerotic Lesions

AUTHOR: Anita Lorraine Crompton

DATE SUBMITTED: January 2009

COMMITTEE CHAIR: Robert Crockett, PhD

COMMITTEE MEMBER: David Clague, PhD

COMMITTEE MEMBER: Kristen Cardinal, PhD 


\begin{abstract}
The Impact of Lipid Percentage on Fibrous Cap Stability in Atherosclerotic Lesions

Anita Lorraine Crompton
\end{abstract}

Coronary artery disease (CAD) is a common cause of sudden cardiac death. Much of the disease is not completely understood, which makes treatment and prevention difficult. Many researchers are using technology, such as advanced imaging techniques and finite element analysis, to better understand the disease. While there is much progress being made to look at the analysis of actual excised diseased arteries, there is still not a standardized model to predict the future of any one lesion. The purpose of this study is to explore the possibility of creating a standardized model to predict the mechanical stability of the fibrous cap due to lipid content in atherosclerotic lesions. 
TABLE OF CONTENTS

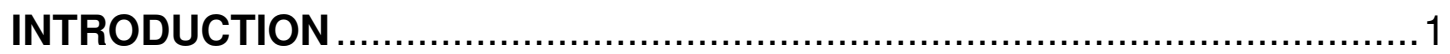

CHAPTER ONE: ATHEROSCLEROSIS PROGRESSION AND

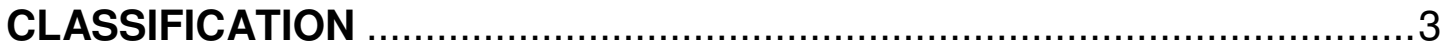

NORMAL ARTERY ANATOMY AND PHYSIOLOGY ..............................

PROGRESSION OF ATHEROSCLEROSIS ...........................................

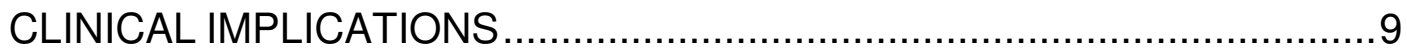

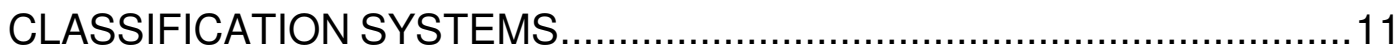

CHAPTER TWO: USING TECHNOLOGY TO DISCOVER PLAQUE

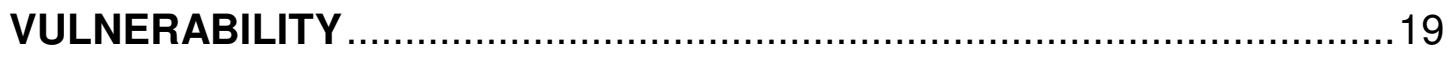

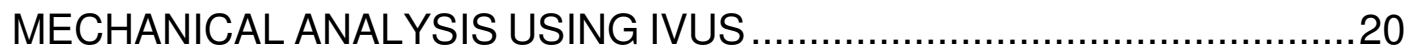

MECHANICAL ANALYSIS USING MR IMAGING …............................22

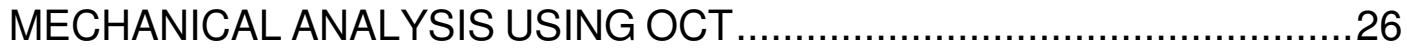

CHAPTER THREE: THE IMPACT OF LIPID PERCENTAGE ON FIBROUS

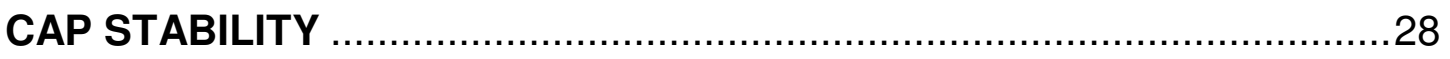

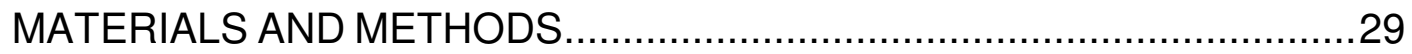

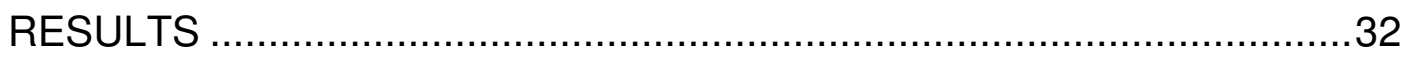

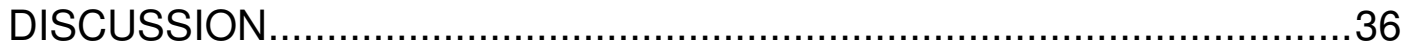

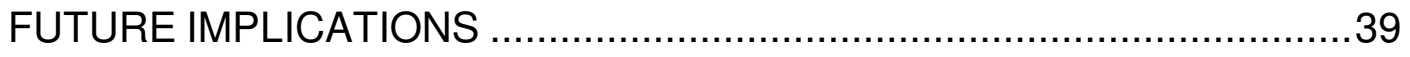


APPENDIX .

REFERENCES.

.78 


\section{LIST OF FIGURES}

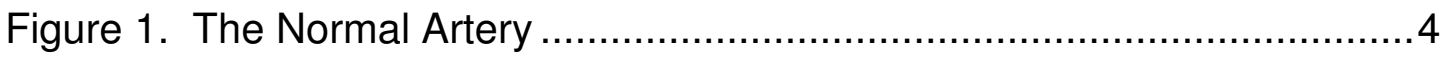

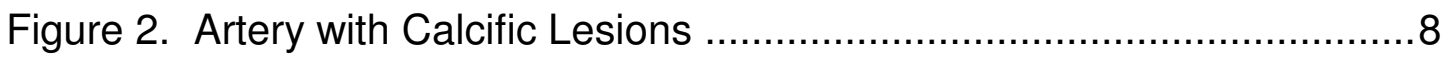

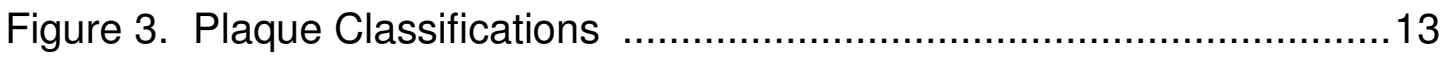

Figure 4. Types of Vulnerable Plaque ....................................................15

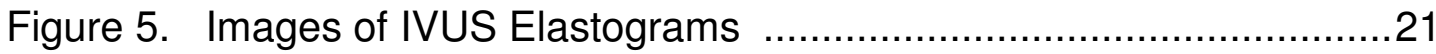

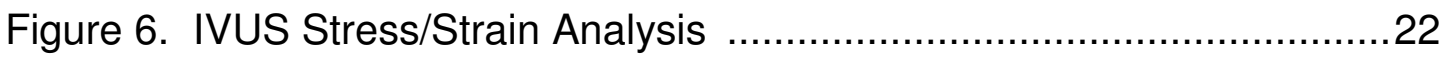

Figure 7. FEA Geometries Based on MR Images ...................................23

Figure 8. Maximum Stresses of Vulnerable Plaques ................................24

Figure 9. Analysis of Plaque Deformation ............................................27

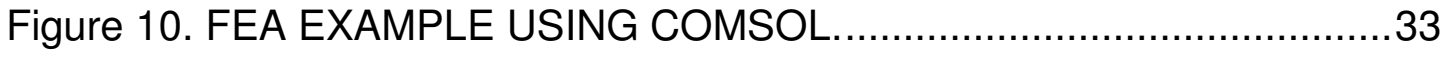

Figure 11. FEA Results with a $65 \mu \mathrm{m}$ Fibrous Cap....................................34

Figure 12. FEA Results with a $100 \mu \mathrm{m}$ Fibrous Cap..................................34

Figure 13. FEA Results with a a 200 um Fibrous Cap...............................35

Figure 14. FEA Results with a 250 m Fibrous Cap..................................35 


\section{LIST OF TABLES}

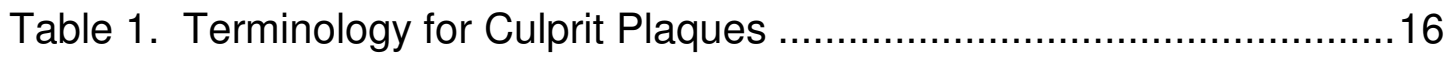

Table 2. Risk Factors for Vulnerable Plaques.........................................17

Table 3. Elastic Modulus of Artery and Lesion Components .......................31 


\section{INTRODUCTION}

Coronary artery disease (CAD) is the leading cause of death in United States. CAD is simply described as the lack of oxygen transport to the myocardium due to the inefficiency of the coronary artery to correctly transport blood. Because the heart is a vital muscle to the transport oxygen, nutrients, and waste throughout the body, coronary artery disease can often be fatal. Many efforts have been made to prevent deaths due to this disease; however there are still much needed improvements on current treatment and preventative methods. Atherosclerosis can cause CAD when plaque builds up in the lumen of arteries that provide blood to the heart. Eventually, this buildup can significantly (or completely) close the lumen and disrupt efficient blood flow. It can also fissure or rupture, causing the formation of a thrombus that can eventually get caught elsewhere in the vascular system.

When the heart muscle is not receiving enough blood, angina pectoris can occur, which causes chest pain, but is not immediately fatal to the myocardial cells. If the myocardial cells do not receive enough blood for long periods of time, they can die, causing a myocardial infarction. This is a very serious complication of CAD as it is often fatal.

In order to prevent myocardial infarctions doctors may choose from either minimally invasive clinical treatments, such as angioplasty or stents, or more 
invasive open-chest surgery. In severe cases, bypass surgery can be performed, where the surgeon takes a part of the patient's saphenous vein and "re-routes" the bloodstream past the blockage. Although bypass surgery is usually successful, there may be limitations on the availability of a healthy saphenous vein due to a limited supply and other possible diseases. While synthetic grafts are used in some areas of the body, they are not able to be used for coronary arteries due to their small diameter. If disease behavior and biomechanics could be better understood, dangerous disease states could be detected early and accurately. With this knowledge, doctors would be able to provide safer and more effective treatment.

Although clinical knowledge of atherosclerosis has rapidly increased over the last couple of decades, it is still very difficult to predict its progression in a specific patient. Research in vascular physiology and physical and numerical modeling may one day allow for significantly more effective disease detection and treatment. This paper discusses the progression of atherosclerosis, the mechanical properties of the tissues involved, and the vulnerable states of the disease. A finite element method is then used to test the vulnerability of different lesion morphologies, followed by a discussion of how the model can be applied clinically. 


\section{CHAPTER ONE: ATHEROSCLEROSIS PROGRESSION AND CLASSIFICATION}

Atherosclerosis is a disease that affects the tunica intima (the innermost layer) of arteries. Unfortunately, much about the physiologic initiation and progression of the disease is still not understood. Many theories have evolved over time, and today it is agreed upon that inflammation plays a major role.

\section{NORMAL ARTERY ANATOMY AND PHYSIOLOGY}

The cardiovascular system is extremely important to the human body, as the circulation of blood to every cell in the body is necessary for survival. Since oxygen can only diffuse freely $200 \mu \mathrm{m}$, the vascular system must be able to pump blood to every cubic centimeter of the body. In addition to the large amount of capillaries necessary to reach every cell, the heart must be efficient enough to pump blood through the entire arterial system. In order for the heart to be efficient, is necessary for the vascular system to also deliver oxygen-rich blood to the myocardial cells.

This system is composed of many arteries and veins that allow blood to flow between the heart, lungs, and other tissues in the body. Arteries are the vessels responsible for delivering blood from the heart to all the tissues in the 
body; therefore, normal function is of great importance. Arteries are composed of three concentric layers, or tunics: the intima, media, and adventitia. The intima is the innermost layer and makes up the lumen of the vessel. It contains a monolayer of endothelial cells that continue from the endocardium of the heart. Because it is in direct contact with flowing blood, the endothelium provides a low friction interface that discourages platelets from coagulating. The middle layer, or media, is the thickest layer in these arteries and contains smooth muscle cells and elastin that control vasodilation and vasoconstriction. These cells are what give the vessel most of its tensile strength. The outer layer, called the adventitia, surrounds the vessel and contains collagen fibers which aid in protection and reinforcement. A normal artery can be seen in Figure 1.

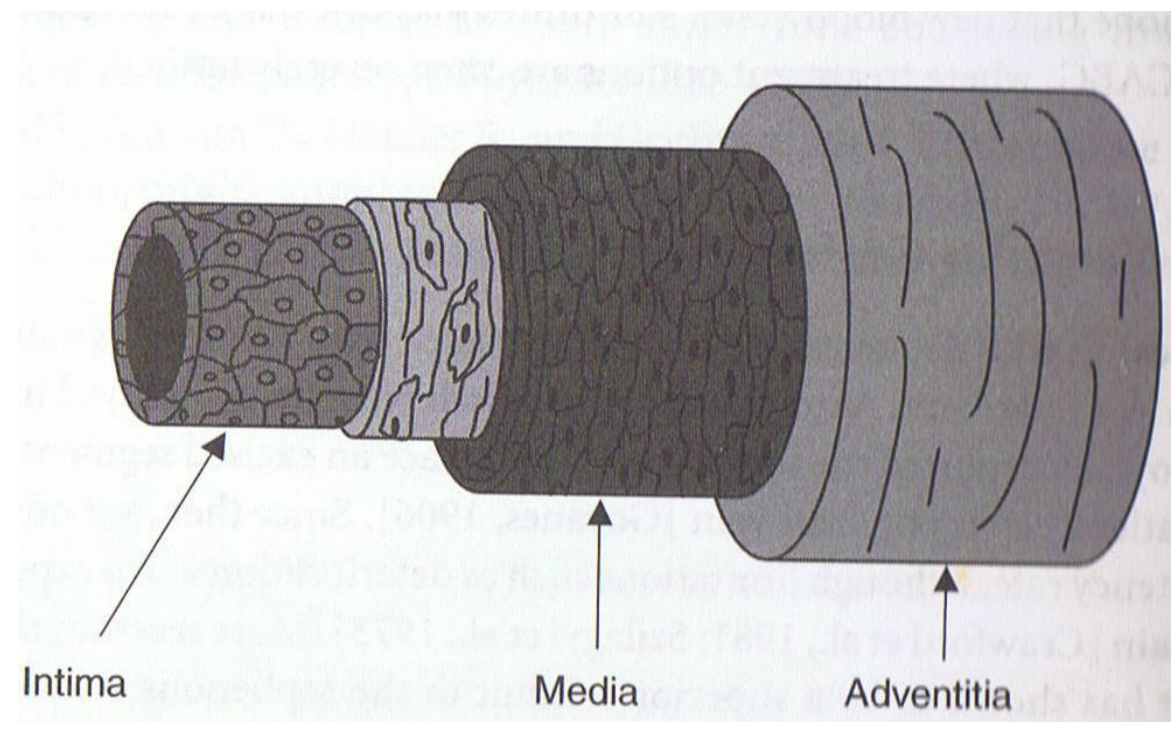

Figure 1. THE NORMAL ARTERY A healthy artery consists of three tunics: the intima, media and adventitia. The intima contains the endothelial lining, which has nonthrombogenic properties and is in direct contact with the blood. 


\section{PROGRESSION OF ATHEROSCLEROSIS}

The development of a clinically significant atherosclerotic lesion typically takes decades, and there are many types of lesions and factors involved in disease progression. Plaque buildup due to atherosclerosis is thought to be an inflammatory response that builds up smooth muscle cells, calcium, and other products over time.

The initiation of a lesion is due to the adhesion of mononuclear leukocytes to the endothelium. The exact reason for this is unknown, but it is believed that a disruption in the endothelial lining, possibly due to normal blood flow or infection, may cause this inflammatory response. However, there is also speculation that the adhesion of leukocytes can happen without endothelial disruption, so the subject still remains somewhat controversial. After adhering to the endothelial lining, the leukocytes are drawn into the intima by chemoattractants. This causes a local inflammatory response, and the leukocytes become macrophages. The macrophages then engulf lipids and become foam cells. This phagocytosis can happen when low density lipoproteins from the blood plasma become oxidized and bind to the macrophages. An accumulation of these foam cells is typically referred to as a fatty streak, which is the initial precursor to the progression of advanced atherosclerosis. Fatty streaks are present in the first decades of life, and some research even shows that initial fatty streaks can be present upon birth. 
It is possible for a disease state consisting of fatty streaks to completely reverse, so is not considered clinically dangerous. As the disease progresses, lipoproteins accumulate beneath the endothelial lining. This may happen after the lipoproteins are released by necrotic subendothelial foam cells. The exact reason for the death of foam cells is unknown, but it may be due to signals that cause the cells to undergo apoptosis. An accumulation of lipoproteins underneath the endothelial lining is termed atheroma.

As time and accumulation of foam cells progresses, growth factors are released that encourage the growth of smooth muscle cells and fibrous tissue. The smooth muscle cells produce an extracellular matrix which contributes to the fibrous properties of a more advanced lesion. Collagen and smooth muscle cells grow around the atheromatous core to help prevent its clotting factors from coming into contact with the bloodstream, and a fibrous cap develops. This is often thought to help stabilize the lesion, but is also a controversial issue. A lesions containing an atheromatous core surrounded by a fibrous cap is a fibroatheroma. A fibroatheroma may have multiple lipid pools surrounded by fibrous tissue. The thickness and mechanical properties of the fibrous tissue varies greatly between lesions and is largely dependent on biological factors.

Some lesions develop calcific regions, which can be located anywhere within the lesion, but are usually closer to the media. The exact mechanism of this 
calcification is unknown, but some researchers hypothesize that it may be due to the mineralization of vesicles from dead cells. Another speculation is that smooth muscle cells produce proteins that promote bone formation and mineralization. 
(a) MR image of a plaque

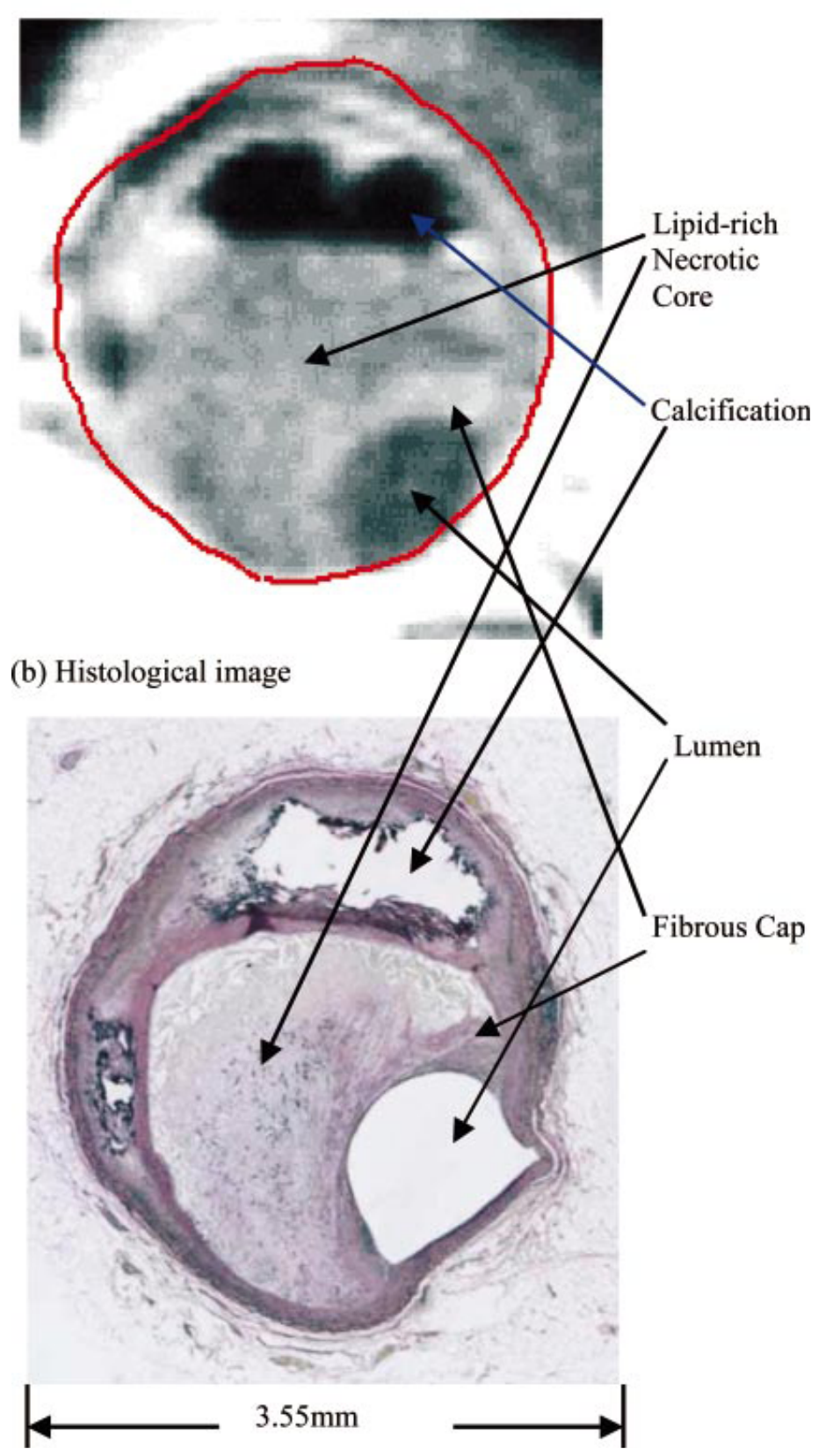

Figure 2. ARTERY WITH CALCIFIC REGIONS MRI and histological image from a study done by Tang et al. (a) MR image (b) histological image ${ }^{44}$

Figure 2 shows a histological image and its corresponding MRI of an atherosclerotic lesion containing an atheroma, fibrous cap, calcium. The 
morphology of each lesion varies greatly between each person, and can even vary between arteries in the same person. Efforts are currently being made to discuss methods of classifying these morphologies so that clinicians can better choose the proper treatment for their patients.

\section{CLINICAL IMPLICATIONS}

An atherosclerotic lesion becomes clinically relevant when it causes stenosis of the lumen, or becomes likely to rupture or cause a thrombus. A severely stenosed lumen can be debilitating, especially when it is in the coronary arteries and causes angina pectoris. If the fibrous cap ruptures, a thrombus will most likely form when blood is exposed to clotting factors below the endothelial surface. The thrombus may occlude the artery at the lesion site, or break loose, get caught and inhibit blood flow elsewhere.

There are many possible causes for plaque rupture. One possible cause is stress on the intimal lining due to normal physiologic stresses, such as blood flow. The constant pulsatile flow of blood causes fatigue and weakens the fibrous cap over time. High blood pressure can impose a greater than normal stress, and thus is a risk factor for plaque disruption. Hemodynamic (shear) stresses usually do not facilitate plaque rupture since the mechanical stresses due to the pulsatile flow of blood exceed any stresses related to the 
circulation of blood. Other triggers may be internal; for instance, newly formed thin walled blood vessels inside the plaque may bleed into the lesion and cause internal pressures on the fibrous cap.

Lesions which are prone to rupture include those with large lipid pools, thin fibrous caps, and caps with low collagen content. Large atheromatous cores are typically classified as those in which the lipid pool occupies $40 \%$ or more of the plaque. Since the lipid core is softer than the fibrous cap, it does not absorb nearly as much stress. This extra stress on the fibrous cap can cause it to rupture. The size of the fibrous cap varies greatly between lesions, as does the thickness required to consider a cap stable. For instance, the range of cap thickness of stable coronary lesions can range from $65 \mu \mathrm{m}$ to $250 \mu \mathrm{m}$, depending on the mechanical properties of the fibrous tissue of the cap. Caps that have higher collagen content and more smooth muscle cells, which make collagen, are more stable because they can handle a greater mechanical load without rupturing. Plaques that contain a considerable number of macrophages tend to be weaker due to the capability of the macrophages to degrade the extracellular matrix. Plaques are thinner and have weaker mechanical properties at the shoulders of the lesion, so this is a common site for disruption of the fibrous cap.

Just as many factors can cause plaque vulnerability, many factors are involved with plaque stability. Stable plaques include those with thicker 
fibrous caps and high collagen content, and also plaques that greatly stenose the arterial lumen. It is important to note, however, that lesions which cause a great degree of stenosis may still be clinically relevant due to their ability to cause ischemia. They are also exposed to shear stresses far greater than normal, so hemodynamic flow may cause cap rupture in this case. Plaques which contain calcium deposits are sometimes thought to be more stable because they take some of the mechanical load off of the fibrous cap. This, however, is still up for debate and is not yet proven.

\section{CLASSIFICATION SYSTEMS}

Many researchers have attempted to provide a classification system to draw correlations between plaque stability, cellular content and progression of the disease. The American Heart Association, through the work of H. C. Stary et al., developed a classification system in 1995 based on disease progression. This system divided the disease into six different states, the first three of which were considered early and stable, and the last three of which were considered advanced and vulnerable. The first three types, named type I, type II, and type III, described the disease progression from initiation, to fatty streaks and dots, and finally to the accumulation of a lipid core. The types beyond type III are considered advanced lesions and clinically relevant. 
Once the lesion has a considerable lipid core, it is considered a type IV lesion, which is the first of the advanced lesions. This legion contains a large accumulation of foam cells, which make up an eccentric lipid core visible to the naked eye, but does not normally narrow the lumen. It also has not yet developed a significant increase in smooth muscle cells or fibrous tissue. As far as mechanical stability, this type of lesion may be prone to fissure because of the lack of a strong fibrous cap.

A lesion is considered to be type $\mathrm{V}$ if it has a decent amount of other materials, such as fibrous tissue or calcium, but it may or may not have a lipid core. A fibroatheroma (lipid core surrounded by a fibrous cap) is a type Va lesion. This also includes multilayered fibroatheromas (multiple atheromas layered in the intima and fibrous caps in between them). If the lesion contains calcific regions, it is termed type $\mathrm{Vb}$. A lesion with minimal lipid content that lacks a lipid core is a type $\mathrm{Vc}$ lesion. It could be made up of either fibrous tissue or mineralized deposits.

Lesions of types IV and V become type VI lesions when they develop disruptions such as a fissure, rupture, hematoma, or formation of a thrombus. Stary et al. refer to this type as a complicated lesion. A disruption of the surface makes the lesion type Via; a hematoma or hemorrhage, type Vlb; and formation of a thrombus, type VIc. Any lesion can also contain more than one 
of these features, making it a type Vlab, Vlac, Vlbc, or Vlabc. The plaque ruptures of type VI lesions are what cause clinical events.
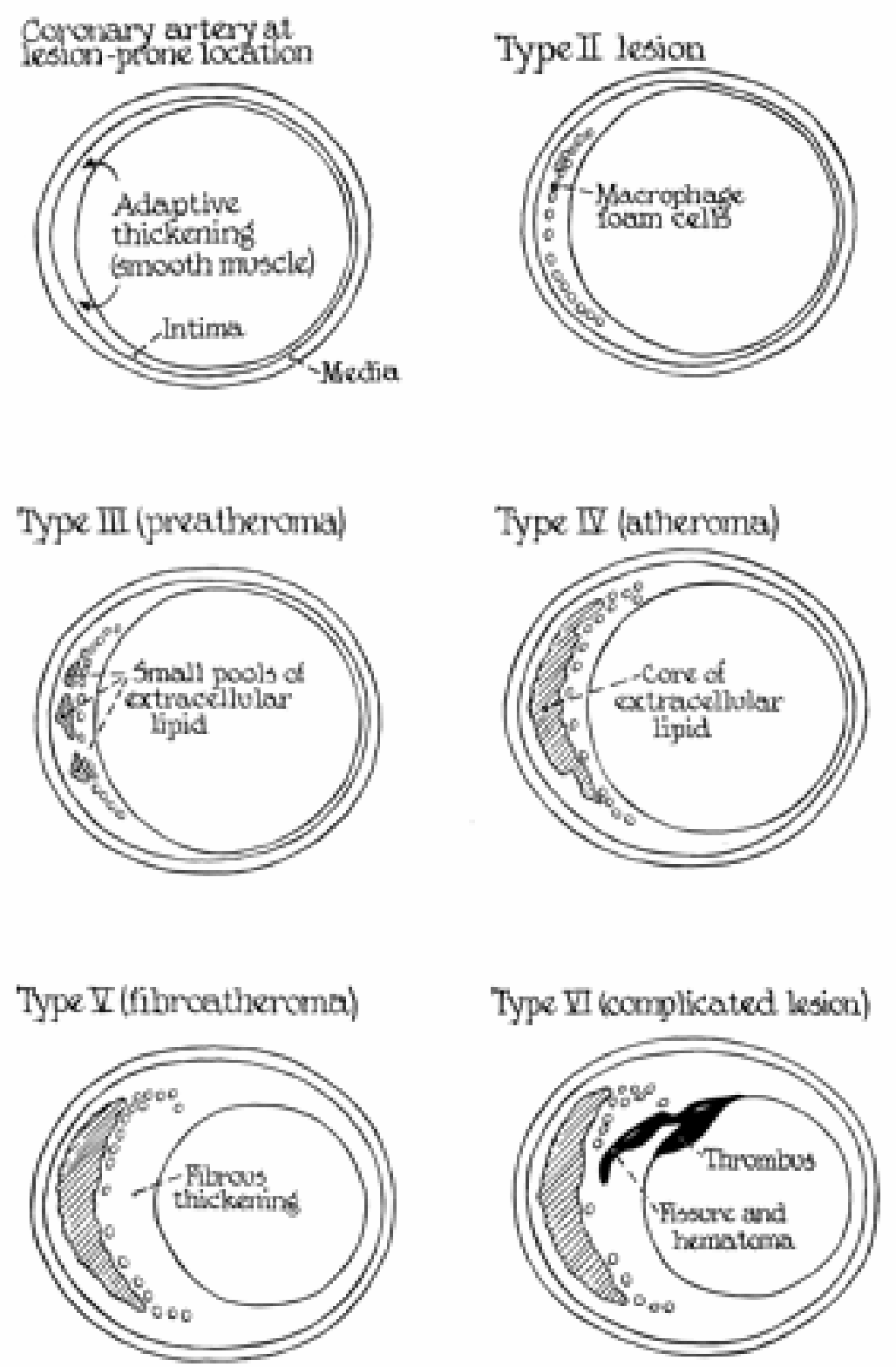

Figure 3. PLAQUE CLASSIFICATIONS Cross sections of each type of lesion as described by Stary et al. ${ }^{43}$ 
Cross sections of each type of lesion described by Stary et al. are shown in Figure 3. This classification system has been used to classify atherosclerosis in many studies since its creation in 1995; however, recent developments in the understanding of the disease have led some researchers to develop different techniques for determining the clinical relevance of various disease states.

In 2003, the American Heart Association published an article by Morteza Naghavi et al. that focused on plaque vulnerability rather that disease progression. This system makes some sense since it is the vulnerable lesions that are the most clinically relevant. Their system uses nomenclature to describe lesions, rather than lumping lesions into different classifications. A combination of major and minor risk factors is used to describe the risk of plaque rupture. These risk factors be due to the physical properties of the lesion, and can also be due to the physiologic state of the patient (such as those prone to platelet coagulation and hypertension). Figure 4 is used by the group to outline different types of vulnerable plaque based on the physical properties of the lesion. It is the intent of this system to treat each physical property of the lesion as a separate risk factor that may or may not develop in a specific order. This way, each lesion can be defined according to its exact physical elements, without implying how long the lesion has been present. 


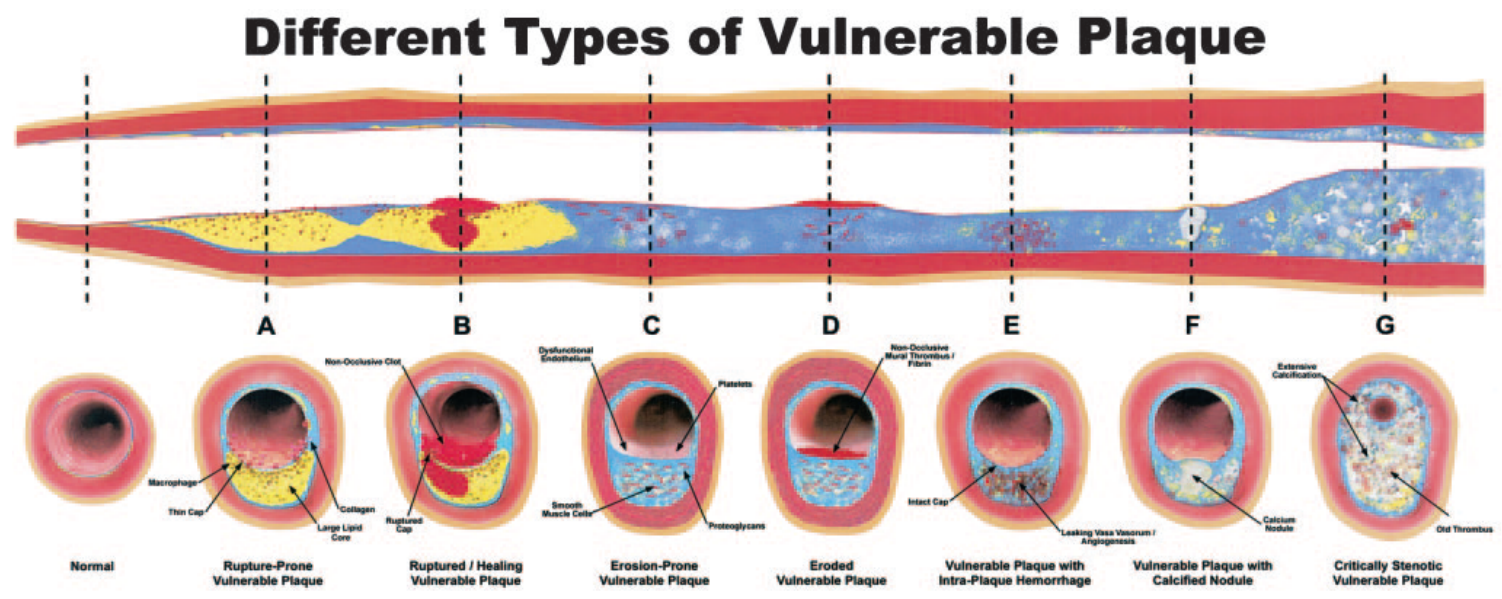

Figure 4. TYPES OF VULNERABLE PLAQUE Examples of different types of vulnerable plaque as described by Naghavi et al. ${ }^{34}$

Naghavi et al. also aimed to unify the somewhat subjective research language. They thought that the adjectives used by researches to describe histology and plaque vulnerability could have different meanings, depending on who used them. Their proposed definitions are as follows:

Culprit plaque: A plaque that has caused a coronary occlusion and death.

Vulnerable plaque: A plaque including risk factors that make it succeptible to becoming a "culprit" plaque.

Table 1 by Naghavi et al. describes many previously used terms to describe the sort of plaque disruption that caused a culprit plaque. 
Table 1: Terminology for Culprit Plaques

\begin{tabular}{lcc}
\hline Author & Year & Description Used \\
\hline Olcott & 1931 & Plaque rupture \\
Leary & 1934 & Rupture of atheromatous abscess \\
Wartman & 1938 & Rupture-induced occlusion \\
Horn & 1940 & Plaque fissure \\
Helpern & 1957 & Plaque erosion \\
Crawford & 1961 & Plaque thrombosis \\
Gore & 1963 & Plaque ulceration \\
Byers & 1964 & Thrombogenic gruel \\
Chapman & 1966 & Plaque rupture \\
Constantinides & 1966 & Plaque rupture \\
\hline
\end{tabular}

Table 2. Different terminology used to describe culprit plaques, as researched by Naghavi et al. ${ }^{34}$

After describing the difference between culprit and vulnerable plaque, Naghavi et al. outlined some risk factors for vulnerable plaque. The major risk factors are shown in Table 2. They include active inflammation, a thin fibrous cap with a large lipid core, surface disruption with superficial platelet aggregation, fissured or injured plaque, and severe stenosis. A thin fibrous cap in this classification system has a width of $100 \mu \mathrm{m}$ or less, and a large lipid core is one that makes up $40 \%$ or more of the lesion volume. They consider severe stenosis as a major risk factor because shear stress on the plaque surface increases with the narrowing of the lumen. 


\section{Table 2: Risk Factors of Vulnerable Plaque}

Major

\begin{tabular}{|l|l|}
\hline Active Inflammation & $\begin{array}{l}\text { Superficial calcified modules } \\
\text { (close to fibrous cap) }\end{array}$ \\
\hline $\begin{array}{l}\text { Thin fibrous cap }(<100 \mu \mathrm{m}) \text { with large lipid } \\
\text { core }(>40 \% \text { of plaque volume) }\end{array}$ & $\begin{array}{l}\text { Yellow color seen during } \\
\text { angioplasty }\end{array}$ \\
\hline $\begin{array}{l}\text { Surface disruption and superficial platelet } \\
\text { aggregation }\end{array}$ & Intraplaque hemorrhage \\
\hline Fissured or injured plaque & Endothelial dysfunction \\
\hline Severe stenosis & $\begin{array}{l}\text { Positive (toward tunica media) } \\
\text { remodeling }\end{array}$ \\
\hline
\end{tabular}

Table 3. Major and minor risk factors for vulnerable plaque determined by Naghavi et al.

The minor risk factors outlined in the group's work are also outlined in Table

2. They include: superficial calcified nondules, yellow color on angioscopy, intraplaque hemorrhage, endothelial dysfunction, and positive remodeling. If calcium nodules are located near the cap instead of on the medial side of the lesion, they can protrude through the cap, causing rupture. A yellow color on angioscopy can denote a large lipid core and thin fibrous cap, in which case it could be a major risk factor. An intraplaque hemorrhage can disrupt the plaque stability. Endothelial dysfunction is considered a minor risk factor due to the possibility of inflammation and the observed correlation to coronary disease and stroke. Remodeling of the intima that preserves the lumen and instead expands the artery can be seen as a minor risk factor due to the correlation of clinical events with non stenosed arteries. These minor risk 
factors, while not a direct precursor to coronary events, have been observed in arteries undergoing coronary events, so they are worth noting in the prediction of plaque vulnerability.

This method of describing atherosclerosis provides detailed communication between researchers. It seems that in recent years, scholars in the field have started to shy away from the popular Stary et al. "type" classification system, and have instead defined lesions based on their individual properties. For the purposes of this paper, individual traits will be used to describe various lesions. 


\section{CHAPTER TWO: USING TECHNOLOGY TO DISCOVER PLAQUE VULNERABILITY}

The use of technology to diagnose high risk states of atherosclerosis is a growing field of research. Currently, angiography and the diagnosis of patient risk factors are the only methods of predicting potentially fatal clinical events. Angiography comes with a great possibility of risk to the patient because of its invasive nature. One major drawback is that it only allows the physician to observe the endothelial lining of the lesion, which means he/she can not determine much other than the degree of stenosis.

The identification of patient risk factors allows for correlation to plaque vulnerability, and may aide in the prediction of a clinical event, but it does not perfectly predict that possibility. Many researchers are attempting to develop non-invasive techniques for the diagnosis of vulnerable disease states by finding correlations between medical images and mechanical stability. Images can be combined with previous knowledge about physical properties of lesions and vulnerability to predict more accurately the behavior of a specific lesion.

Medical images, such as MRIs, provide entire cross sections of arteries with lesions. They show great promise in distinguishing between the different materials of the plaque, and are already a widely used diagnostic tool. Not 
only is it a great non-invasive technique for looking at tissues inside the body, but it can also pick up on materials not visible to the naked eye. The media used to scan can vary depending on the image type. For instance, ultrasound and MR techniques use harmless sound and magnetic waves to determine the shape of the tissue of interest, while CT and fluoroscopy techniques use radiation. The type of imaging used depends on the make-up and density of the tissue of interest. In the vascular field, a few techniques are currently being researched to determine lesion composition. These include ultrasound (US), magnetic resonance (MR) imaging, and optical coherence tomography (OCT).

Research is being done to correctly correlate images with known mechanical properties for use in finite element analysis. This may sound like straightforward research in theory, but the numerous combinations of lesion materials and mechanical properties makes data unification pretty difficult. The aim of this chapter is to explore current research in each of these areas, and consider how they are capable of fitting together.

\section{MECHANICAL ANALYSIS USING IVUS}

Intravascular ultrasound (IVUS) elastography can be used as a functional imaging technique, because it allows for both visualization of lesion components and compressive radial strain. An example of an IVUS 
elastogram is shown by Figure 5, which was produced in a study done by Radj A. Baldewsing et al. The figure shows the elastograms with the corresponding histological images of the excised arteries used. They compared this elastogram with a finite element analysis done on a geometry obtained from the ultrasound image.
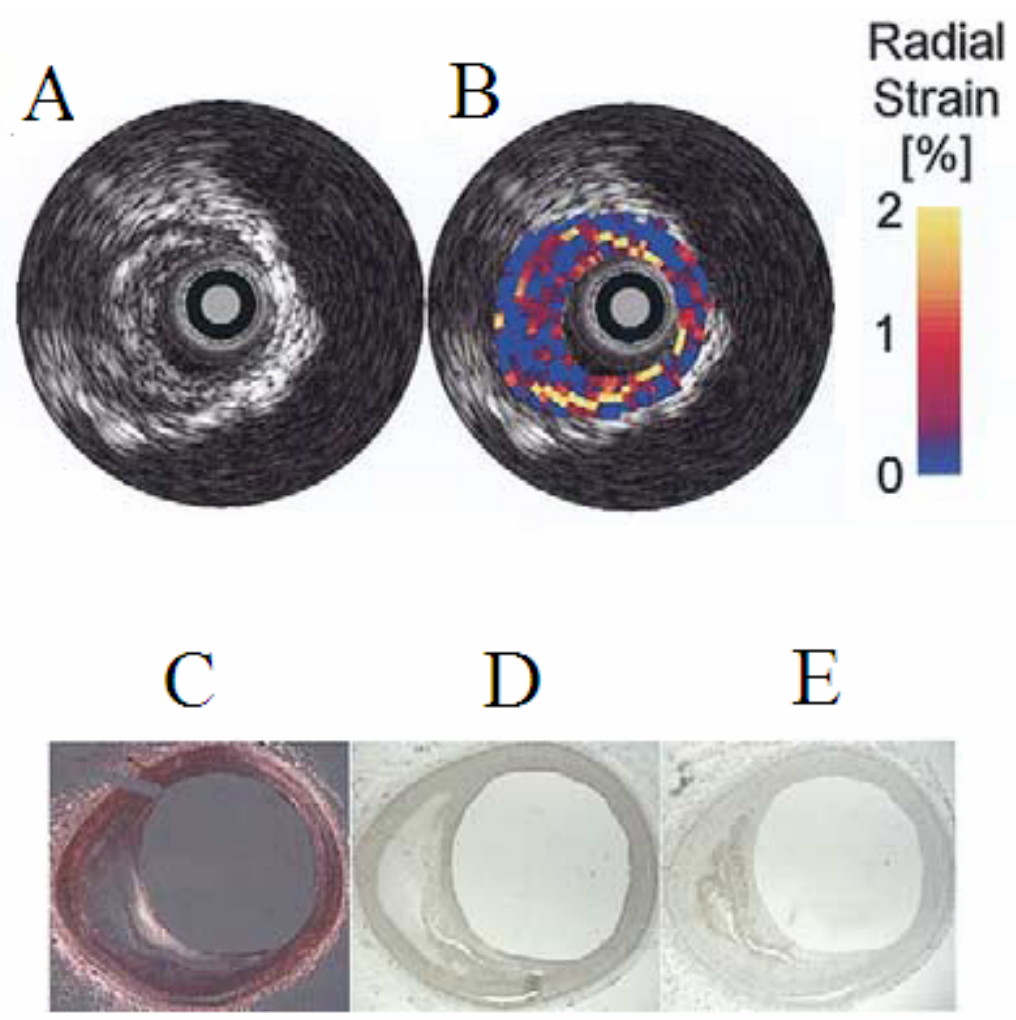

Figure 5. IMAGES OF IVUS ELASTOGRAMS Images of an artery cross section from the work of Baldewsing et al. (a) IVUS image. (b) IVUS elastogram. (c)-(e) histological images.

Their results are shown in Figure 6. While the IVUS elastogram is a good indicator of arterial strain, the group argues that a finite element analysis may be needed to verify that certain areas of strain are in fact due to lesion components. They say that the strain in IVUS elastography may be altered 
due to artery material properties, geometry, and placement of the IVUS catheter. The lesion and arterial components were given linear elastic and incompressible material properties. The justification for this is that the range of physiologic deformations is small enough for the system to be locally linear elastic.

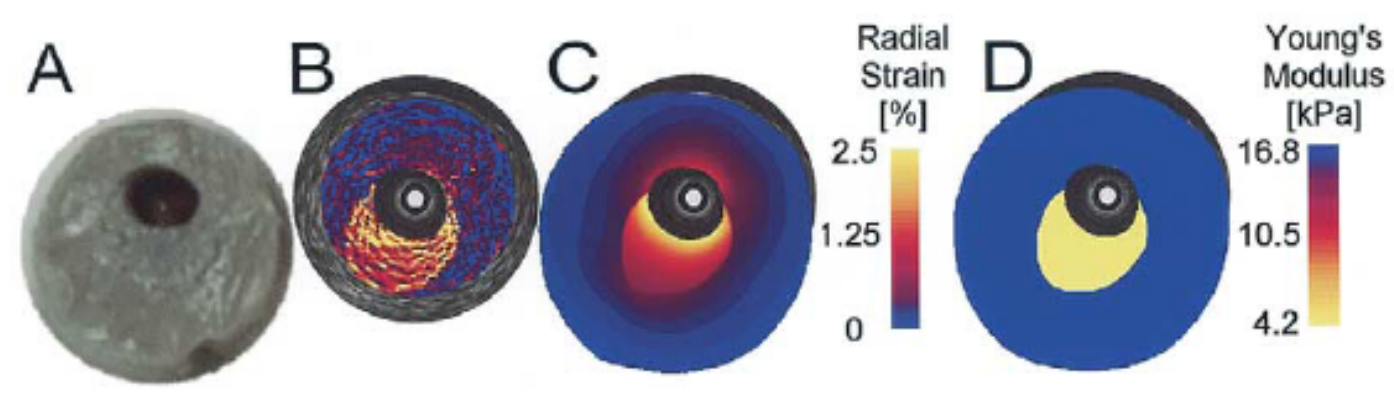

Figure 6. IVUS STRESS/STRAIN ANALYSIS Results of the stress/strain analysis by Baldewsing et al. (a) optical image (b) IVUS elastogram (c) FEA analysis (d) diagram of Young's modulus used in the FEA.

\section{MECHANICAL ANALYSIS USING MR IMAGING}

Magnetic resonance imaging is perfect for looking at soft tissues in the body.

It can have great resolution, and can be manipulated to further single out certain tissue characteristics, such as fat. MR imaging has been used in research to help determine tissue composition of lesions. Many studies have used real MR images to determine lesion geometries for finite element analysis. 
Z. Yong Li et al. used this type of imaging for their finite element analysis of ruptured plaques. They analyzed cross sectional MR images of excised arteries and ran a two dimensional stress analysis using ABACUS. Five vulnerable plaques were used in this study, three that had not ruptured, and two that had. The MR based geometries were obtained from MR segmentation software based on the image characteristics of each material. They also compared the MR based geometry with a histological based geometry for each cross section. Figure 7 shows a comparison from their study.
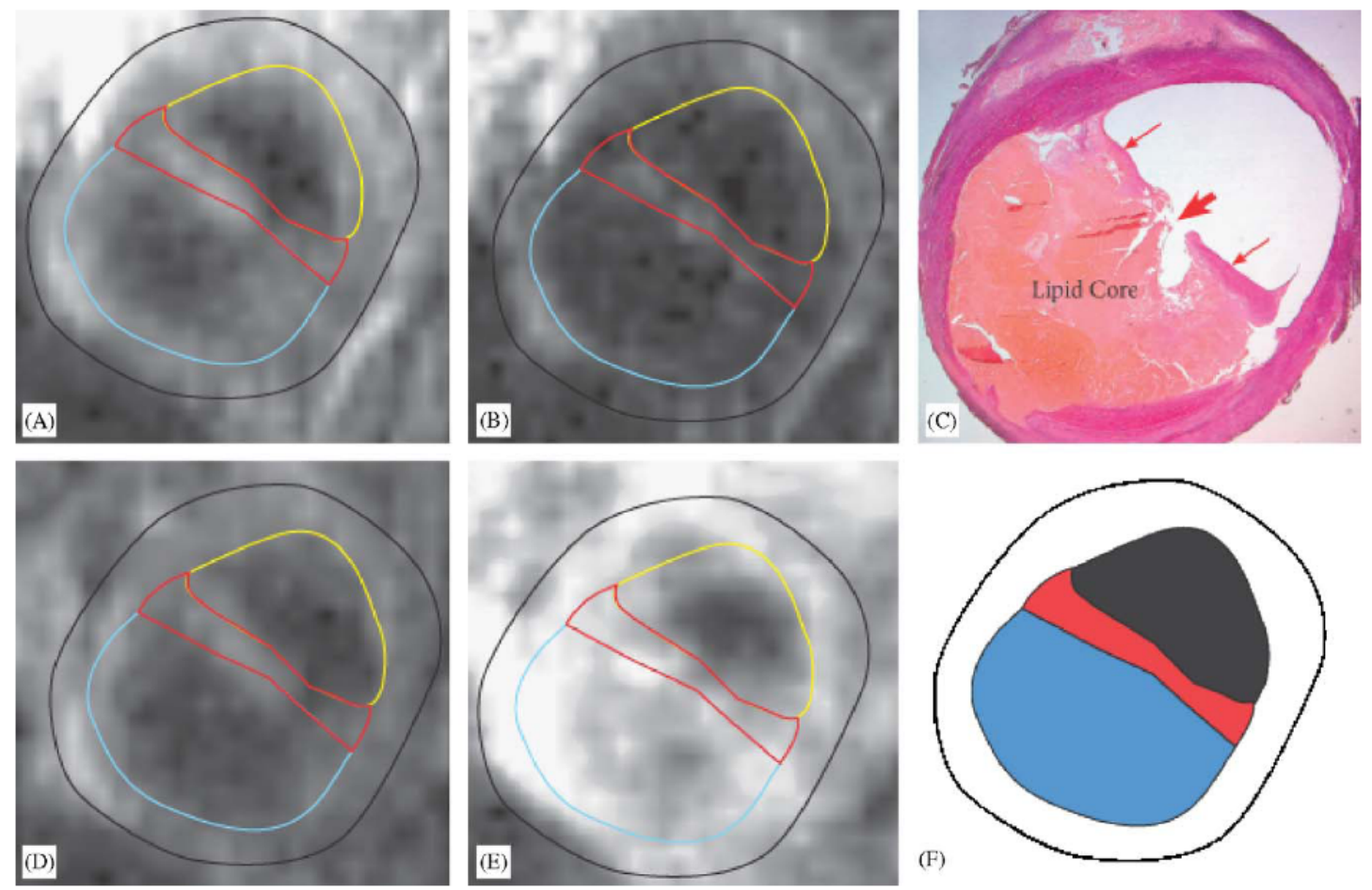

Figure 7. FEA GEOMETRIES BASED ON MR IMAGES Images of a specimen used for FEA in the work of Li et al. (a) (b) (d) (e) MR images. (c) histological image. (d) geometry used for FEA based on MR images. ${ }^{23}$ 
The final geometries contained three different plaque components: the artery wall, lipid pool, and fibrous cap. The materials were given consistent properties throughout the study, so that the results could emphasize the effect of the geometry on plaque rupture. An Ogden strain energy formulation was chosen for the material properties in their finite element analysis. The purpose of this was to try to simulate the non-linear material properties of arteries and atherosclerotic lesions. The results shown in their analysis can be seen in Figure 8. The peak stress of the ruptured plaques are about 6.5 $\mathrm{MPa}$, and $1.5 \mathrm{MPa}$ to $3.5 \mathrm{MPa}$ for the ruptured but vulnerable plaques.

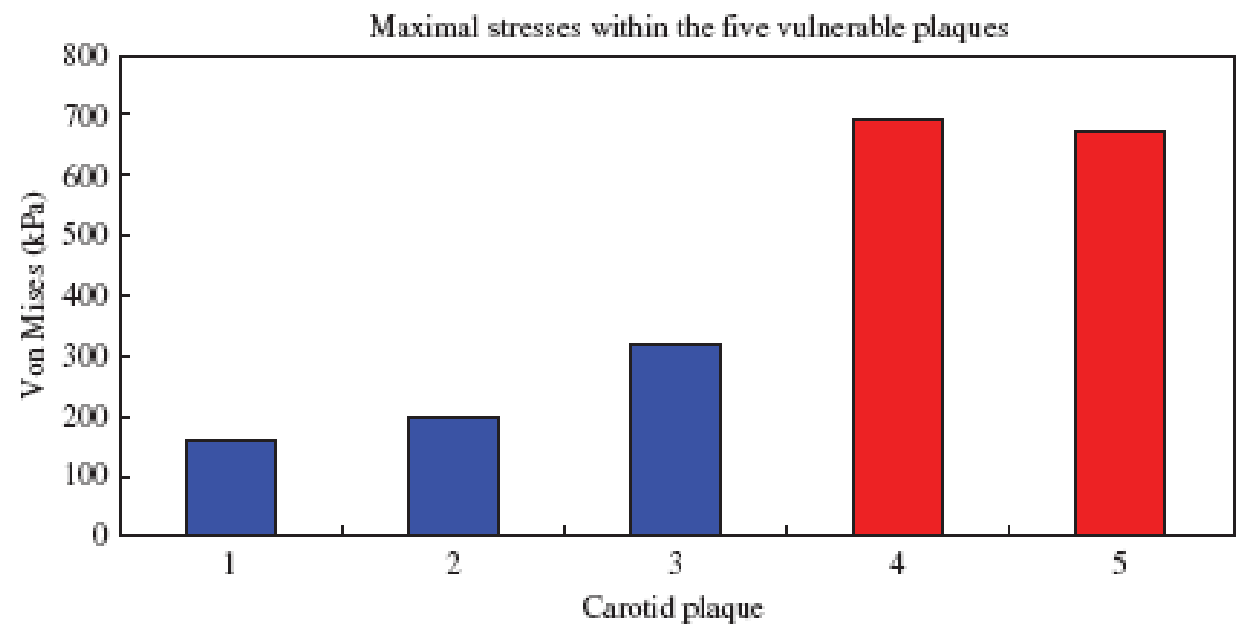

Figure 8. MAXIMUM STRESSES OF VULNERABLE PLAQUES Results shown by Li et al. of the peak stress after finite element analysis of 5 excised arteries. Specimins 1-3 were unruptured, and specimens 4 and 5 were ruptured. ${ }^{23}$

This study showed similarities between the MR and histological based geometries, and showed that MR imaging could be promising to the field because it allows for computer aided geometries. This method could greatly increase the accuracy and repeatability of geometry determination. 


\section{MECHANICAL ANALYSIS USING OCT}

Optical coherence tomography works in a similar manner as ultrasound, but it uses light waves as its medium. OCT is a newer technology, and is promising because of its high resolution $(10 \mu \mathrm{m} \times 25 \mu \mathrm{m})$. The high resolution is a result of technology because it requires a light source that can emit a broad range of frequencies.

Alexandra $\mathrm{H}$. Chau et al. did a study where they compared the analysis of geometries obtained from OCT images with those obtained from histological images. They used two types of lesions: one with a lipid pool and fibrous plaque surrounding it, and one with fibrous plaque surrounding a calcium deposit. The determined geometries (with lipid pools) from each imaging method are shown in Figure 9 along with their stress and strain analysis. Their analysis was on a two dimensional cross section of an excised artery. Their analysis showed that OCT based geometries provide similar stress and strain distributions, but the peak stresses could appear much lower than the histological based geometries. They attributed this inconsistency to the fact that the histological based image may have sharper edges and shoulders due to processing. 


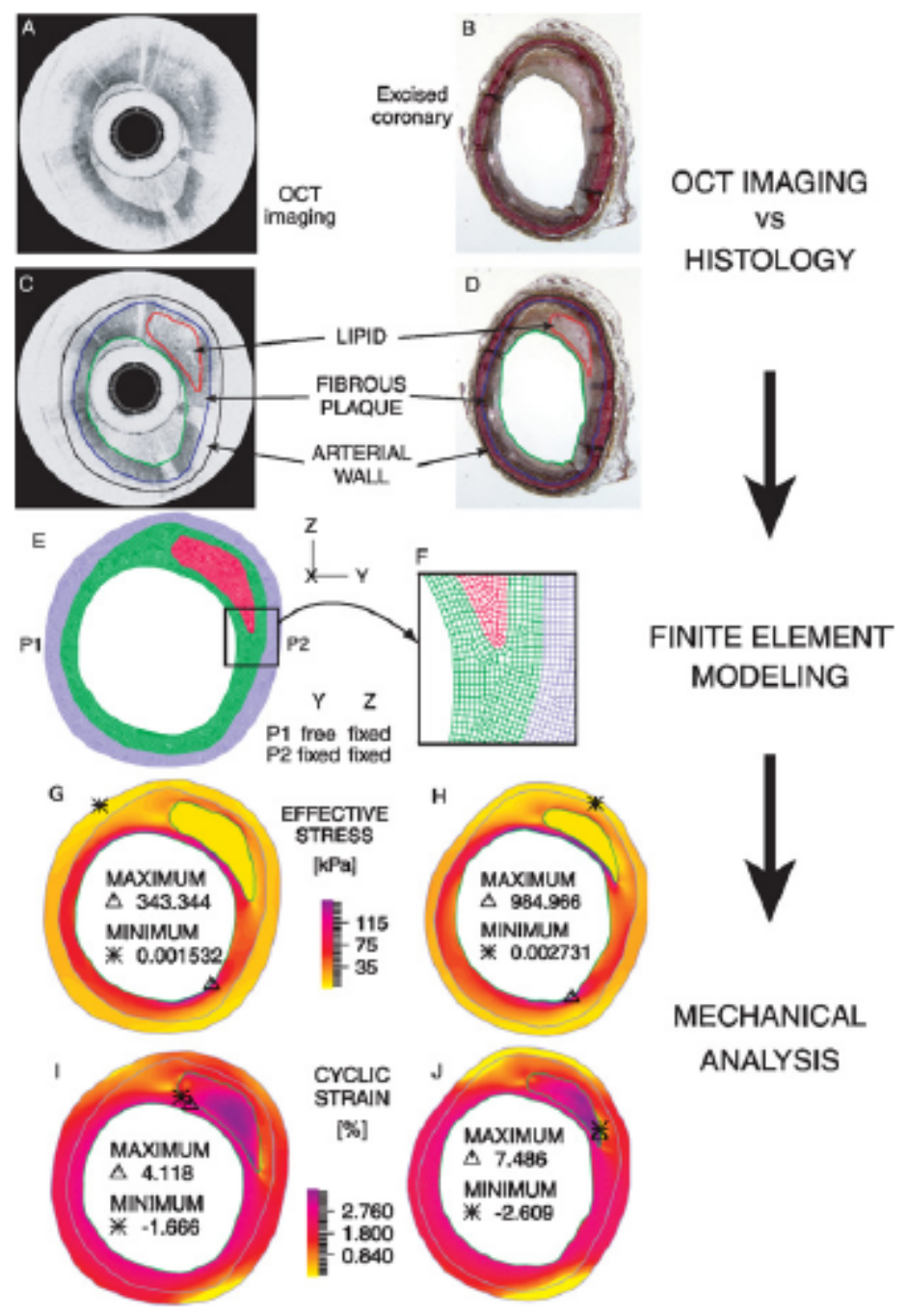

Figure 9. ANALYSIS OF PLAQUE DEFORMATION Comparison of geometry determination and finite element analysis done by Chau et al. The left side is an OCT image set, and the right side is the corresponding histological image. ${ }^{5}$ 


\section{CHAPTER THREE: THE IMPACT OF LIPID PERCENTAGE ON FIBROUS CAP STABILITY}

There is quite a bit of current research in the field of atherosclerosis. Some researchers are doing physical experiments on excised arteries to determine the mechanical properties of each component of a lesion. Others are creating both two and three dimensional finite element analyses based on these mechanical properties, and use geometries based on histological images of excised arteries. Others still are attempting to use imaging techniques to determine mechanical properties, and comparing the finite element analyses of geometries based on imaging to those based on excised arteries.

No research yet has focused on providing a method of standardizing the finite element analysis to draw correlations between different lesion compositions and geometries and mechanical stability. Because each lesion is so different, it would be extremely helpful to create an analysis system where any lesion, regardless of its shape, size, or composition, could be analyzed quickly and accurately for plaque stability.

This project uses finite element techniques to examine the stress concentrations between different plaque compositions. The main focus is to determine the change in plaque stability as the ratio of lipid content to fibrous tissue content changes. A two dimensional finite element analysis was done, 
and the lipid and fibrous tissue content was varied linearly. Each two dimensional drawing represented a cross section of a carotid artery, with a five millimeter diameter. Since the purpose of this study was to look at the effects of lipid vs. fibrous tissue content, each cross section represented a single layered atheroma, with no presence of calcium.

\section{MATERIALS AND METHODS}

Each arterial cross section was analyzed using COMSOL Multiphysics two dimensional stress-strain analysis. The artery was considered to be a closed system, and every component of the artery was given its own material properties. The lumen was not considered part of the system because research showed that hemodynamic stresses are negligible.

.An example of a typical cross section geometry can be seen in Figure 10. This shape was chosen due to a couple factors. The cross section was to be asymmetrical in only one direction, in order to simplify the analysis and obtain continuity of the results. A lesion shape was chosen based on typical lesion shapes shown in studies. After a vague shape was chosen, it needed to be represented mathematically. Many options exist to represent a typical lesion shape; however the chosen shape had to be able to range from $10 \%-90 \%$ lipid, and still be contained in the borders of the circular $5 \mathrm{~mm}$ diameter artery. Although larger lesions tend to distort the outer diameter of the artery, a 
circular shape was chosen throughout all cross sections to avoid any stress concentration gradients due to the artery shape. The final shape of the atheromatous core was made by the area between two offset circles. The diameter of the superficial circle was twice the size of the inner circle. The cap thickness was the distance between the lumen and inner edge of the atheromatous core. The lumen and outer edge of the core were equidistant from the artery wall, and the lesion was also centered in the other dimension.

The materials were given linear elasticity, and the elastic modulus, E, for each is shown in Table 3. The Poisson's ratio for all materials was 0.4999 . These values were kept constant throughout each analysis as a control variable, and are the values used in work by Radj A. Baldewsing et al. The percent stenosis was kept constant at $50 \%$. This was a realistic number for lesions of interest, without being so great as to cause extra shear stress on the lesion due to hemodynamic flow. The percentage of the artery area that makes up the plaque was determined from this stenosis. The lipid and plaque percentages were calculated based on the entire lesion area. The lipid percentage was ranged from $10 \%$ to $90 \%$, and the cap thickness was varied from $65 \mu \mathrm{m}$ to $250 \mu \mathrm{m}$. This is the range of cap thickness that is typically considered vulnerable. The values chosen for thickness were $65 \mu \mathrm{m}, 100 \mu \mathrm{m}$, $200 \mu \mathrm{m}$, and $250 \mu \mathrm{m}$. These values were chosen to represent the smallest realistic cap thickness and the largest vulnerable cap thickness. The two values in between were chosen as references for values in between. The 
applied pressure on all analyses was $16 \mathrm{kPa}$, which is equivalent to about $120 \mathrm{mmHg}$. This pressure was applied to the lumen wall, and was chosen because it represents a systolic blood pressure on the higher end of the normal range for adults.

Table 4. Elastic Modulus of Artery and Lesion Components

\begin{tabular}{|l|l|l|l|}
\hline Material & Artery Wall & Lipid Pool & Fibrous Tissue \\
\hline Elastic Modulus, E & $16.8 \mathrm{kPa}$ & $50 \mathrm{kPa}$ & $1250 \mathrm{kPa}$ \\
\hline
\end{tabular}

The shape and material properties of the arterial wall were kept constant throughout all cross sections. The shape of the artery wall was chosen to be circular, and the lesion was chosen to be off center. This is in part due to the fact that most lesions are typically a bit eccentric, and are located on one side of the artery. The distance between the lumen and arterial wall, and the lipid and arterial wall were chosen to be equidistant, to avoid any unsymmetrical stress concentrations due to a thin artery wall. Since three separate tunics make up the arterial wall, they were averaged into one elastic modulus and thickness. 


\section{RESULTS}

Figure10 shows an example of a typical analysis. Figures 11-14 show plots of the lipid percentage vs. peak stress on each analysis based on the fibrous cap thickness. Each individual analysis can be seen in Appendix A. The results show a linear increase in peak stress as the lipid pool grows. The $R^{2}$ values are consistently close to 1.0 , ranging from 0.927 to 0.976 . The peak stresses for forty to fifty percent range from $2 \mathrm{E} 6$ to $6 \mathrm{E} 6$ depending on the cap thickness. This is higher than the finite element analyses done on geometries based on excised arteries, but this is due to the ideal nature of the geometries. This limitation and the possibilities of overcoming it are explained later in this project. 

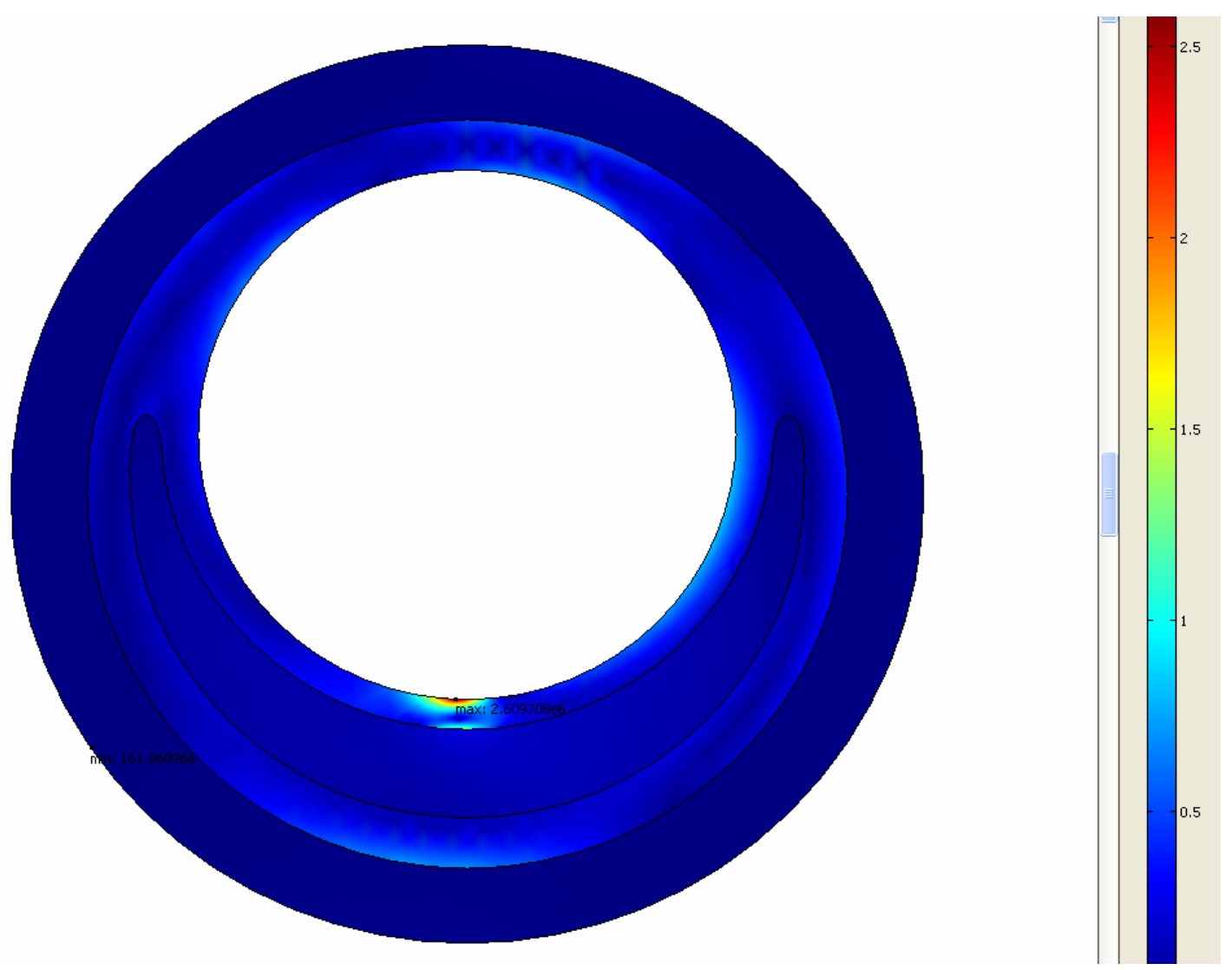

Figure 10. FEA EXAMPLE USING COMSOL Example of a finite element analysis using COMSOL Multiphysics. 


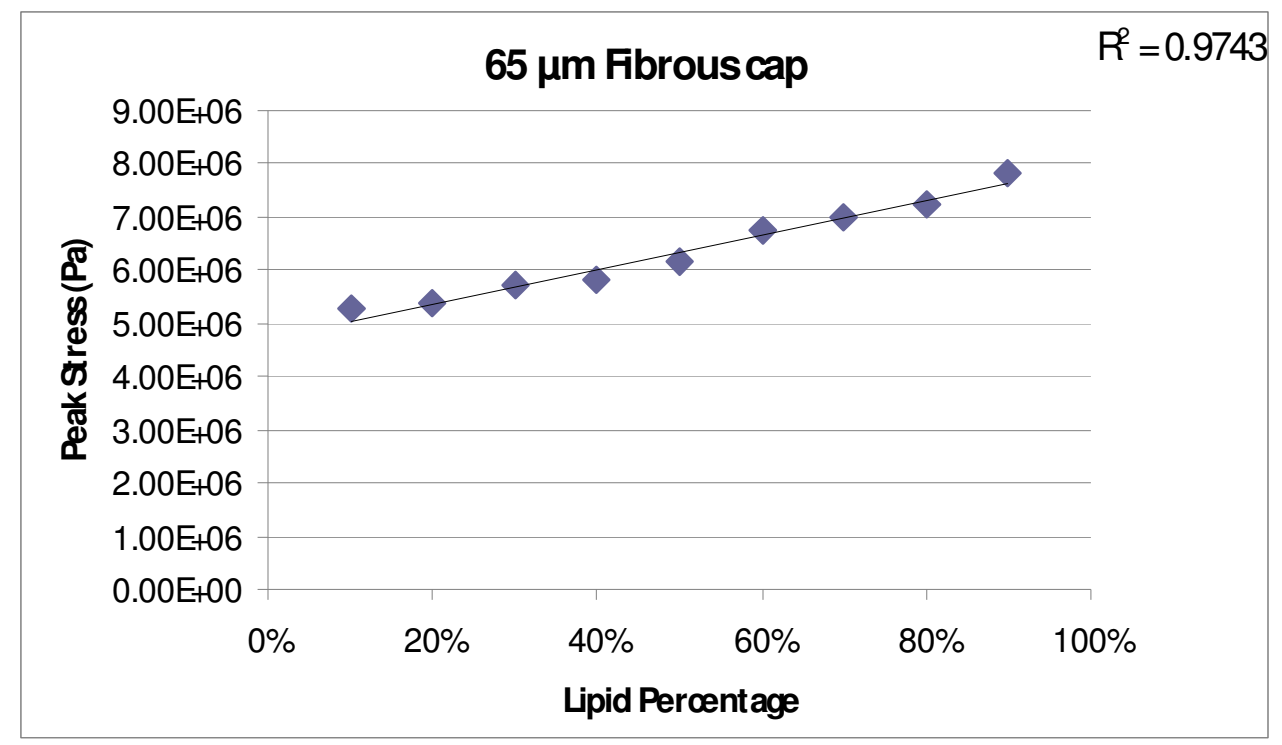

Figure 11. FEA RESULTS WITH A $65 \mu \mathrm{m}$ FIBROUS CAP Results of a finite element analysis of cross sections ranging from $10 \%$ lipid to $90 \%$ lipid with a $65 \mu \mathrm{m}$ fibrous cap thickness.

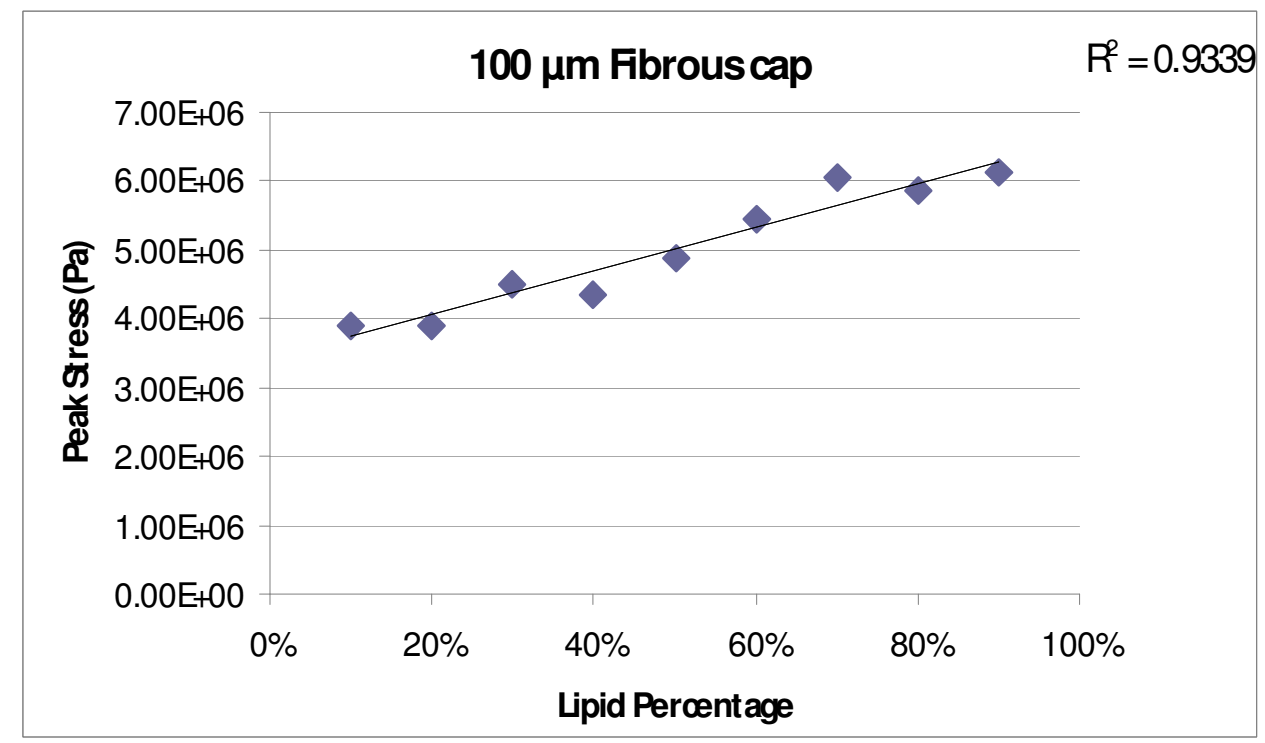

Figure 12. FEA RESULTS WITH A $100 \mu \mathrm{m}$ FIBROUS CAP Results of a finite element analysis of cross sections ranging from $10 \%$ lipid to $90 \%$ lipid with a $100 \mu \mathrm{m}$ fibrous cap thickness. 


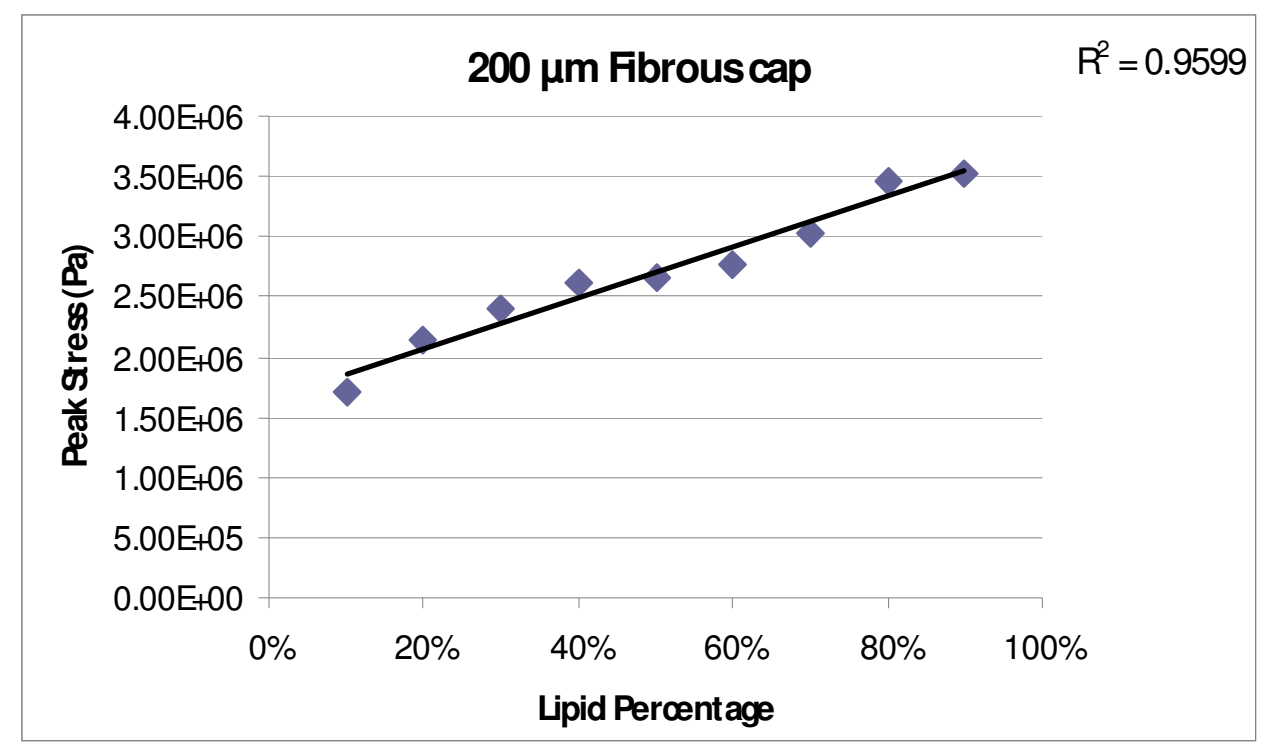

Figure 13. FEA RESULTS WITH A $200 \mu \mathrm{m}$ FIBROUS CAP Results of a finite element analysis of cross sections ranging from 10\% lipid to $90 \%$ lipid with a $200 \mu \mathrm{m}$ fibrous cap thickness.

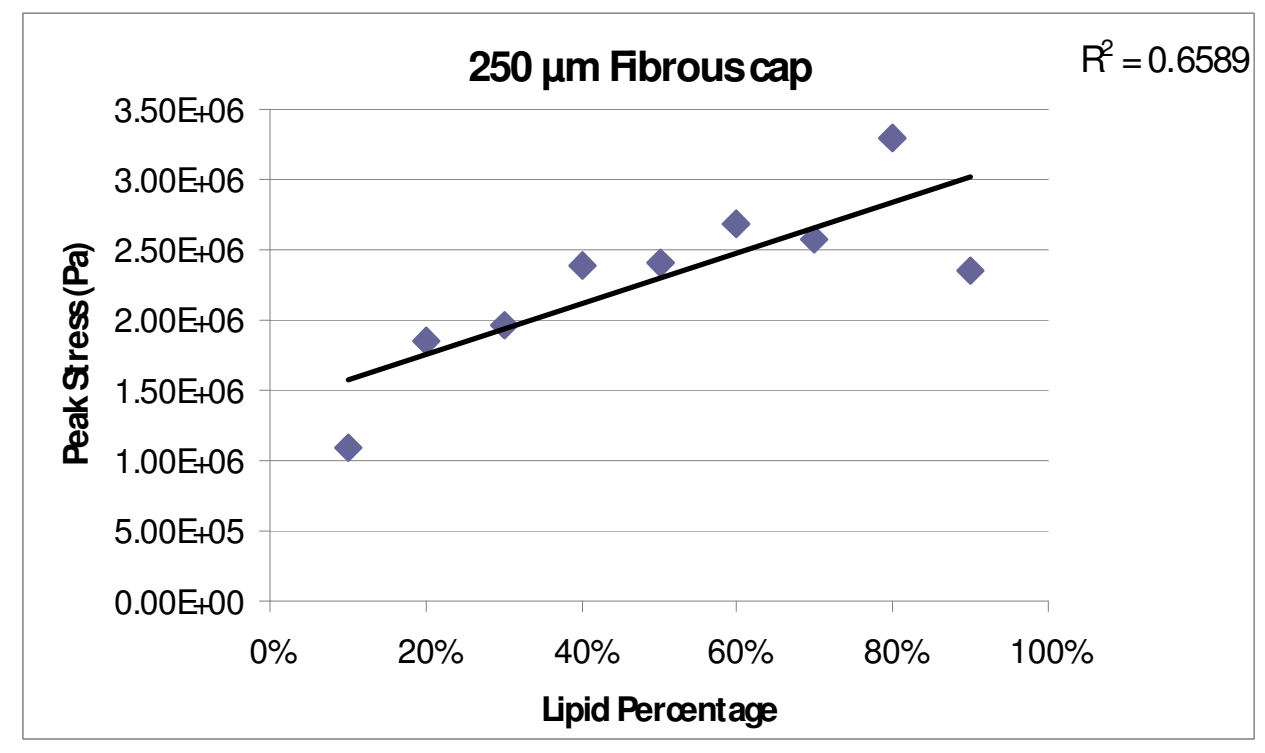

Figure 14. FEA RESULTS WITH A $250 \mu \mathrm{m}$ FIBROUS CAP Results of a finite element analysis of cross sections ranging from $10 \%$ lipid to $90 \%$ lipid with a $250 \mu \mathrm{m}$ fibrous cap thickness. 


\section{DISCUSSION}

The peak stresses of this analysis are noticeably higher than typical finite element analyses done using histological geometries from cross sections of excised arteries. This could possibly be due to the imperfect nature of physiologic geometries.

Excised arteries typically have peak stresses located at the shoulders of the plaque, where curvature of the fibrous cap can be extremely sharp. Also, the composition of both the lipid pool and the fibrous part of the plaque may not be completely uniform throughout; whereas the idealized model is uniform throughout. The peak stresses can also be noticeably different from those obtained by experimentation of excised arteries due to all of the above reasons. Another possibility for discrepancies between excised arteries and ideal models is the possibility of physical imperfections such as fissures. Natural lesions may also contain multiple atheromas and the presence of other materials such as calcium. These factors would indeed affect the mechanical stability of the lesion, but are not portrayed in this project.

Another physiologic feature of artery walls that is not portrayed in the finite element model is the ability of the wall to stretch to a wider diameter during pulsatile flow. In the COMSOL analysis, the arteries are restricted to their $5 \mathrm{~mm}$ diameter, so the wall (and lesion) can be subjected to a higher 
maximum stress than in physiologic conditions. In the physiologic conditions, the minimum stress of the artery should be zero. However, in the finite element analysis, there is a minimum stress that is greater than zero. The difference between the peak stress and minimum stress represents the actual stress on the artery wall if the outer diameter was not constrained. The "peak stress" in the results section depicts this value.

It is important to note that the geometries chosen for this analysis are rather simple, and are not completely indicative of real lesion geometries. For instance, in real lesions, the lipid pools are not shapes made up of offset circles with a perfectly uniform fibrous cap. Instead, natural plaque buildup forms with sharp edges, especially near the shoulders of the lesion. The cap thickness can also vary within the lesion. This "roughness" creates many different stress concentrations throughout the fibrous cap where it could fissure or rupture at stresses well below those of the smooth sections. Since the geometries of this project must use a method that is repeatable and consistent from one lipid pool size to the next, mathematically reproducible shapes are used. The lipid pools of this project have smooth edges, and the fibrous cap is a consistent thickness throughout the lesion. These smooth shapes obviously show stress similar to the smooth sections of real lesions, rather than the rough edges. With further research, the natural stress concentrations could be incorporated into the finite element methods to show more realistic values. However, accounting for these differences between 
actual and ideal lesions is not easy, and requires a great deal of research and experimentation.

A possible fix would be to compare the finite element analysis based on the geometries of actual lesions with those of the standardized geometries. This difference could be plotted for each lipid volume percentage, to see if a correlation is present between the two graphs. A finite element analysis could be done on each histological cross section based on the natural shape of the lesion. Values for peak stress of lesions with similar material volumes (i.e. $40 \%$ lipid and a minimum fibrous cap of $65 \mu \mathrm{m}$ ) could then be averaged to represent a large population. This would help to achieve standardization. Also, the excised lesions would have to be examined to ensure the correct physical properties, such as cap thickness, material concentrations, and the elastic modulus of those materials. Although it is very important to mimic lesion shape as closely as possible, this work would take a large amount of time and resources, so it is beyond the scope of this project.

Another limitation of this project is the simplification of the material properties of plaque. Realistically, each component of plaque probably has at least some non-linear elasticity. However, there are many studies that show how the non-linear material properties may be negligible, so this study does the same. The use of more physiologic material properties in finite element analyses is a large area of research that proves to be quite in depth in the 
areas of mathematics and thermodynamics. Thus, it is considered beyond the scope of this project.

\section{FUTURE IMPLICATIONS}

Although this project does not provide a direct solution to completely understanding plaque stability, it can be used to understand at least a part of it. This project can be part of research to create a standardized model for plaque stability. A standardized model could be an algorithm that takes input parameters specific to a certain lesion and outputs a finite element analysis. The use of imaging modalities certainly would play a big role, and may facilitate lesion analysis without even minimally invasive surgery.

A foreseeable use of a standardized model in combination with medical imaging is the field of diagnostics. Currently, many patients with atherosclerosis go undiagnosed until a major clinical event. Others may know they have some sort of plaque buildup or risk factors, but may not know exactly how the disease will play out. A standard diagnostic tool that predicts future behavior and current risk level would be a great tool for physicians and could prevent many injuries and even deaths due to atherosclerosis. Even though a simple algorithm may not be achieved due to the complexity of the disease, a database that contains possible implications could be very useful in the prevention of disease progression. This database could be a computer 
program in which quantifiable parameters are entered and likely progressions and risk implications are outputted to the physician. A chart could be used to identify risk based on non-quantifiable features, such as shape or nonsymmetrical lesions. These methods could be of great use in the medical field, and help to achieve more efficient patient care.

This sort of model would have a wide variety of applications in the clinical and industrial field. For instance, non-invasive lesion analysis could allow cardiologists to determine plaque stability quicker and more accurately, resulting in safer and more efficient patient care. In industry, a finite element model could be used for device testing before a physical artery model is even made. The use of a computational model could provide easy reproducibility of these tests, thus allowing more analyses to be run. If a large number of tests could be run in a short time, then a wide variety of lesions could be tested. This is especially important because lesions vary so greatly in composition from person to person, and even between lesions themselves.

Eventually, as all the limitations of this project are researched and overcome, a standardized model will come together and greatly improve the understanding of atherosclerosis. 


\section{APPENDIX}

This appendix displays the results of all COMSOL simulations used in this project. 
The following are the finite element analyses for a fibrous cap thickness of $200 \mu \mathrm{m}$ with a lipid concentration ranging from $10 \%$ to $90 \%$ lipid.

Fibrous Cap $=65 \mu \mathrm{m}$ Atheroma $=10 \%$

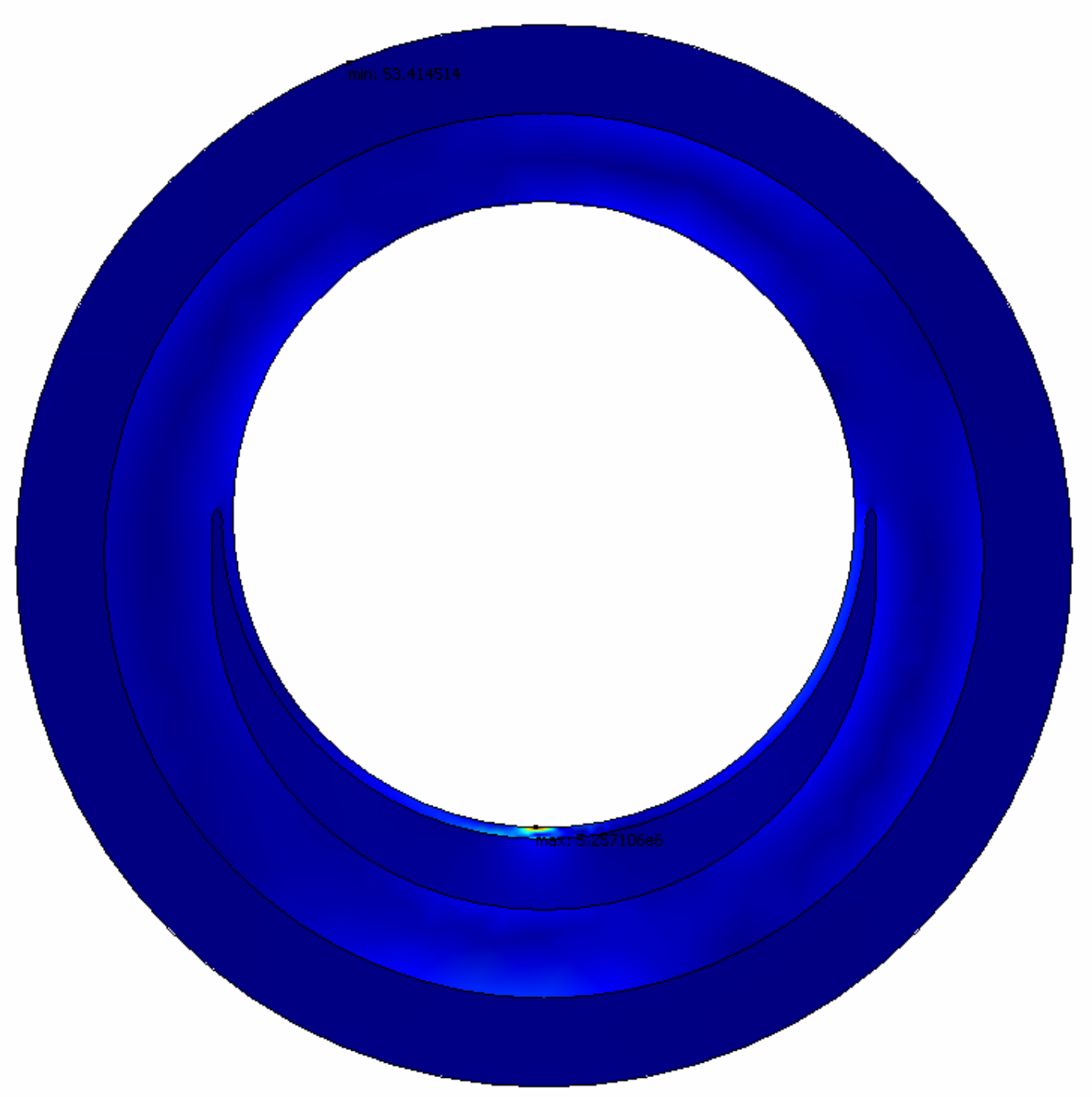


Fibrous Cap $=65 \mu \mathrm{m}$ Atheroma $=20 \%$

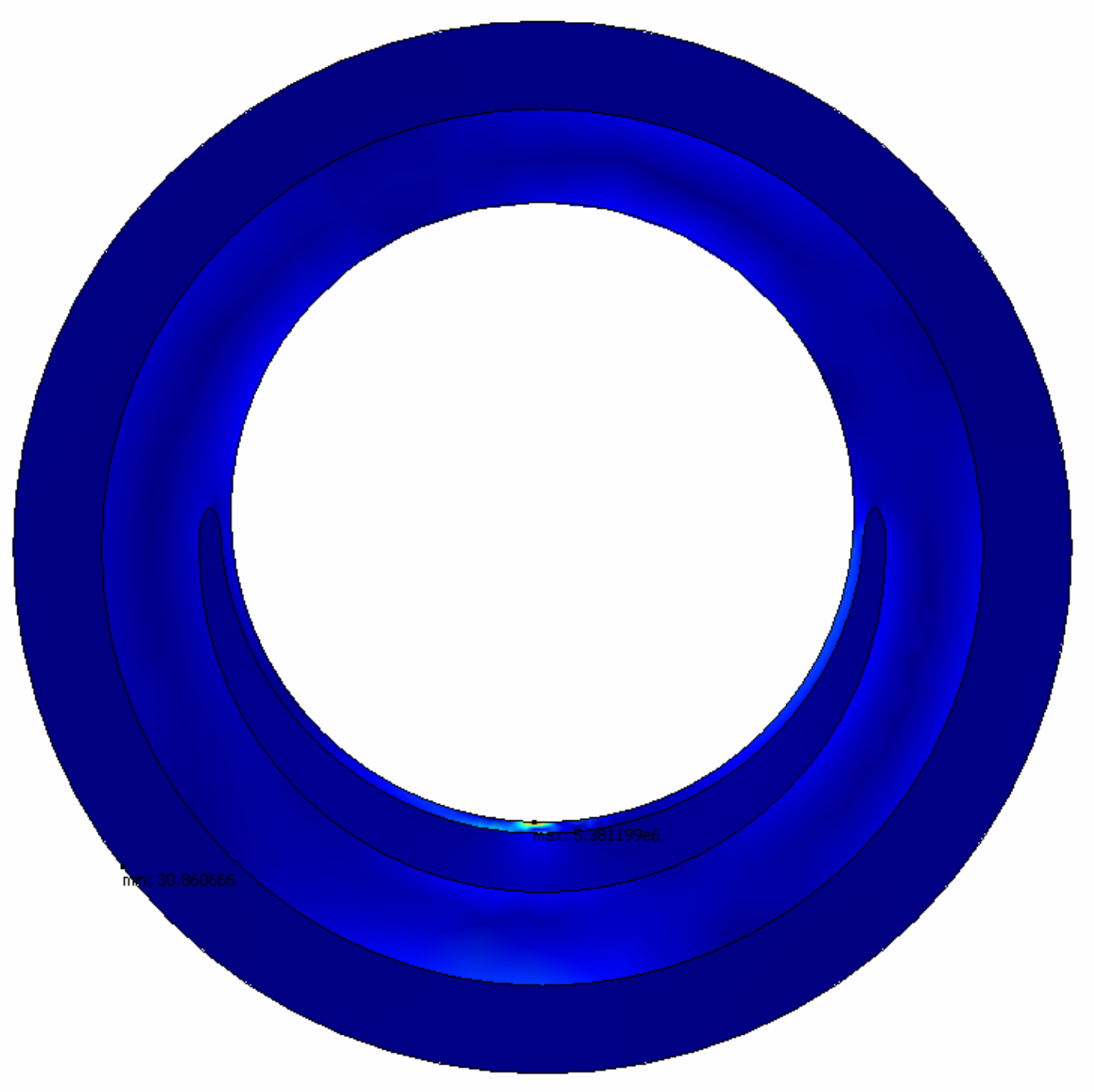


Fibrous Cap $=65 \mu \mathrm{m}$ Atheroma $=30 \%$

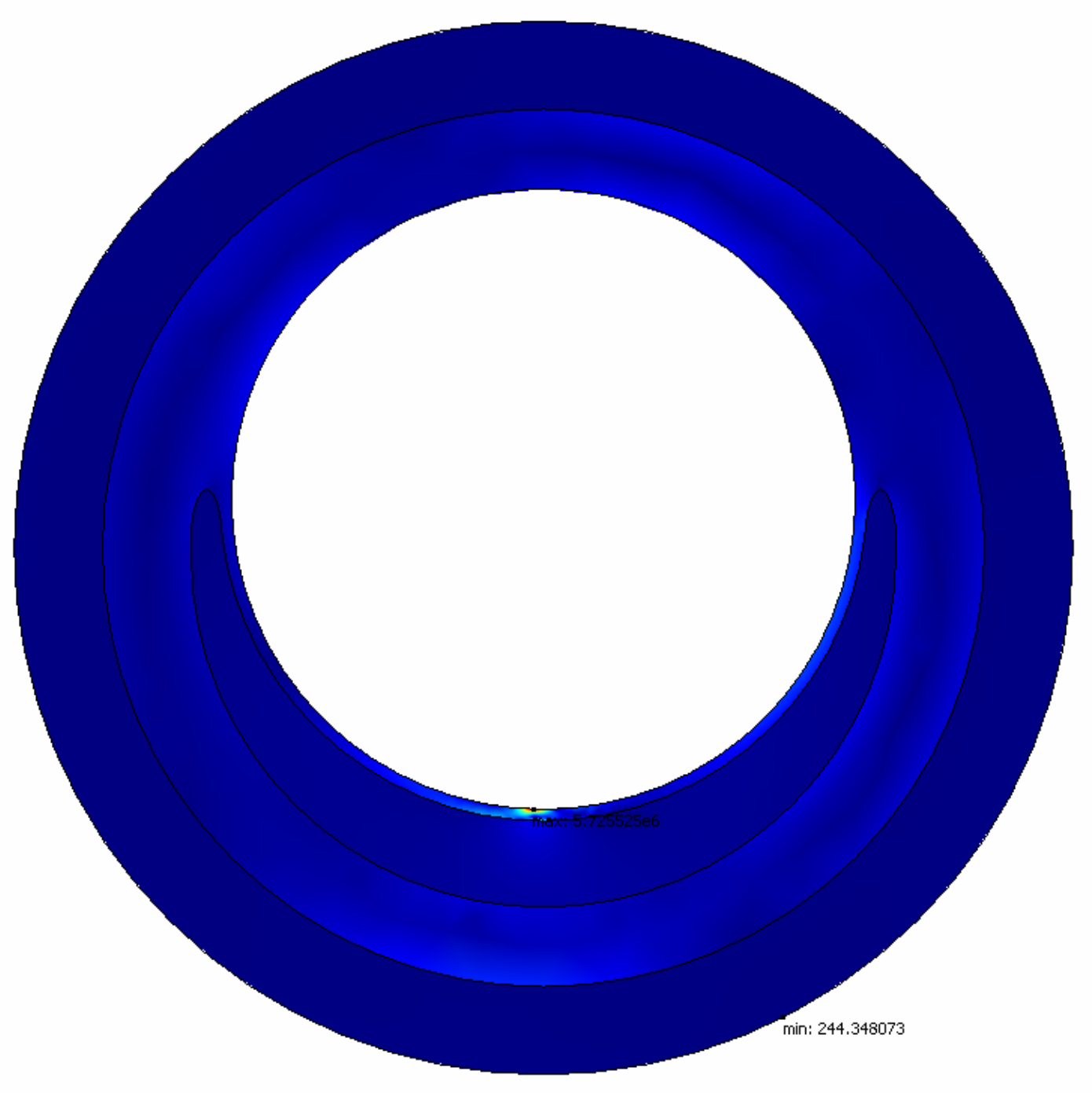


Fibrous Cap $=65 \mu \mathrm{m}$ Atheroma $=40 \%$

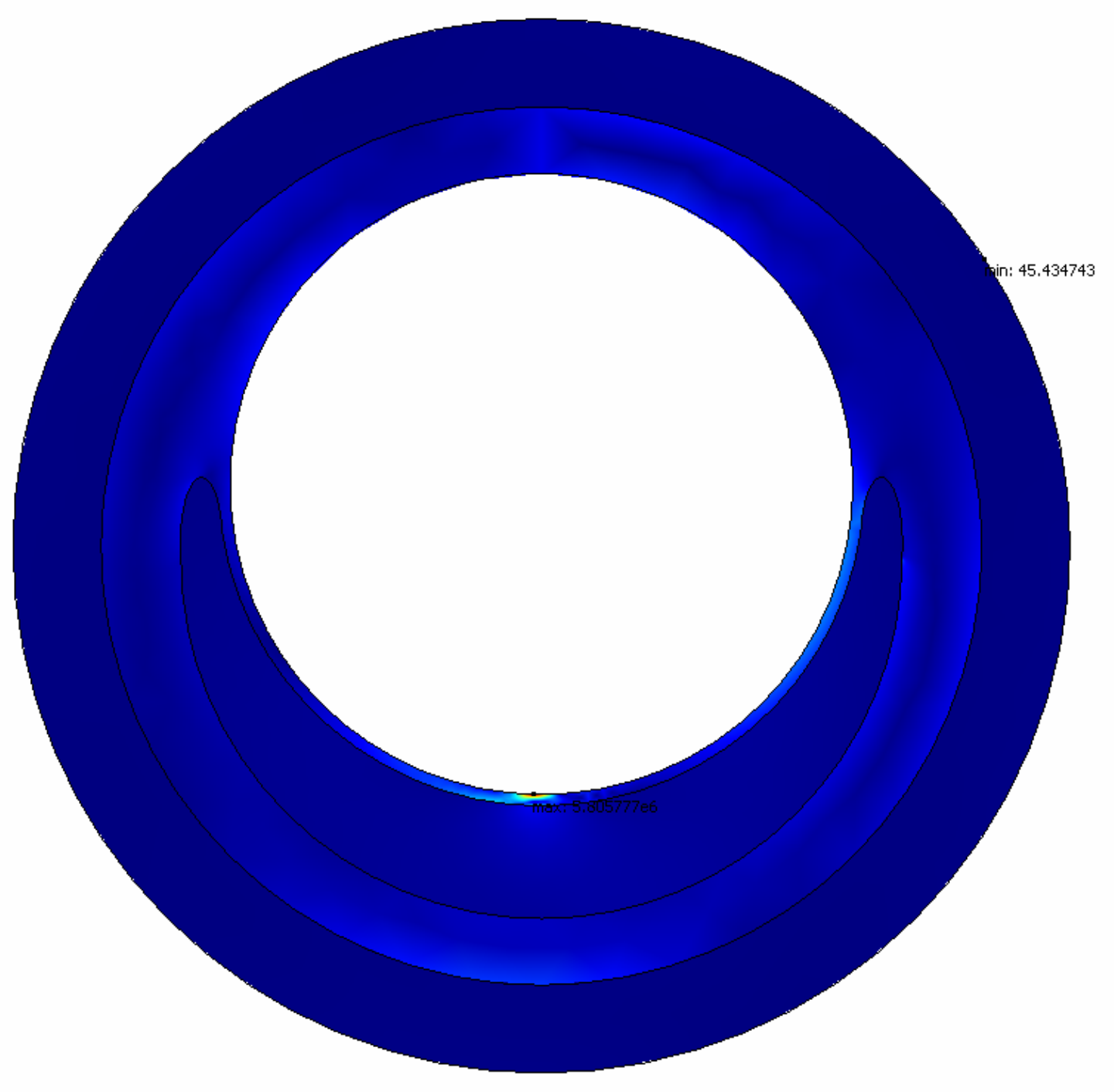


Fibrous Cap $=65 \mu \mathrm{m}$ Atheroma $=50 \%$

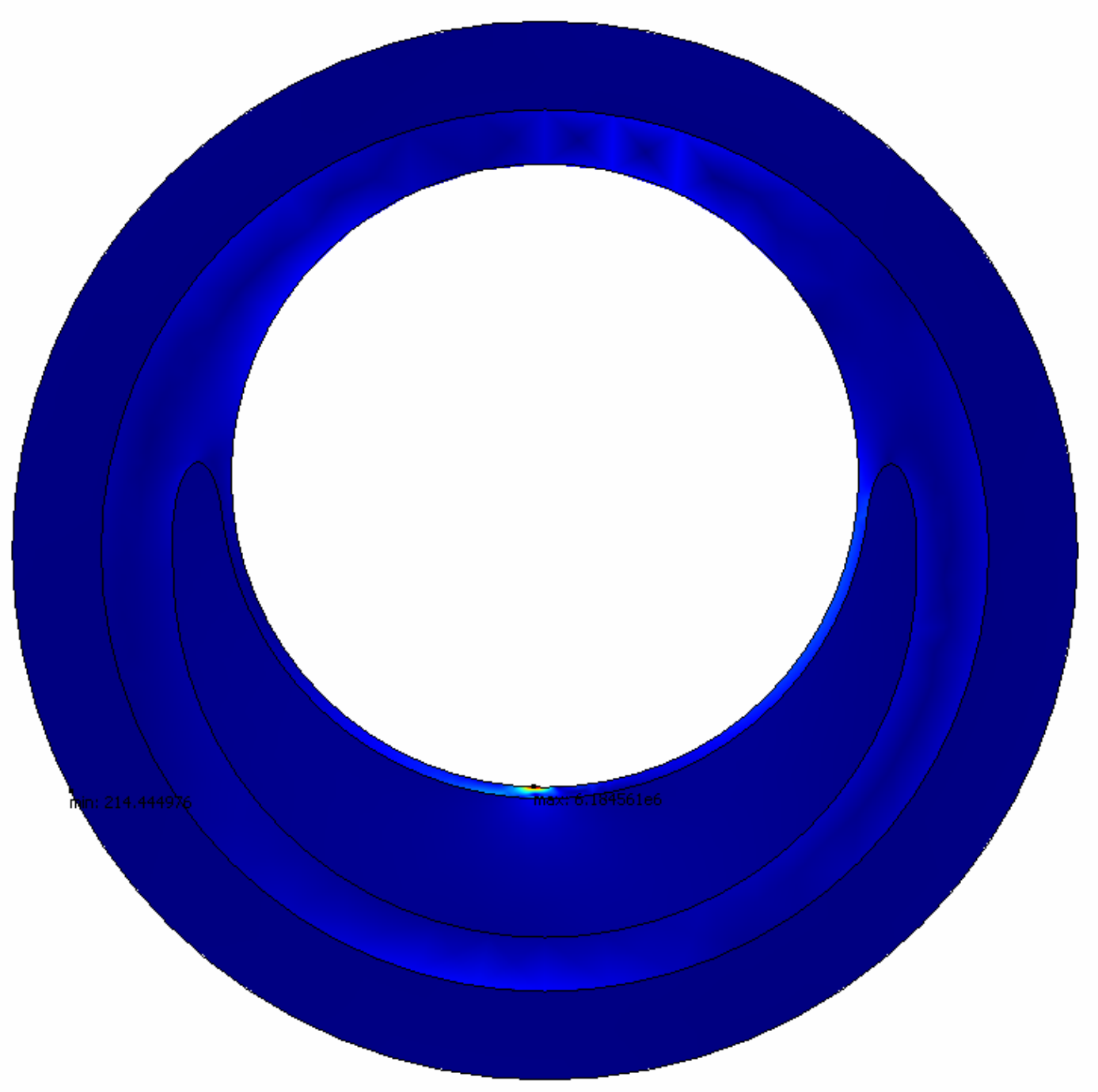


Fibrous Cap $=65 \mu \mathrm{m}$ Atheroma $=60 \%$

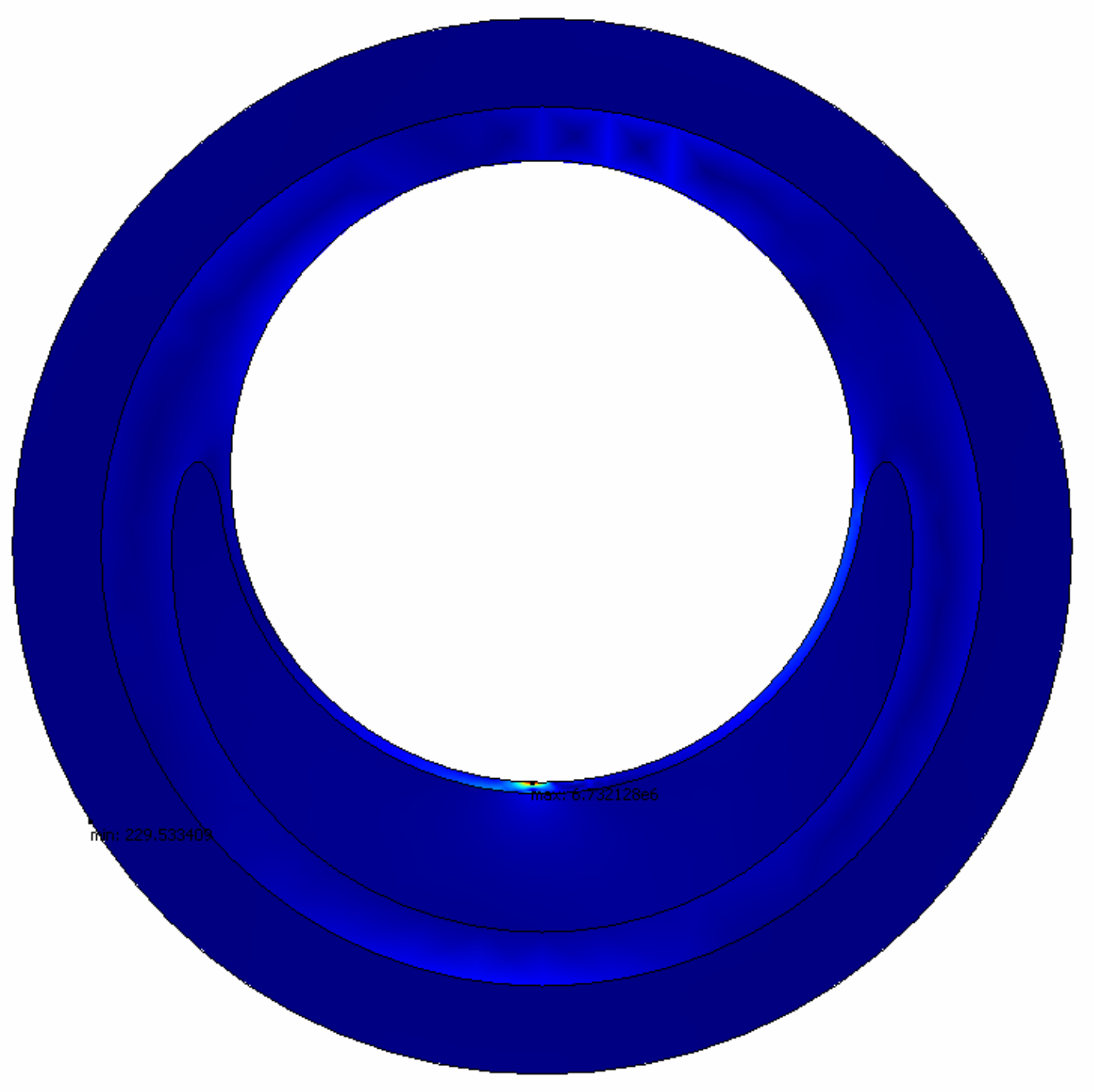


Fibrous Cap $=65 \mu \mathrm{m}$ Atheroma $=70 \%$

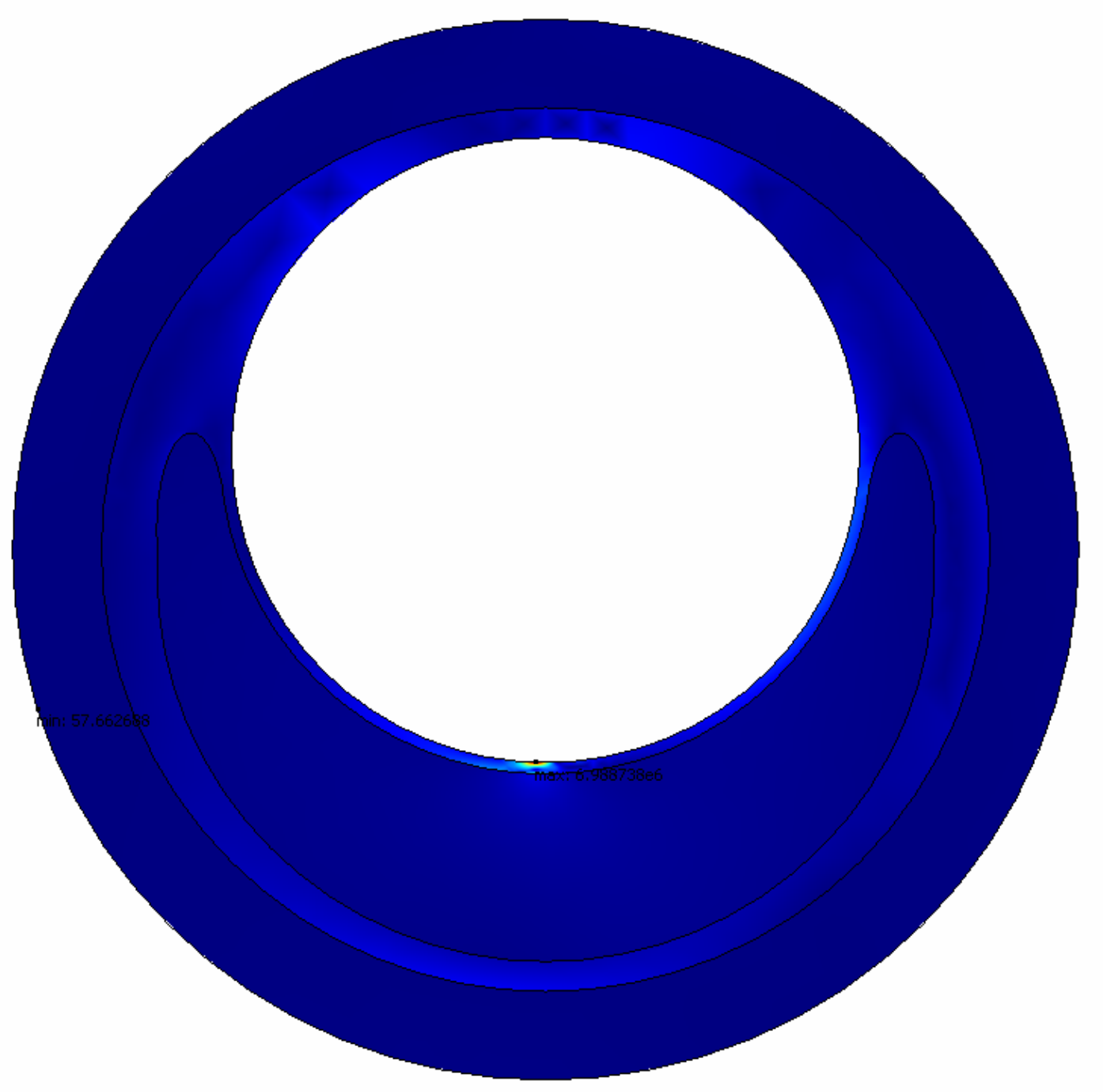


Fibrous Cap $=65 \mu \mathrm{m}$ Atheroma $=80 \%$

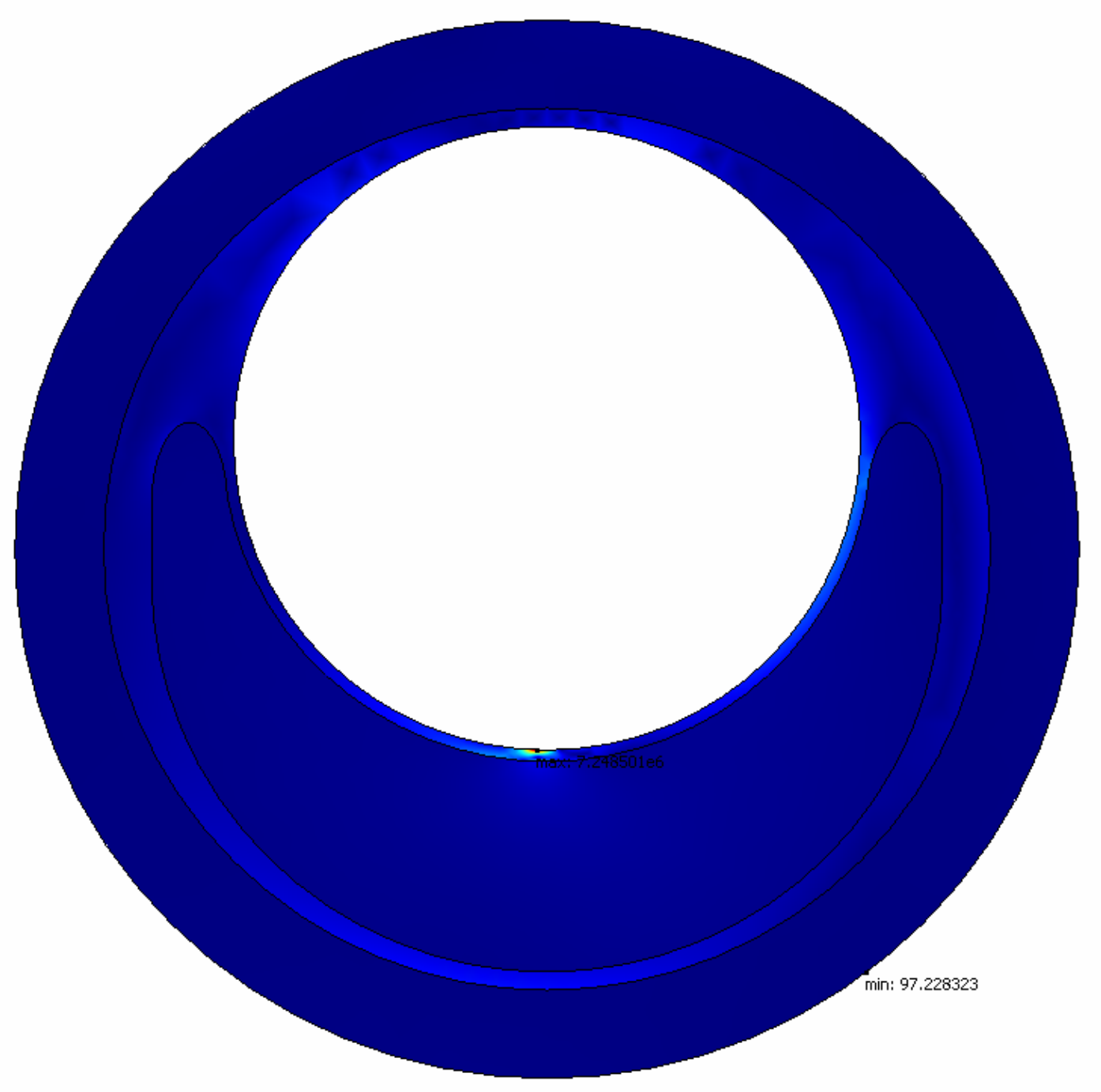


Fibrous Cap $=65 \mu \mathrm{m}$ Atheroma $=90 \%$

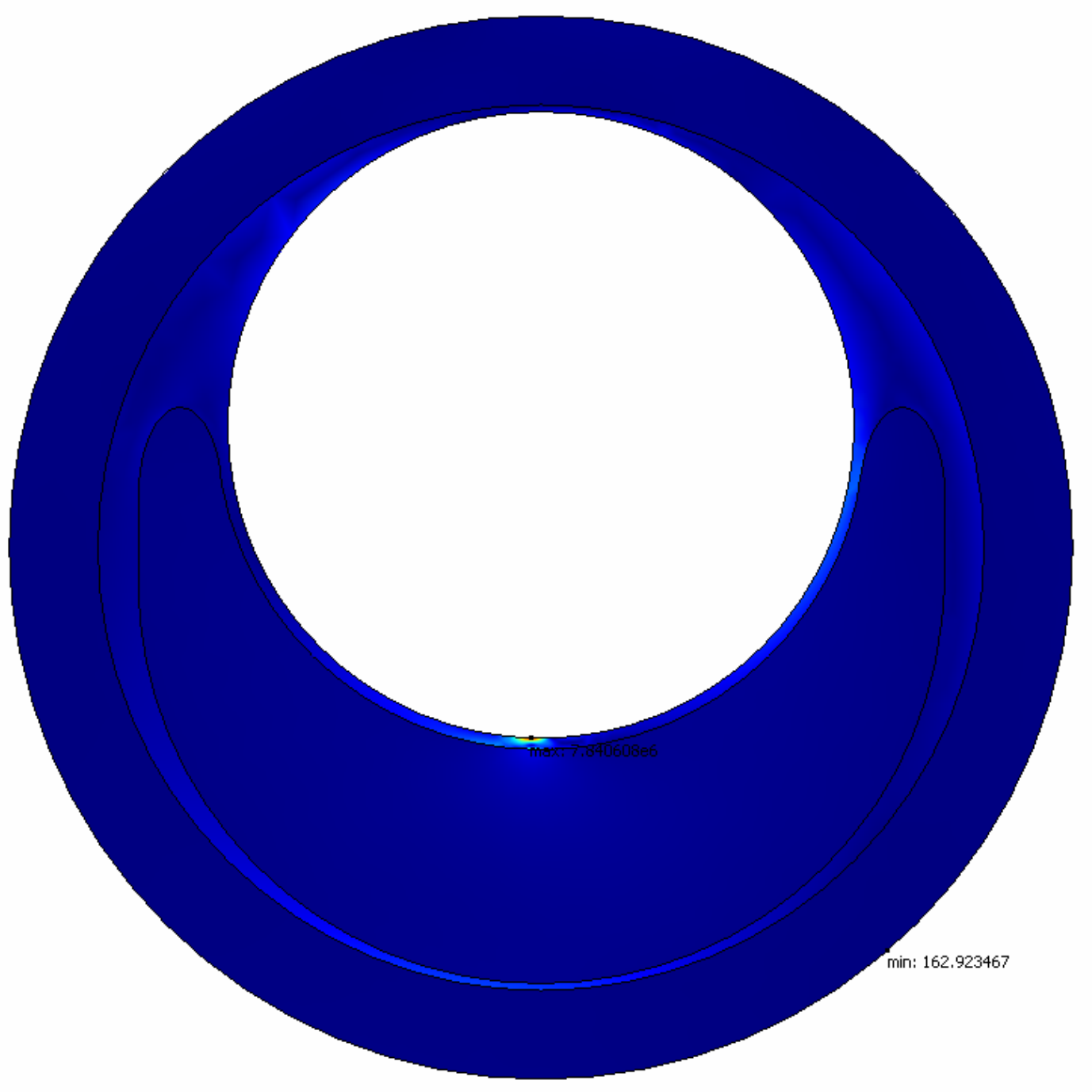


The following are the finite element analyses for a fibrous cap thickness of $200 \mu \mathrm{m}$ with a lipid concentration ranging from $10 \%$ to $90 \%$ lipid.

Fibrous Cap $=100 \mu \mathrm{m}$ Atheroma $=10 \%$

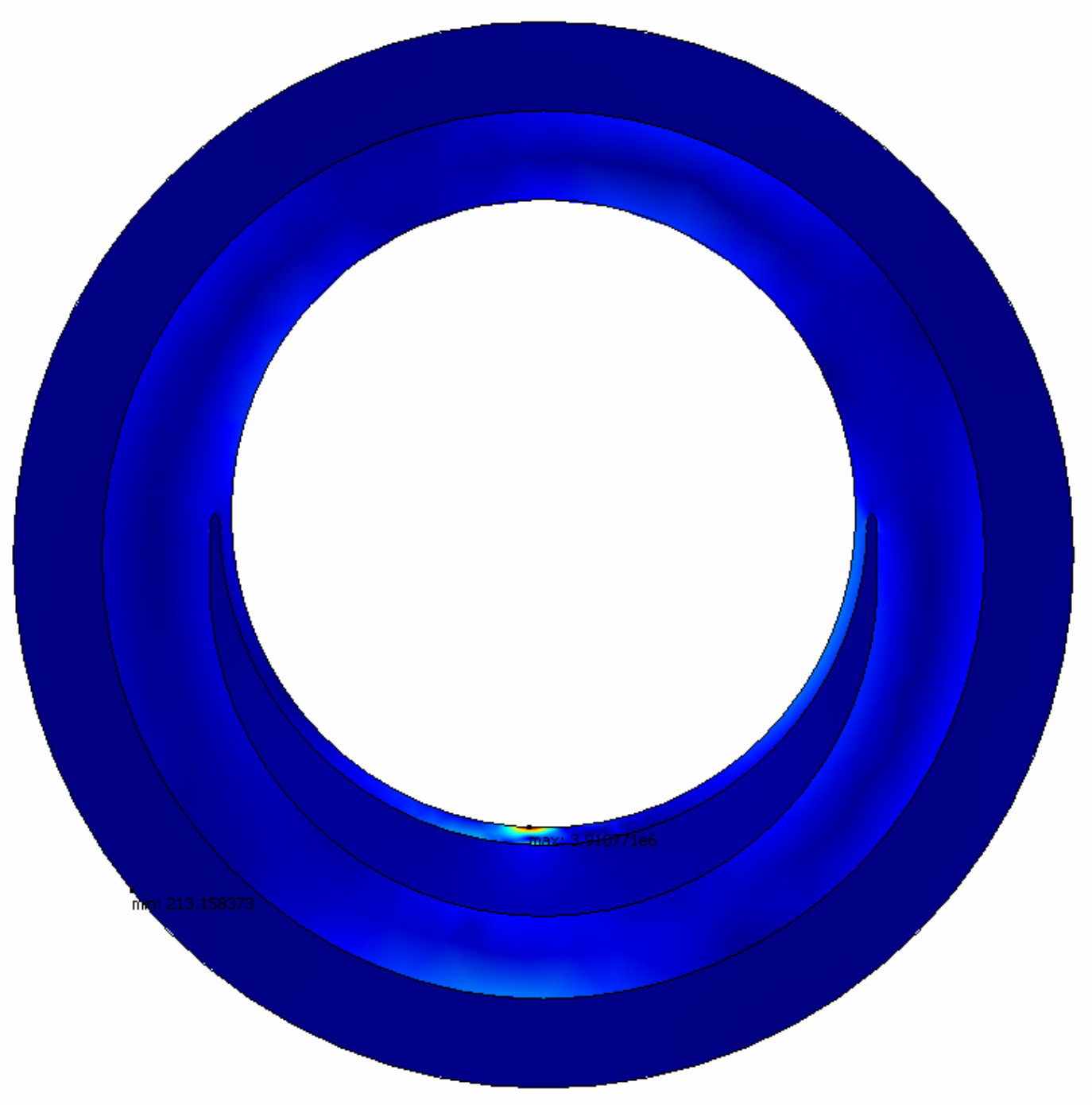


Fibrous Cap $=100 \mu \mathrm{m}$ Atheroma $=20 \%$

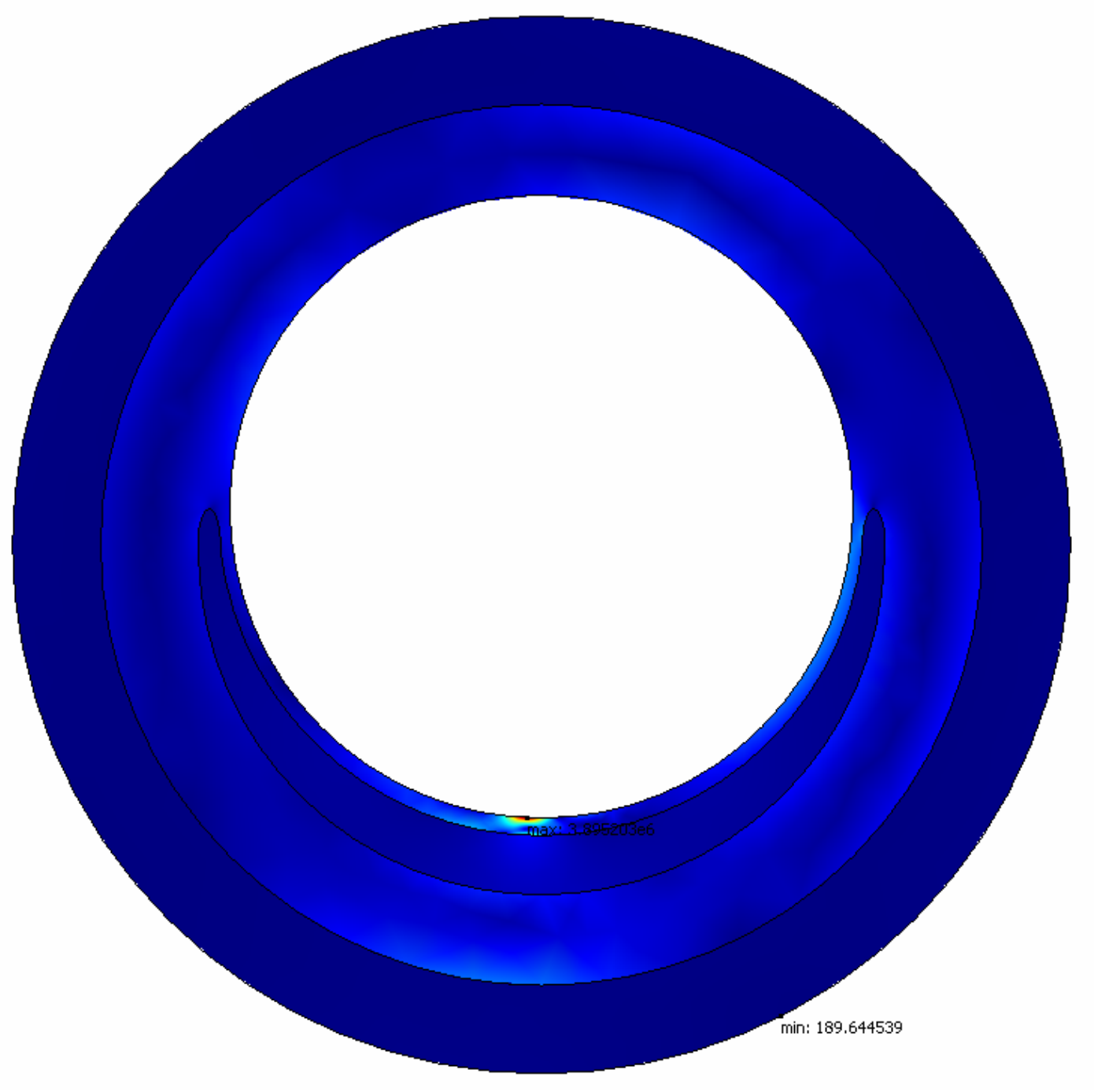


Fibrous Cap $=100 \mu \mathrm{m}$ Atheroma $=30 \%$

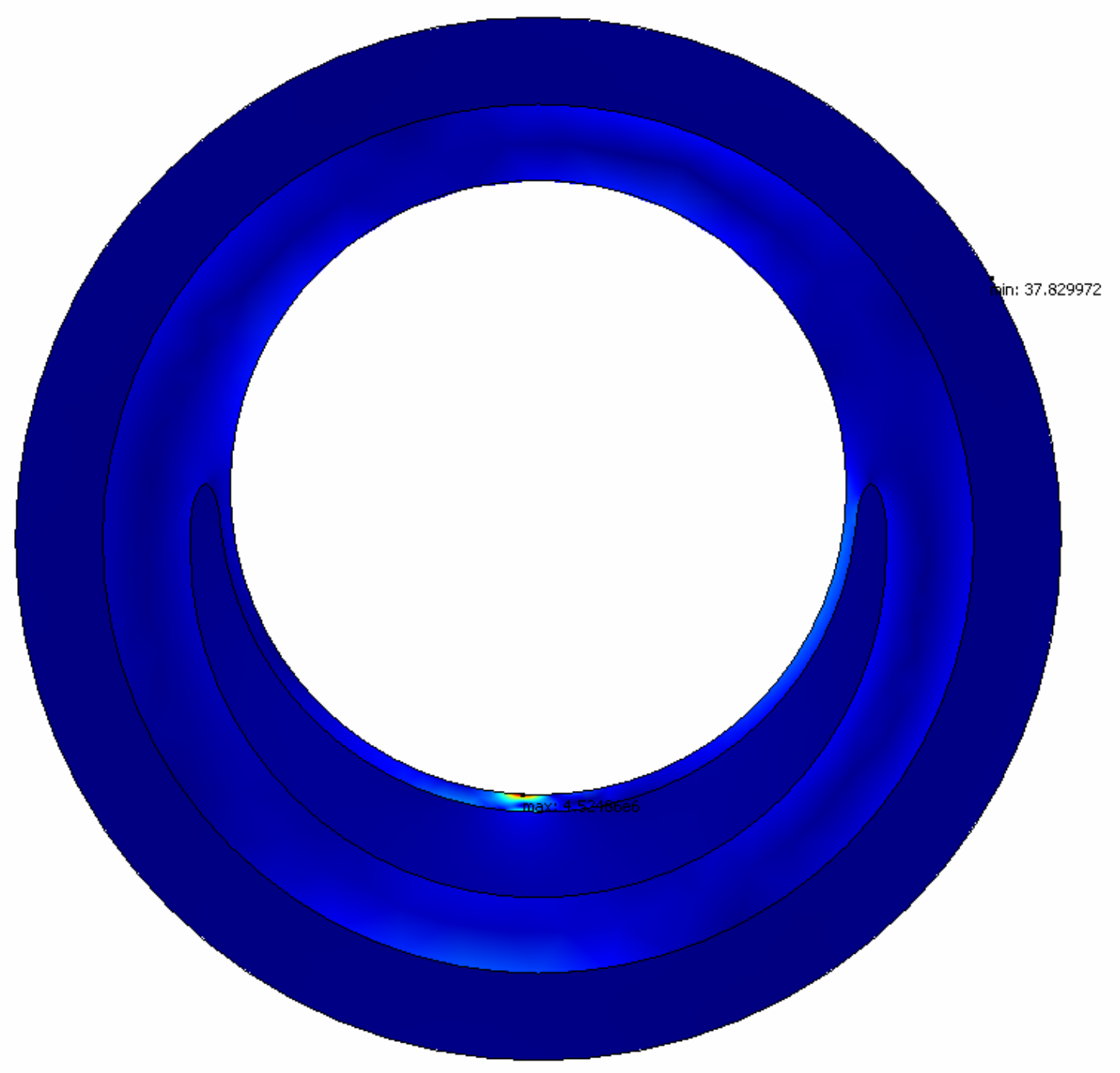


Fibrous Cap $=100 \mu \mathrm{m}$ Atheroma $=40 \%$

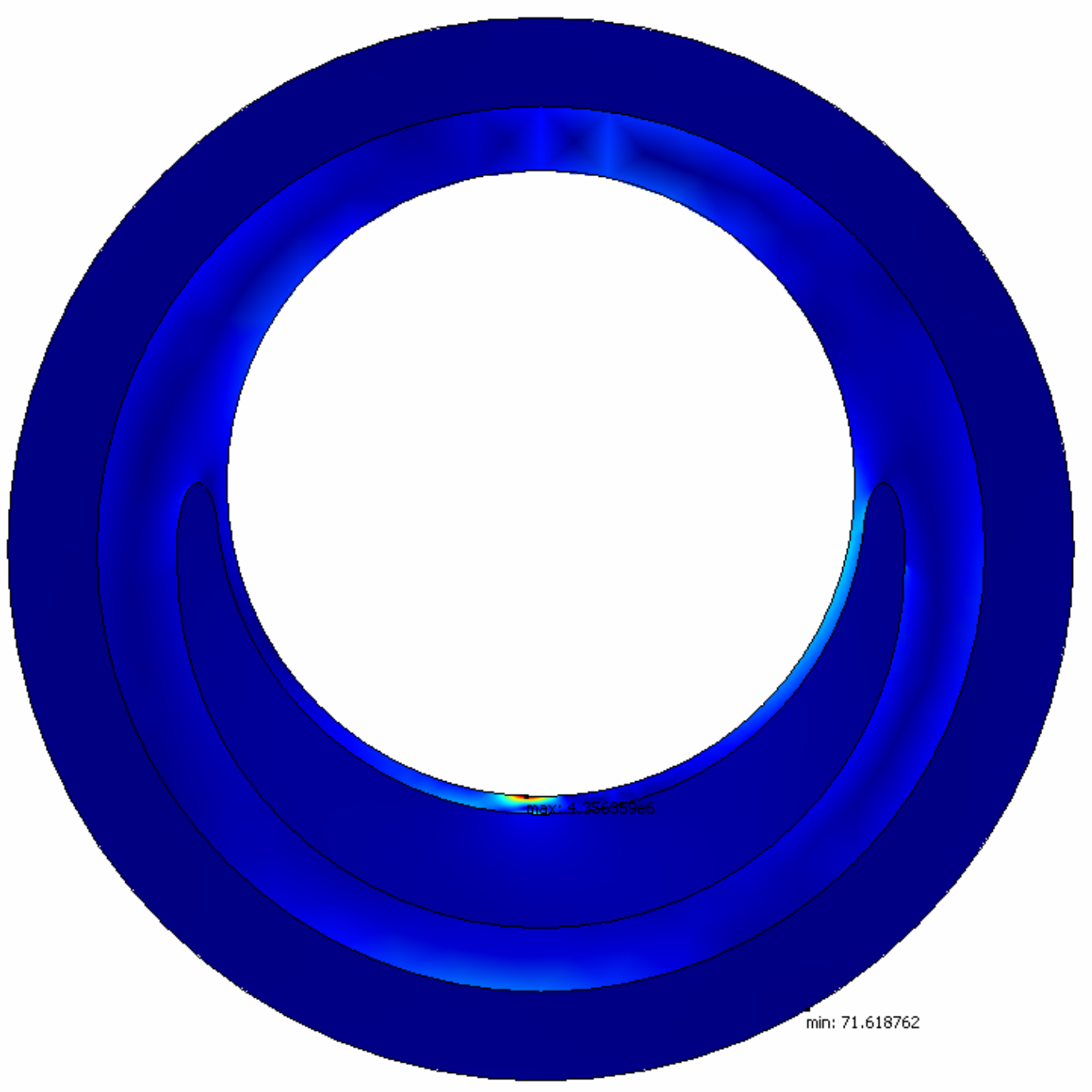


Fibrous Cap $=100 \mu \mathrm{m}$ Atheroma $=50 \%$

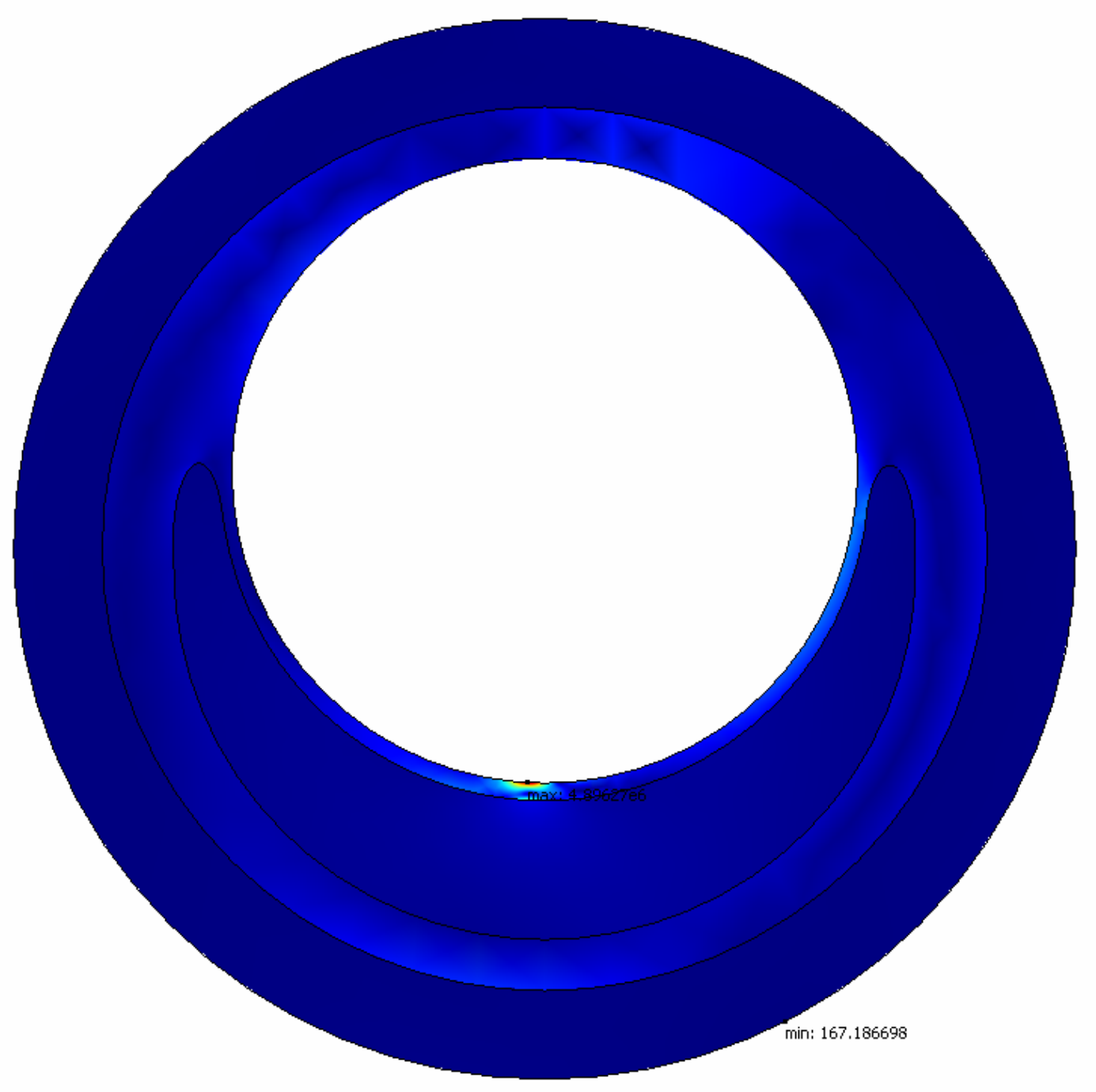


Fibrous Cap $=100 \mu \mathrm{m}$ Atheroma $=60 \%$

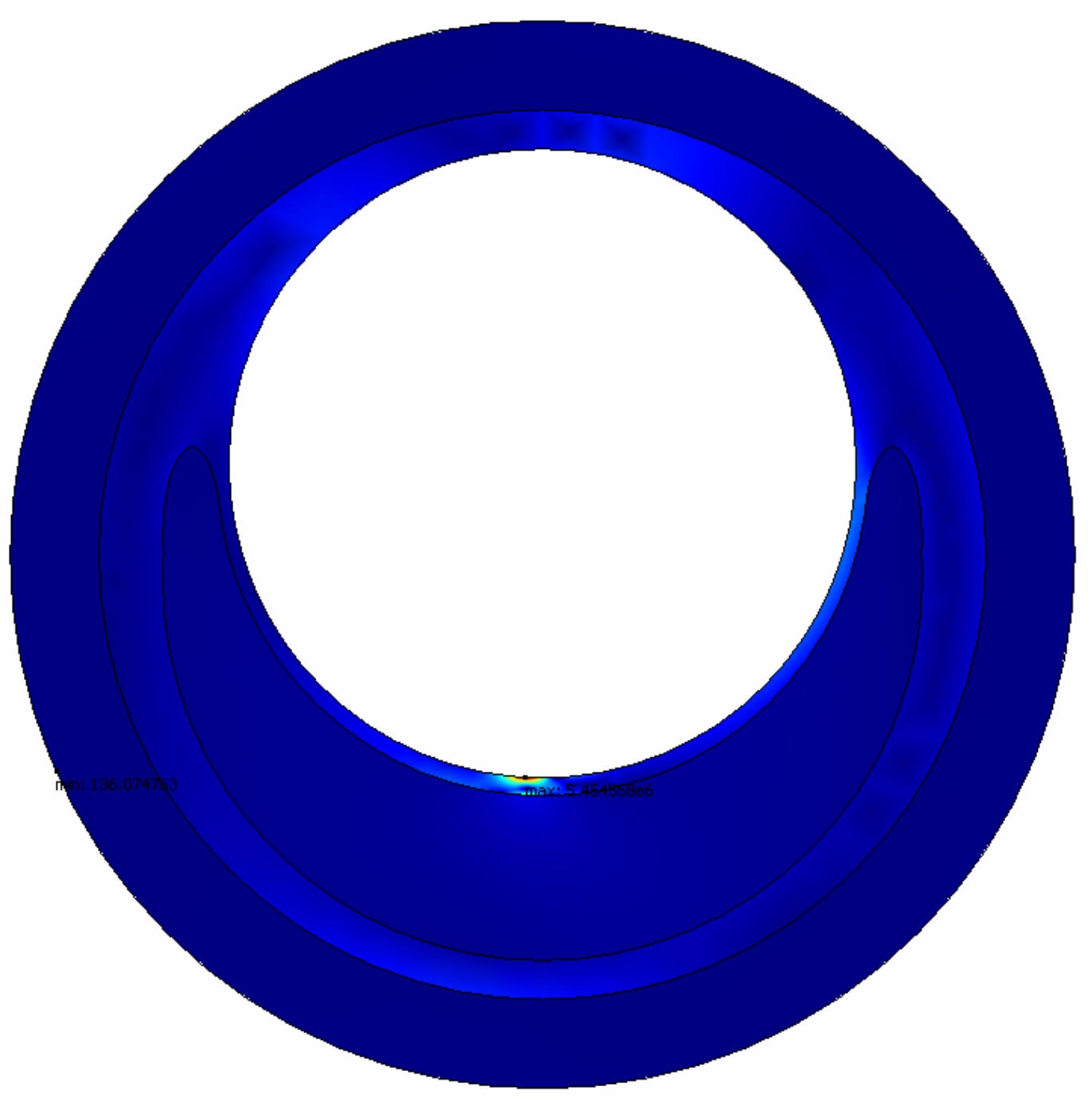


Fibrous Cap $=100 \mu \mathrm{m}$ Atheroma $=70 \%$

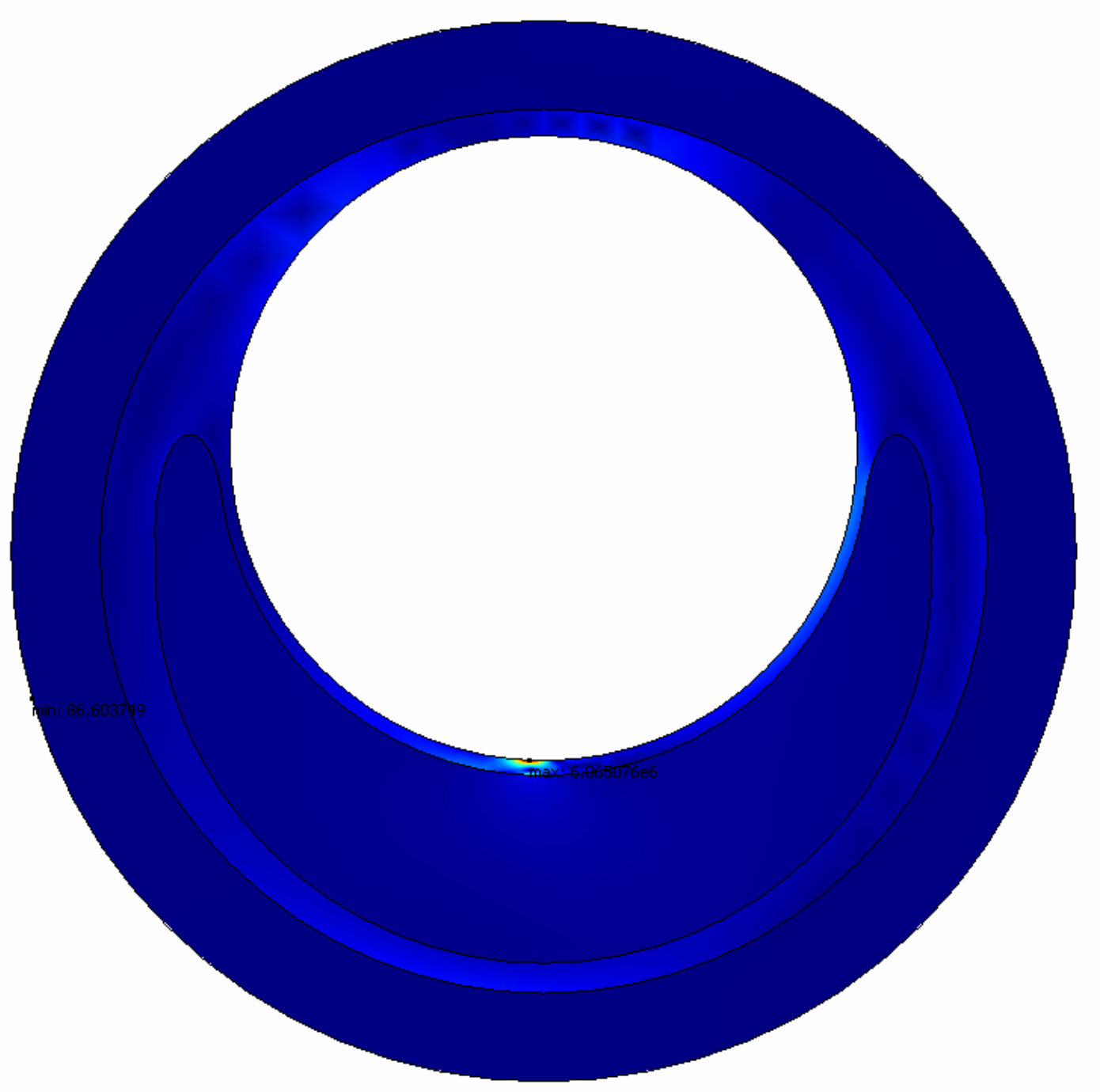


Fibrous Cap $=100 \mu \mathrm{m}$ Atheroma $=80 \%$

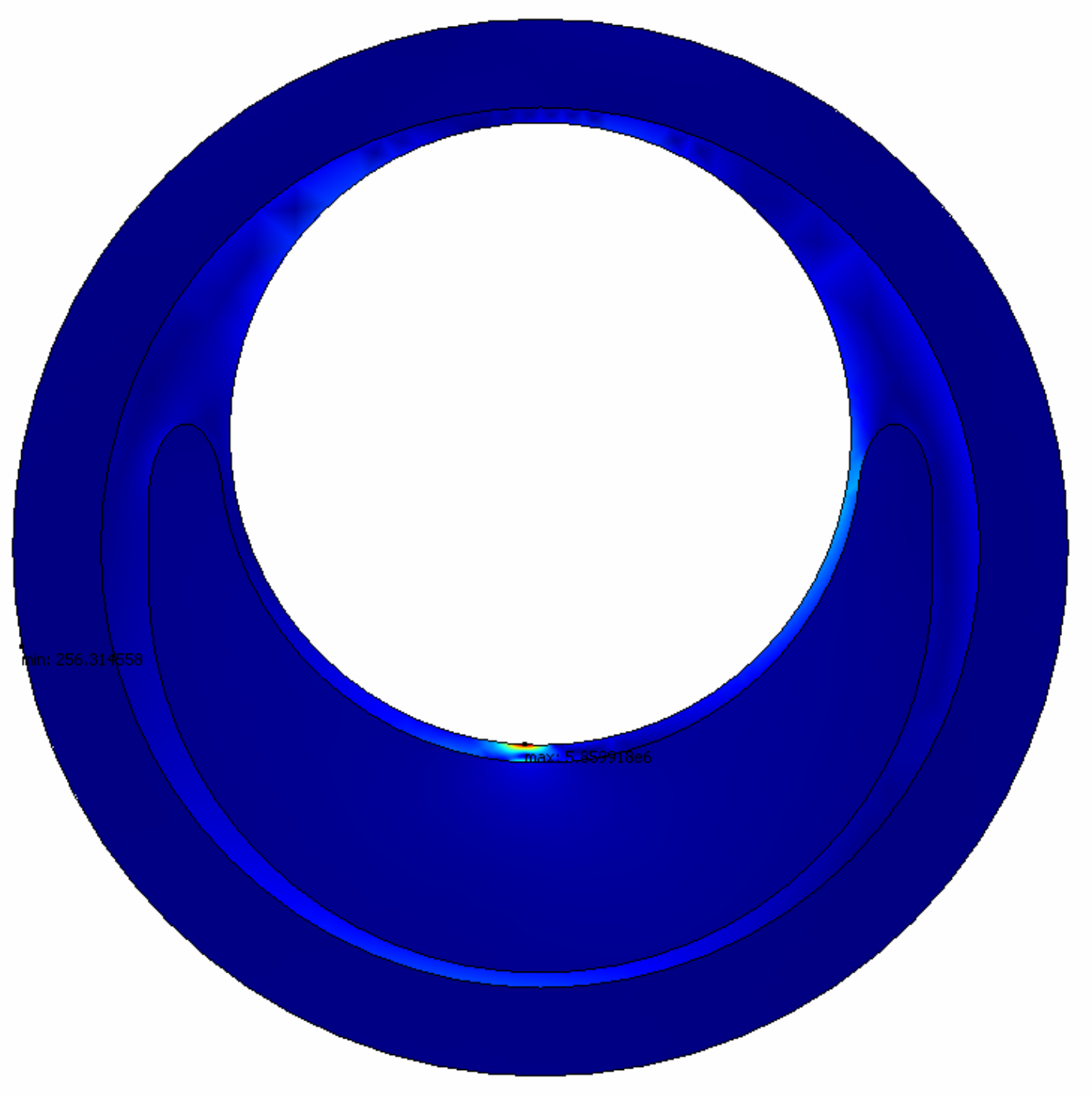


Fibrous Cap $=100 \mu \mathrm{m}$ Atheroma $=90 \%$

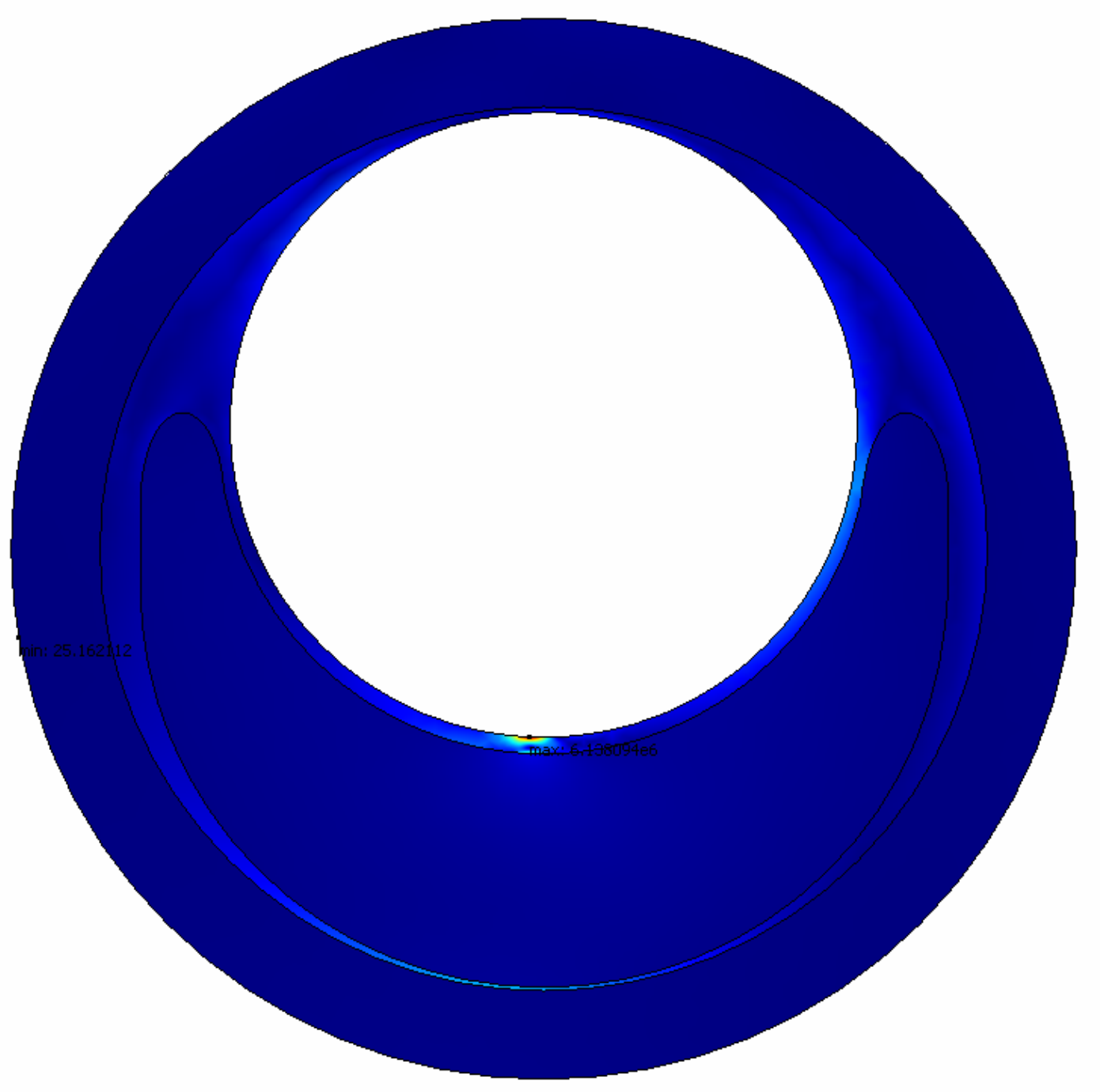


The following are the finite element analyses for a fibrous cap thickness of $200 \mu \mathrm{m}$ with a lipid concentration ranging from $10 \%$ to $90 \%$ lipid.

Fibrous Cap $=200 \mu \mathrm{m}$ Atheroma $=10 \%$

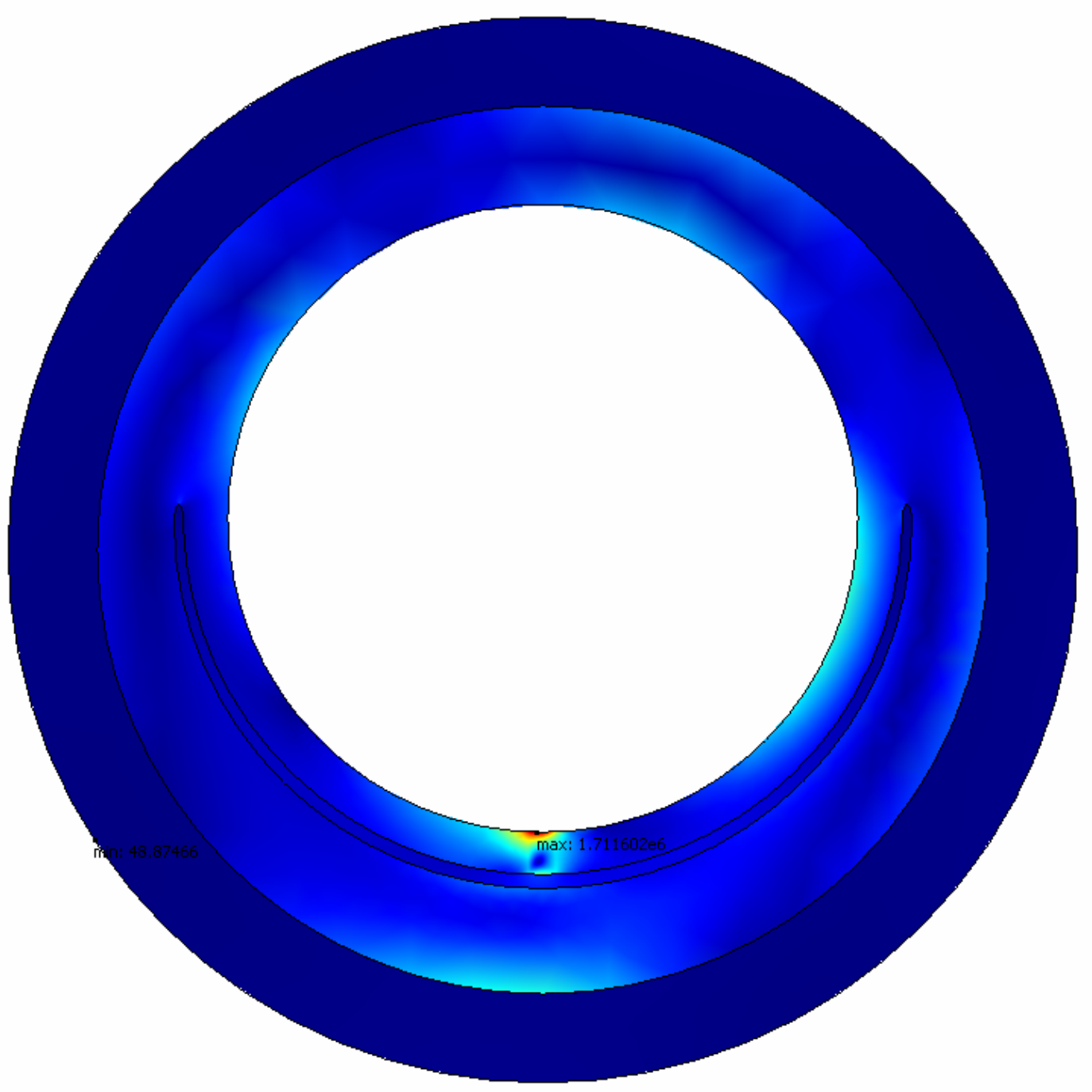


Fibrous Cap $=200 \mu m$ Atheroma $=20 \%$

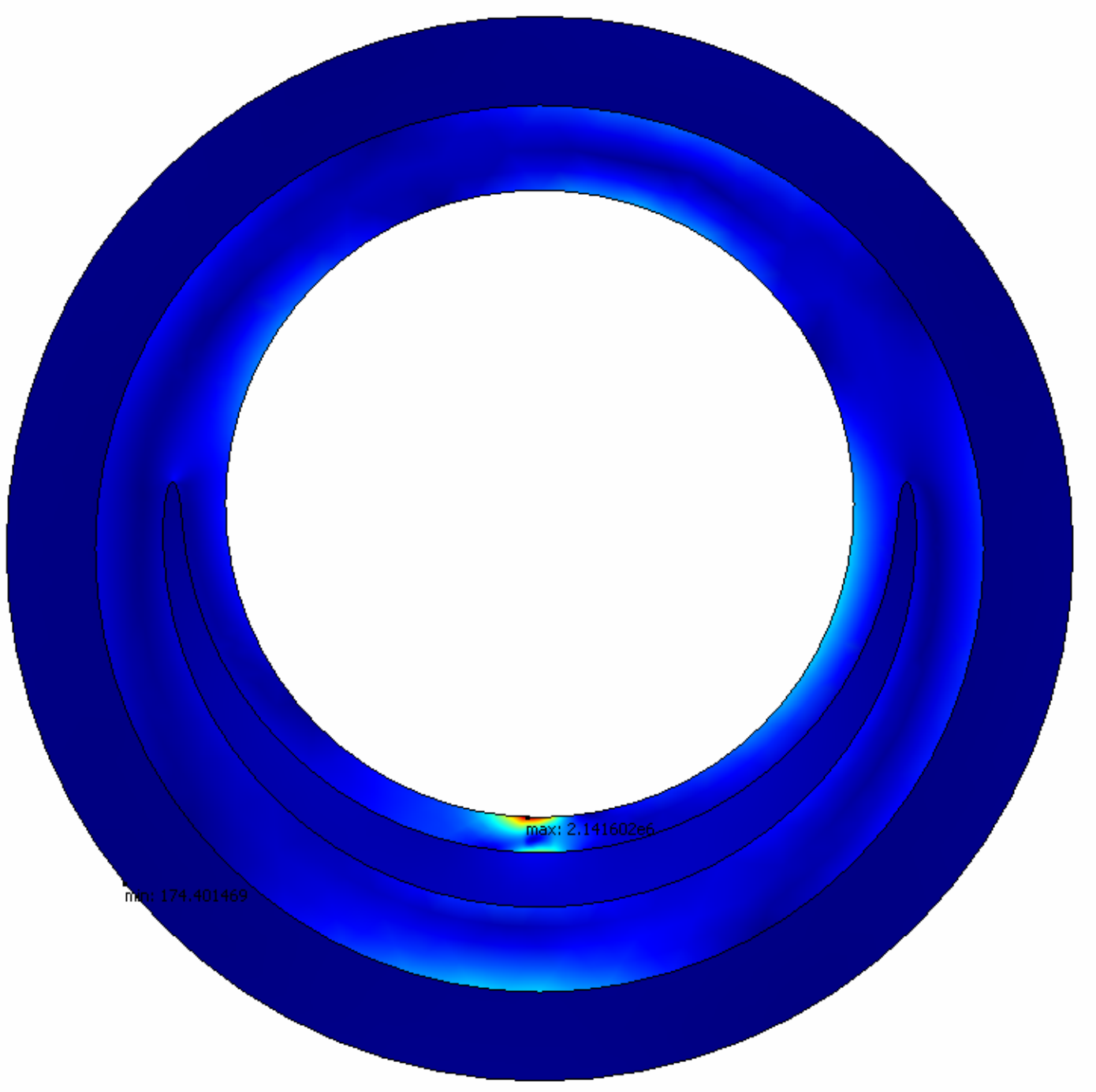


Fibrous Cap $=200 \mu \mathrm{m}$ Atheroma $=30 \%$

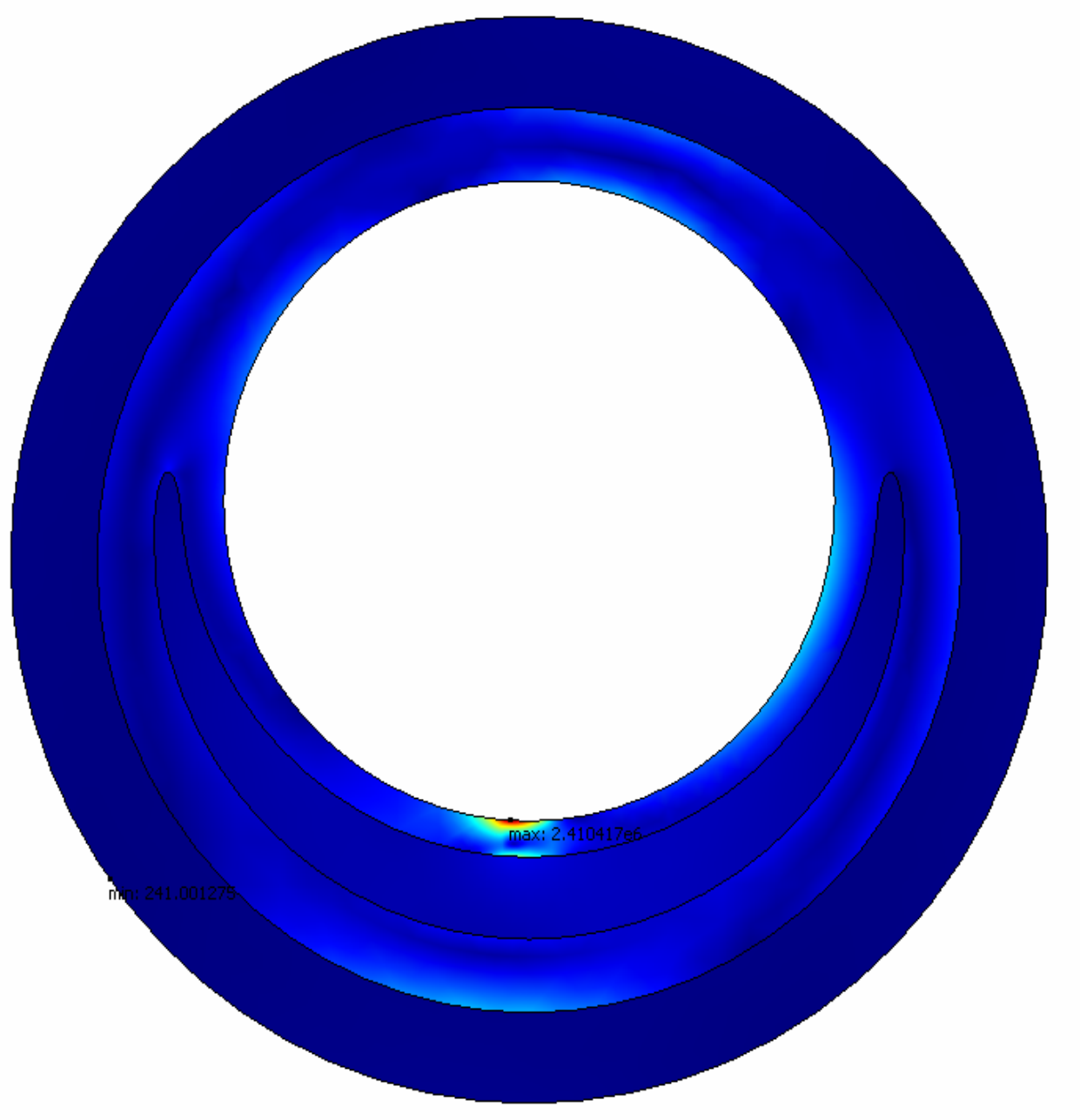


Fibrous Cap $=200 \mu \mathrm{m}$ Atheroma $=40 \%$

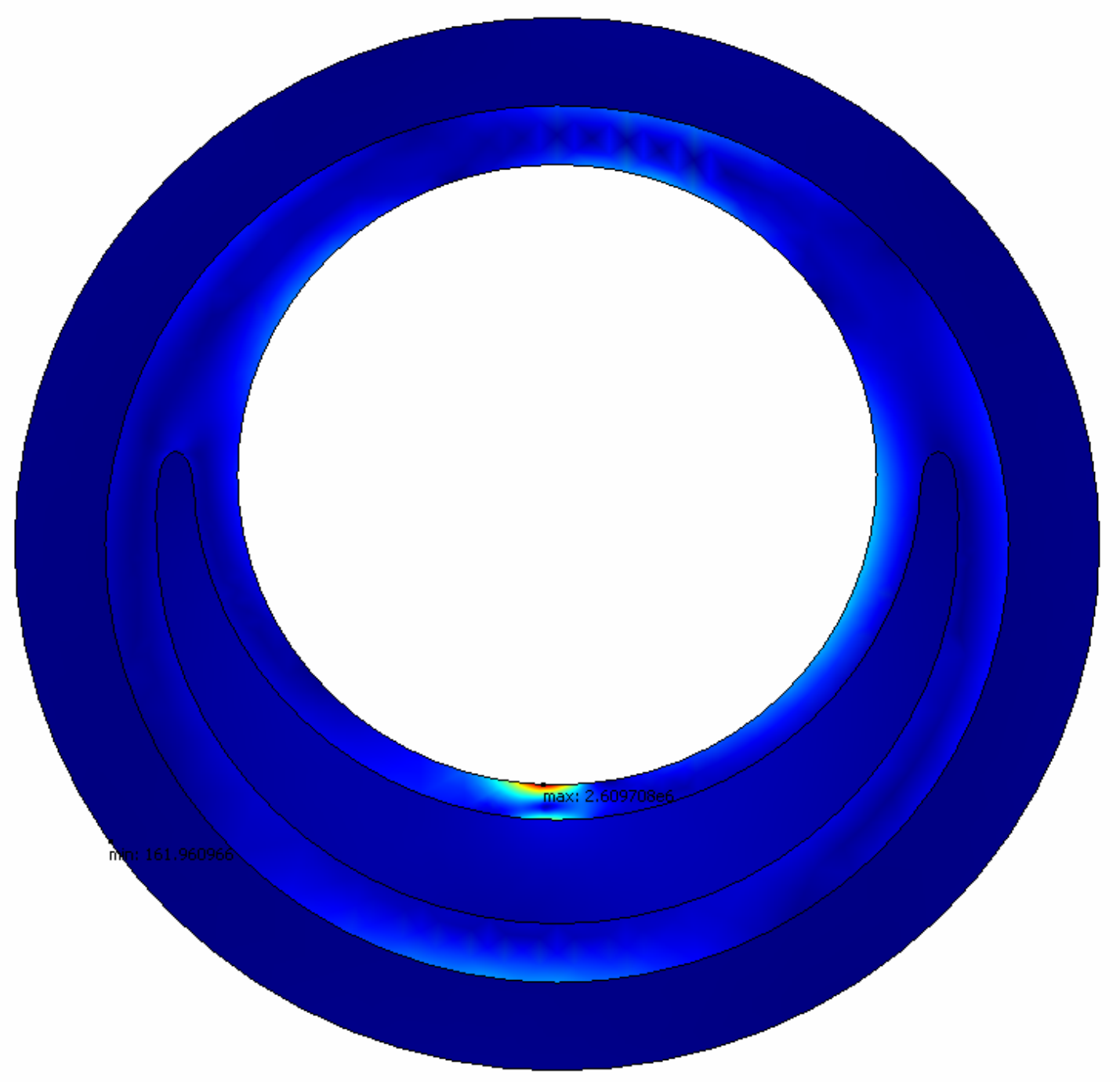


Fibrous Cap $=200 \mu \mathrm{m}$ Atheroma $=50 \%$

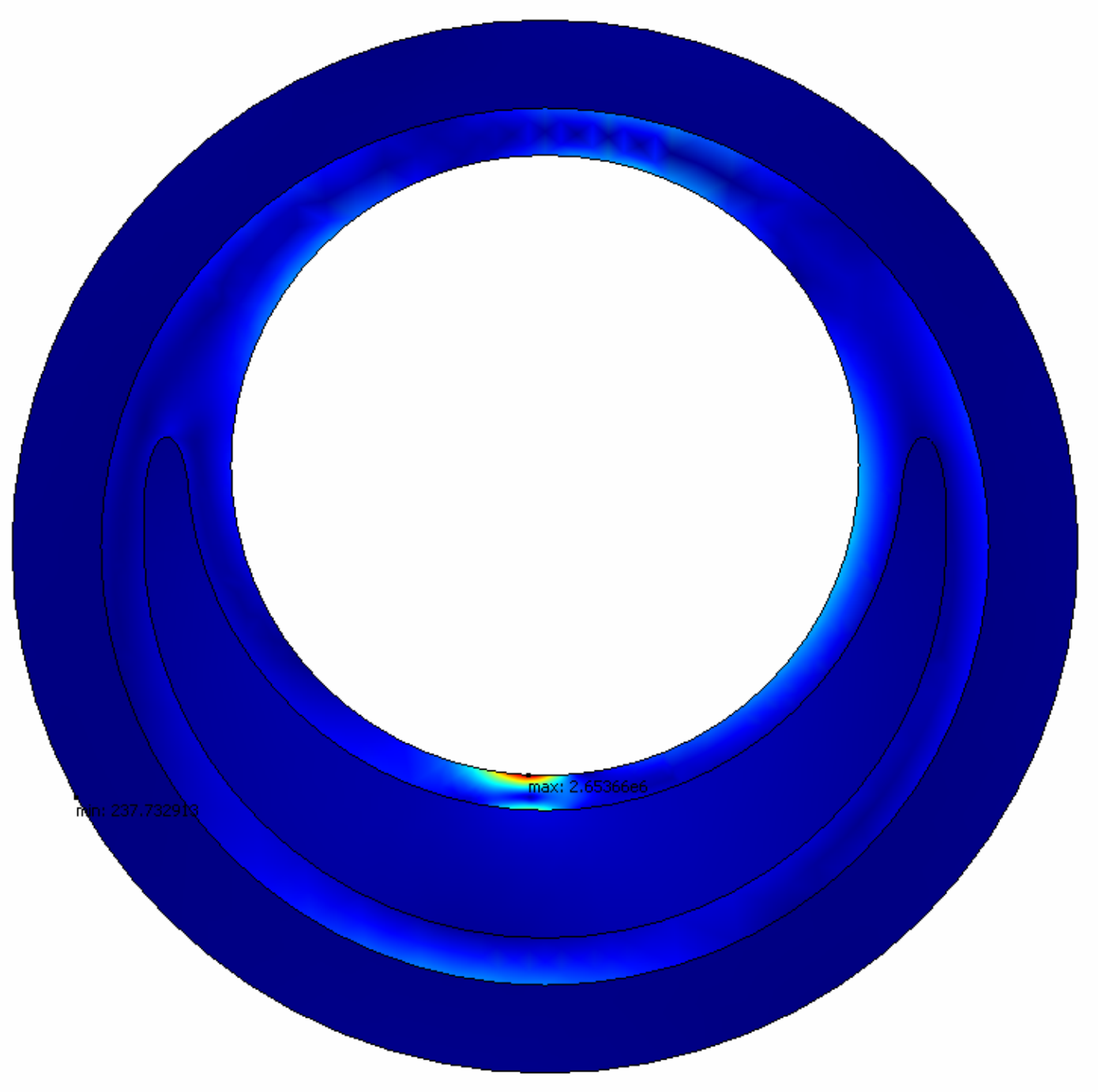


Fibrous Cap $=200 \mu \mathrm{m}$ Atheroma $=60 \%$

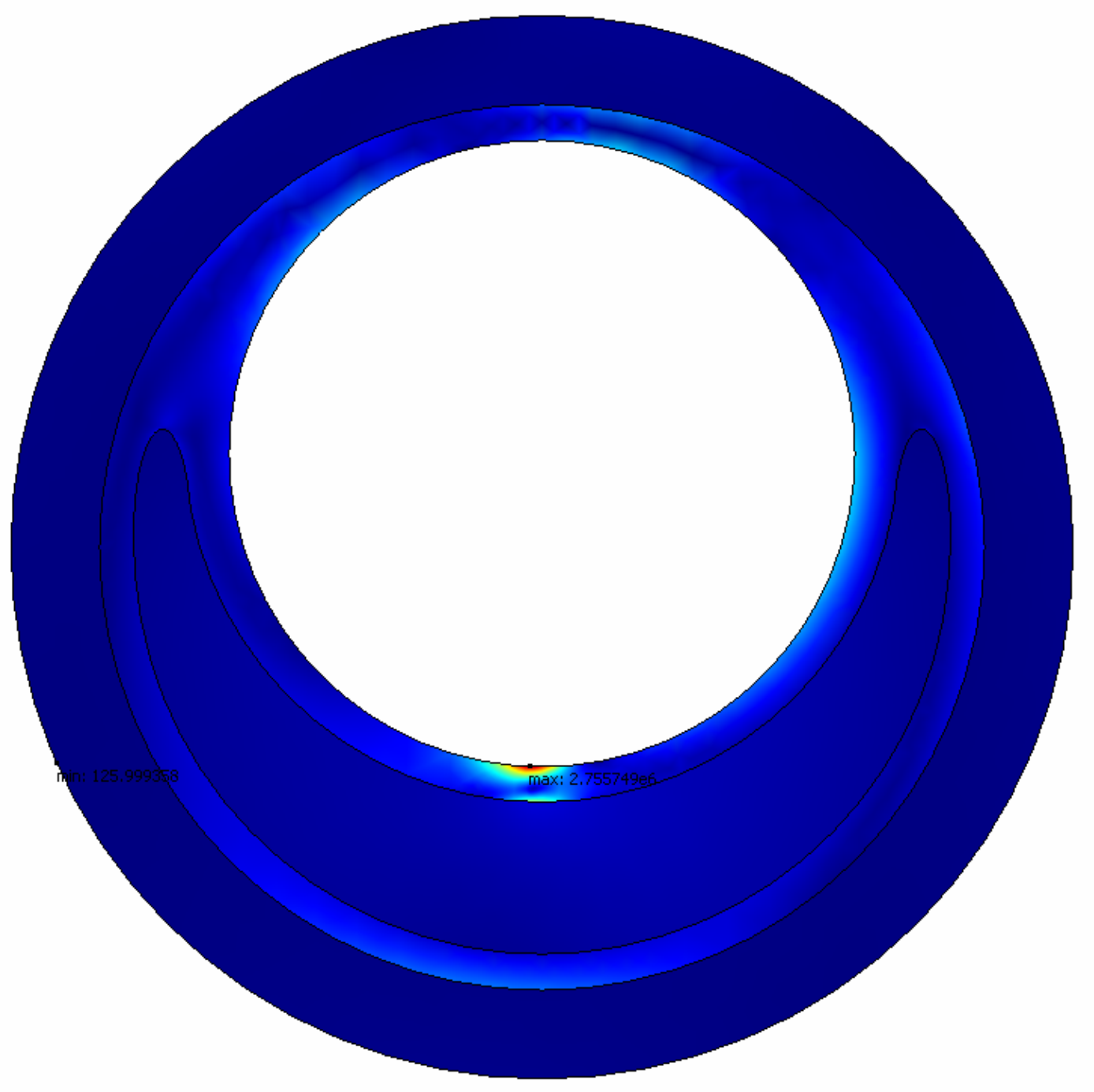


Fibrous Cap $=200 \mu \mathrm{m}$ Atheroma $=70 \%$

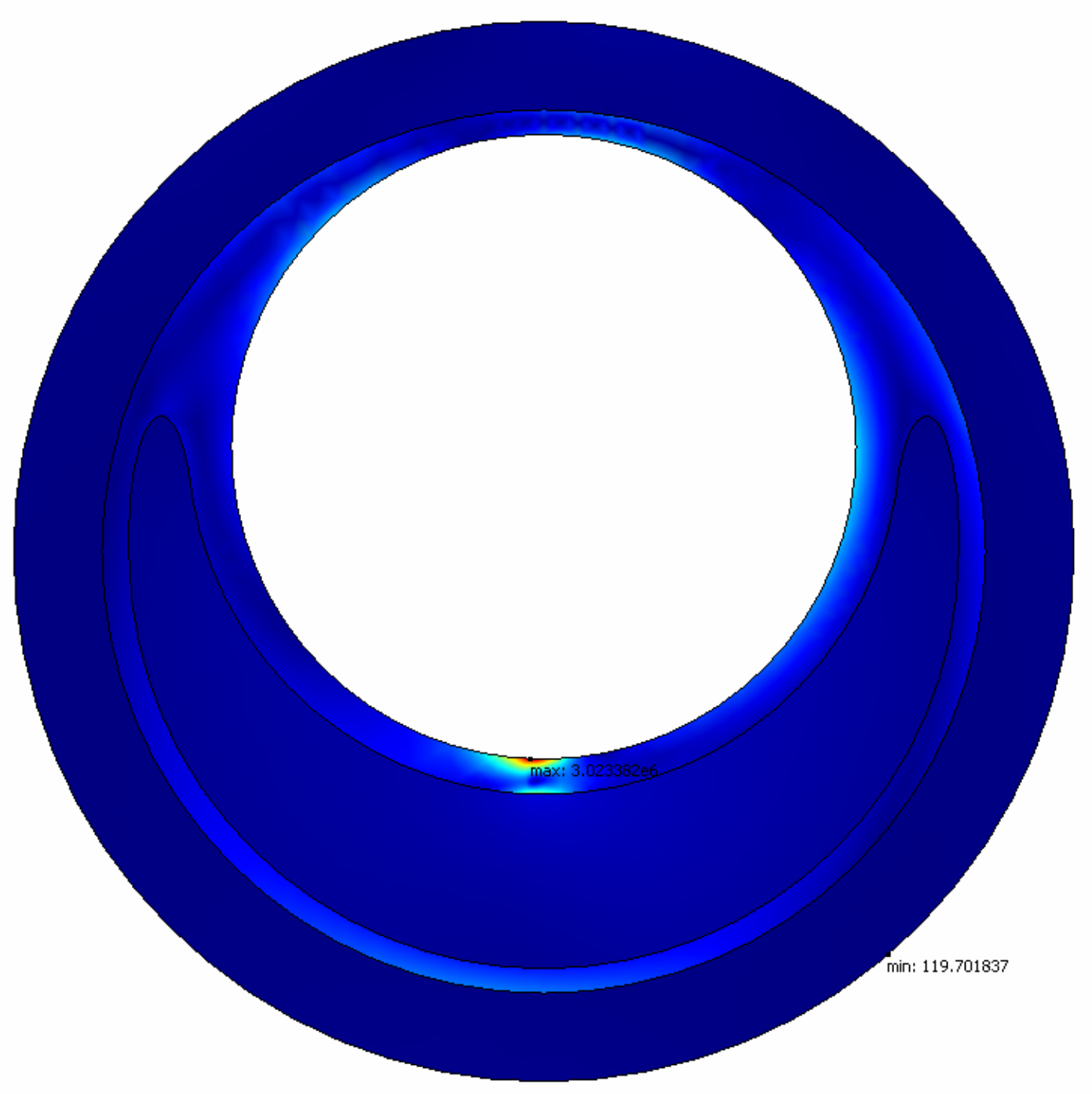


Fibrous Cap $=200 \mu \mathrm{m}$ Atheroma $=80 \%$

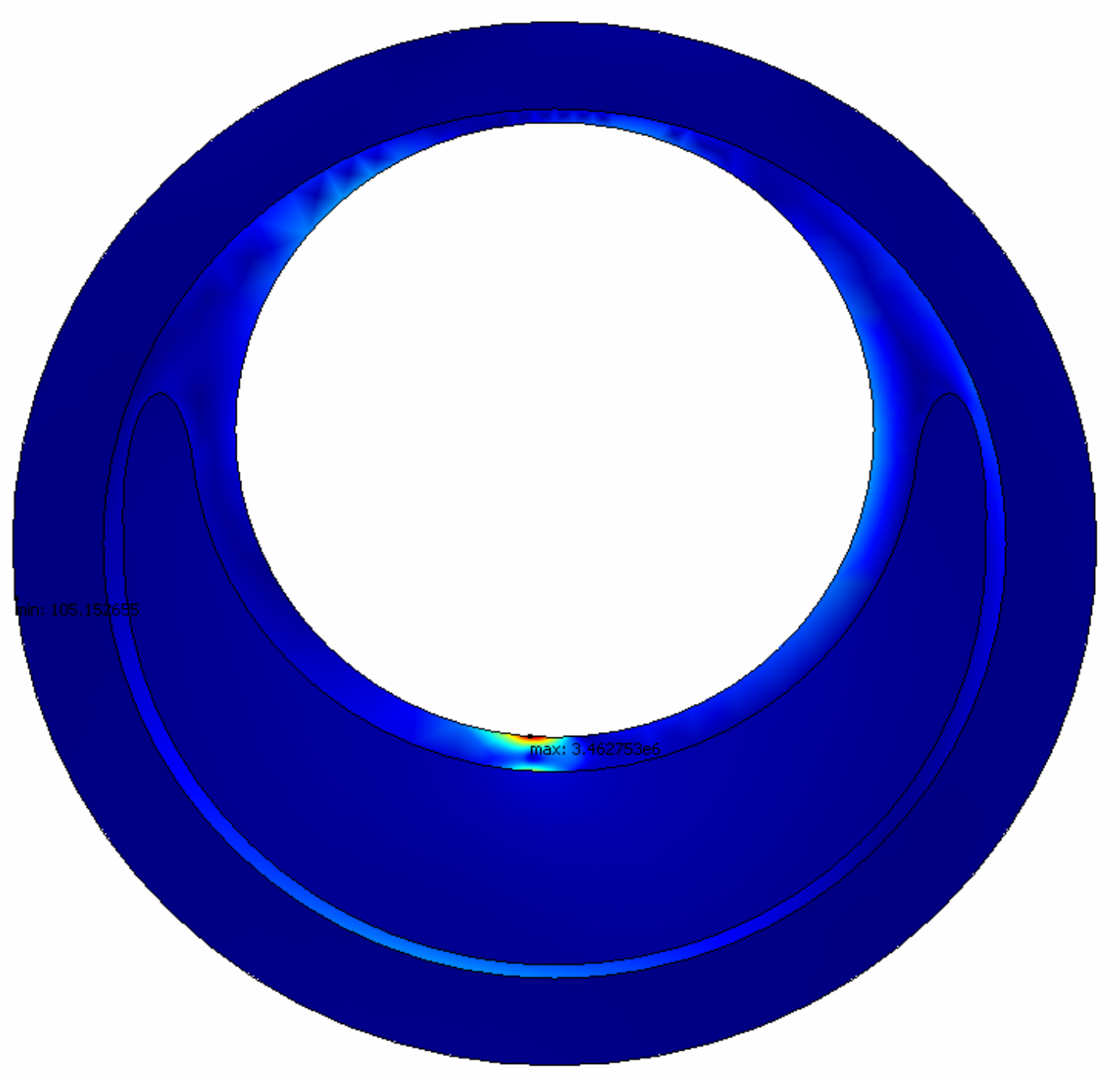


Fibrous Cap $=200 \mu \mathrm{m}$ Atheroma $=\mathbf{9 0} \%$

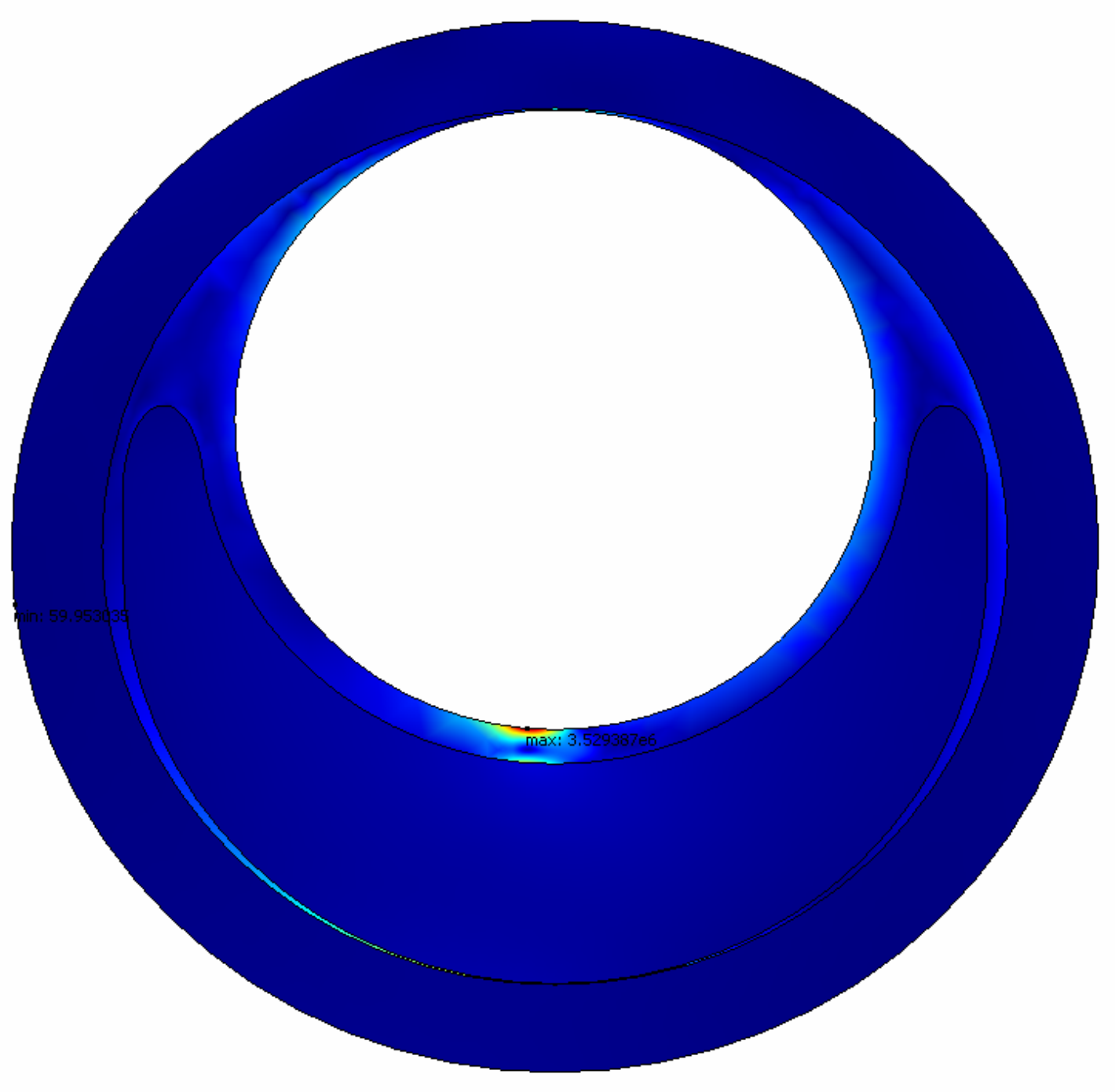


The following are the finite element analyses for a fibrous cap thickness of $250 \mu \mathrm{m}$ with a lipid concentration ranging from $10 \%$ to $90 \%$ lipid.

Fibrous Cap $=200 \mu \mathrm{m}$ Atheroma $=10 \%$

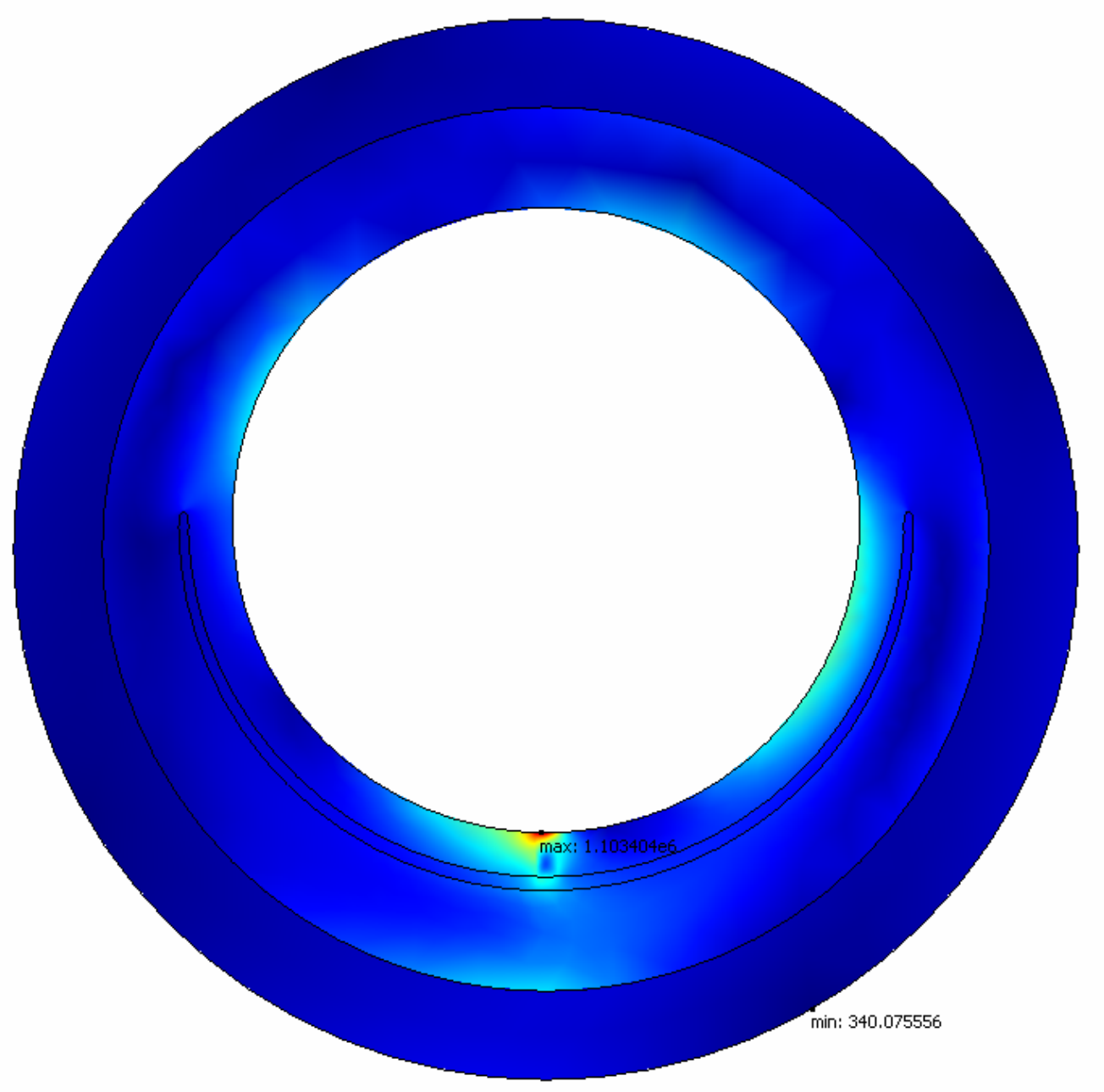


Fibrous Cap $=200 \mu m$ Atheroma $=20 \%$

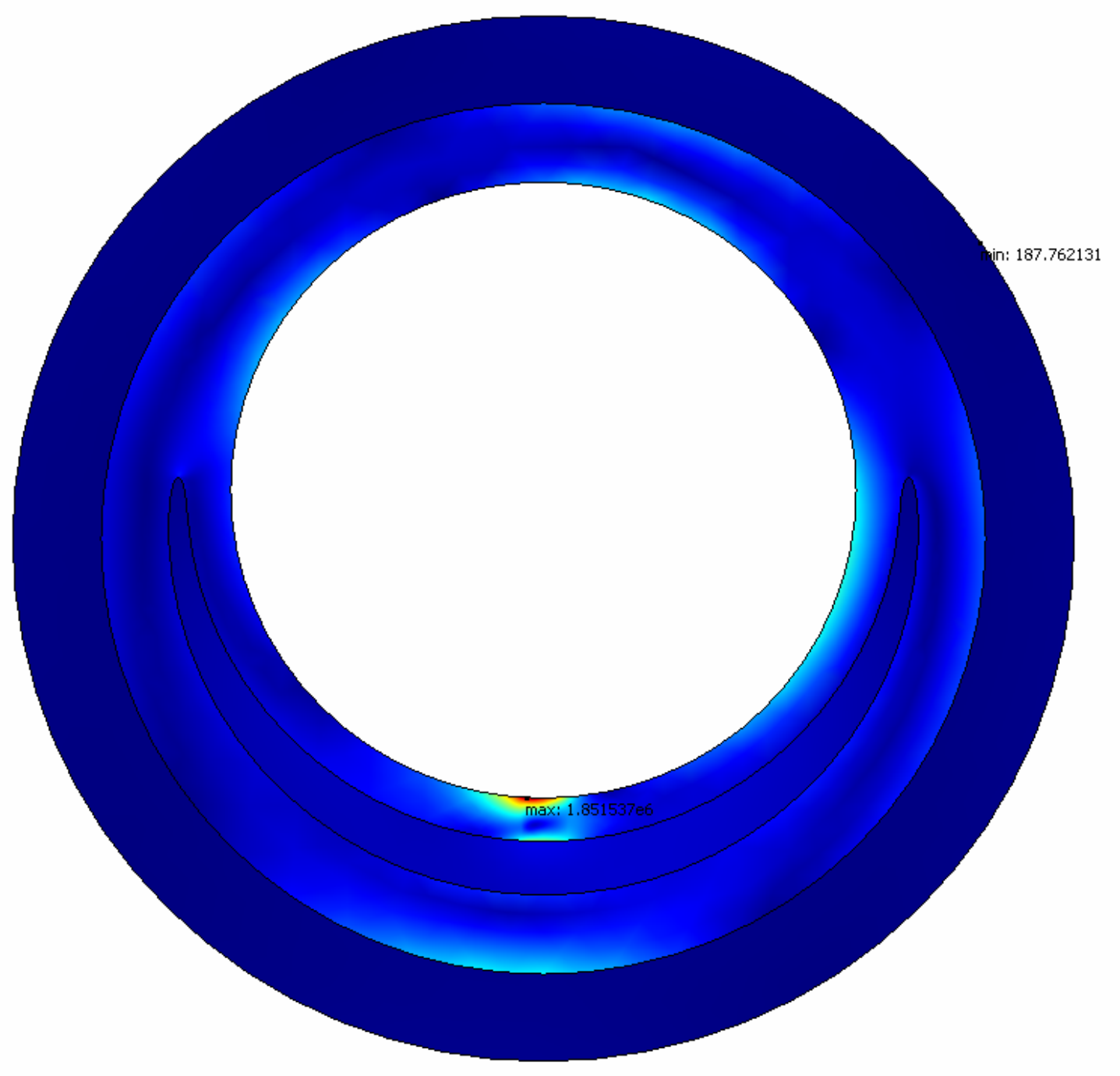


Fibrous Cap $=200 \mu \mathrm{m}$ Atheroma $=30 \%$

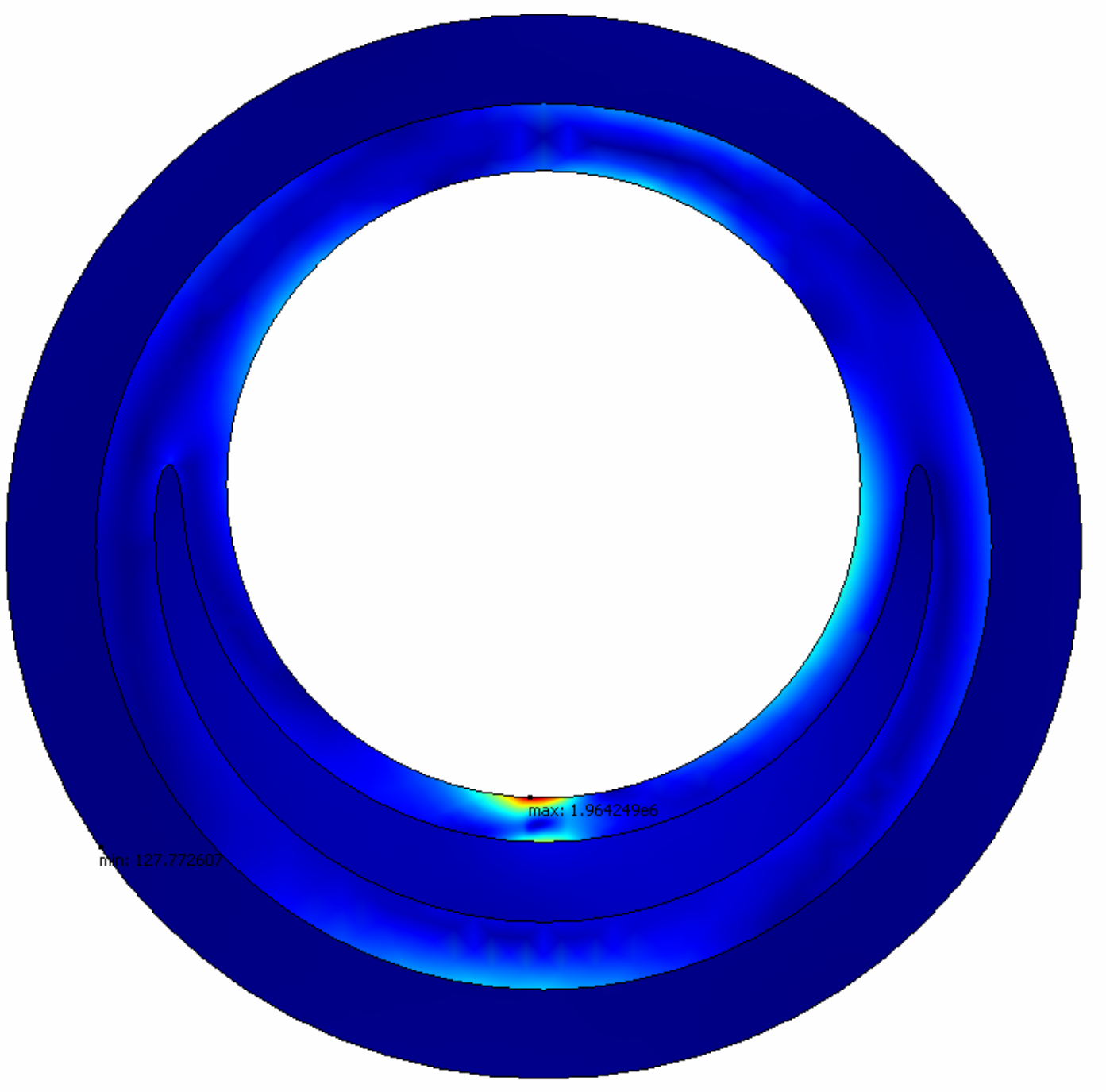


Fibrous Cap $=200 \mu \mathrm{m}$ Atheroma $=40 \%$

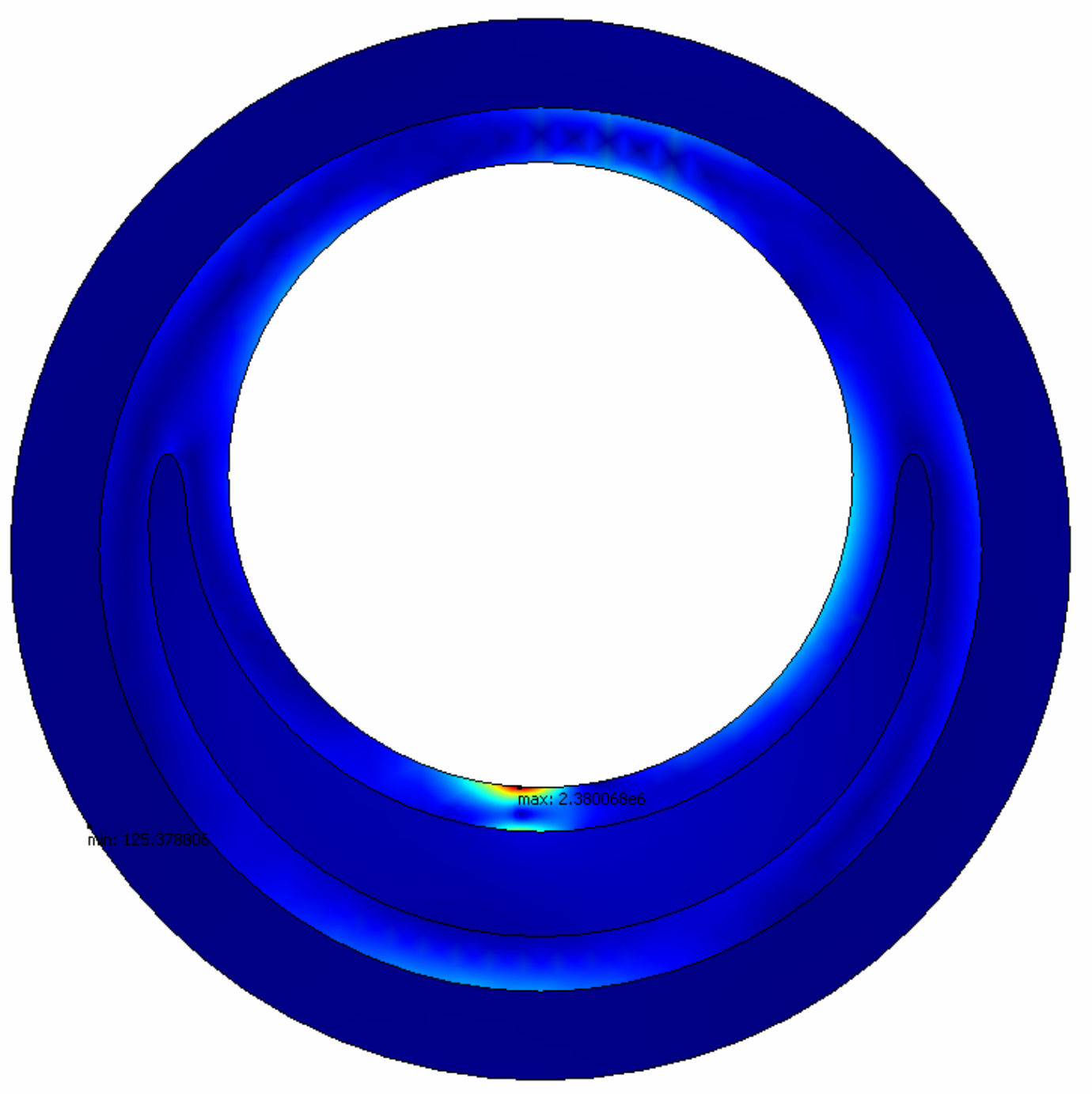


Fibrous Cap $=200 \mu \mathrm{m}$ Atheroma $=50 \%$

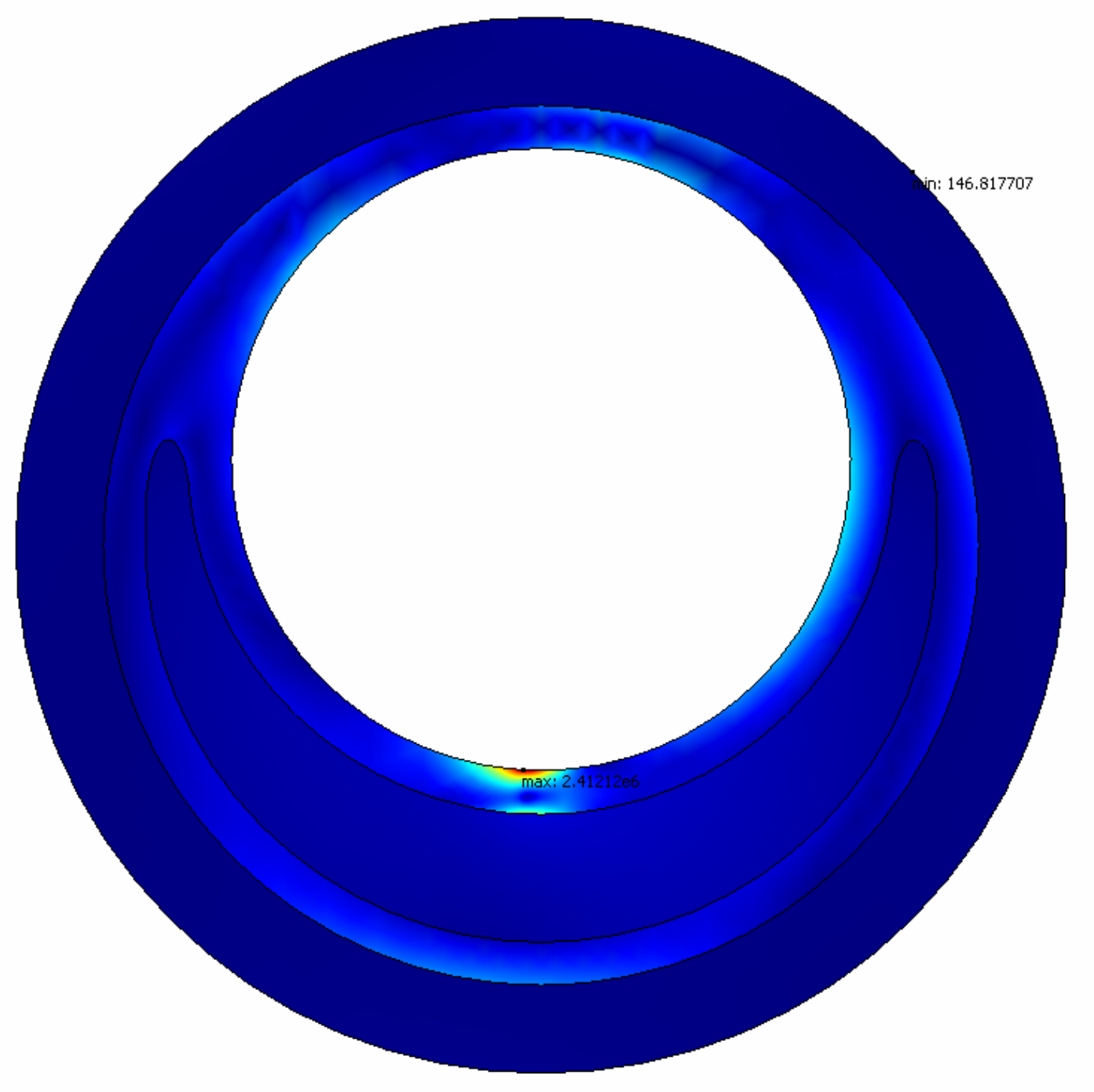


Fibrous Cap $=200 \mu \mathrm{m}$ Atheroma $=60 \%$

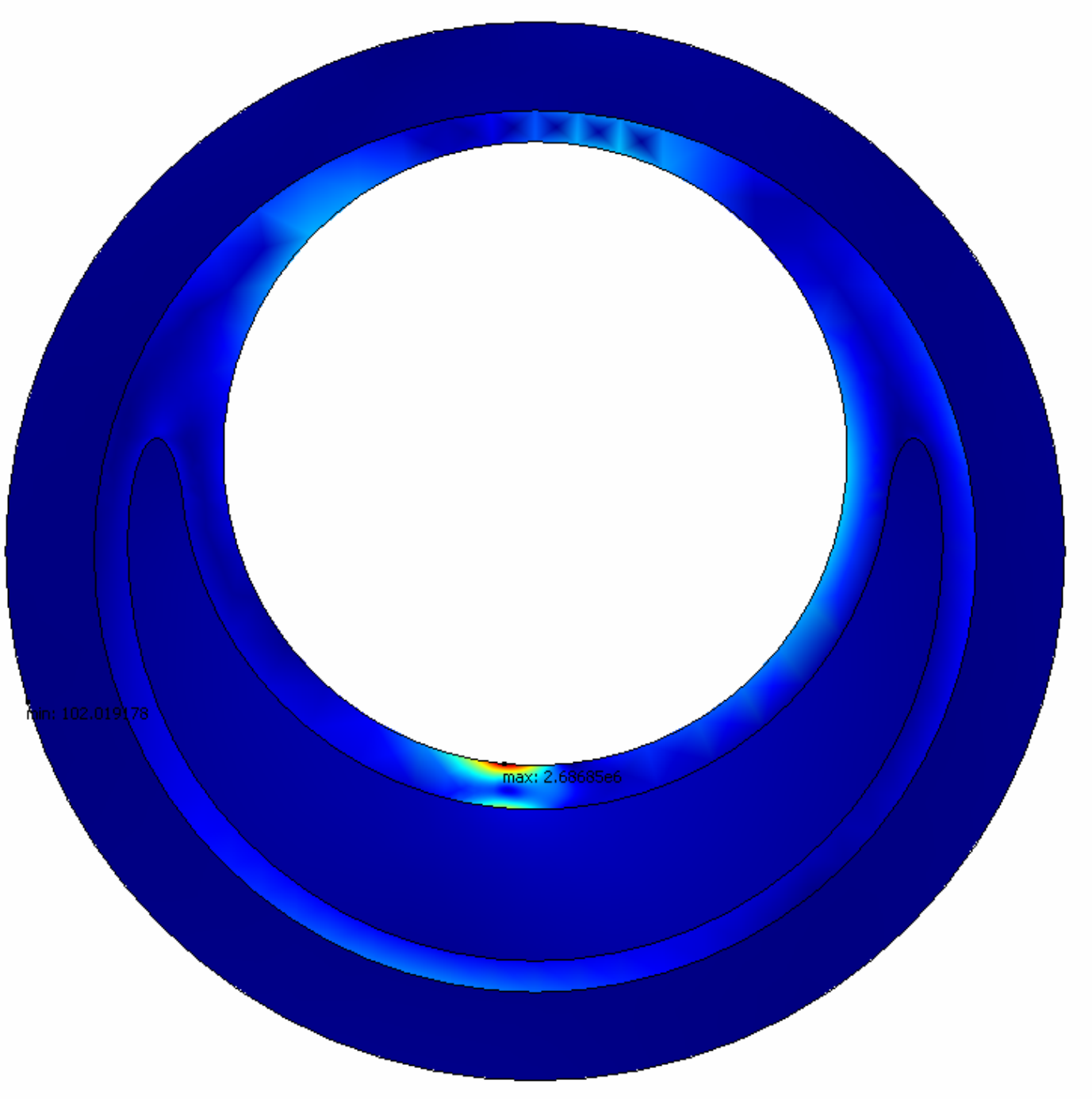


Fibrous Cap $=200 \mu \mathrm{m}$ Atheroma $=70 \%$

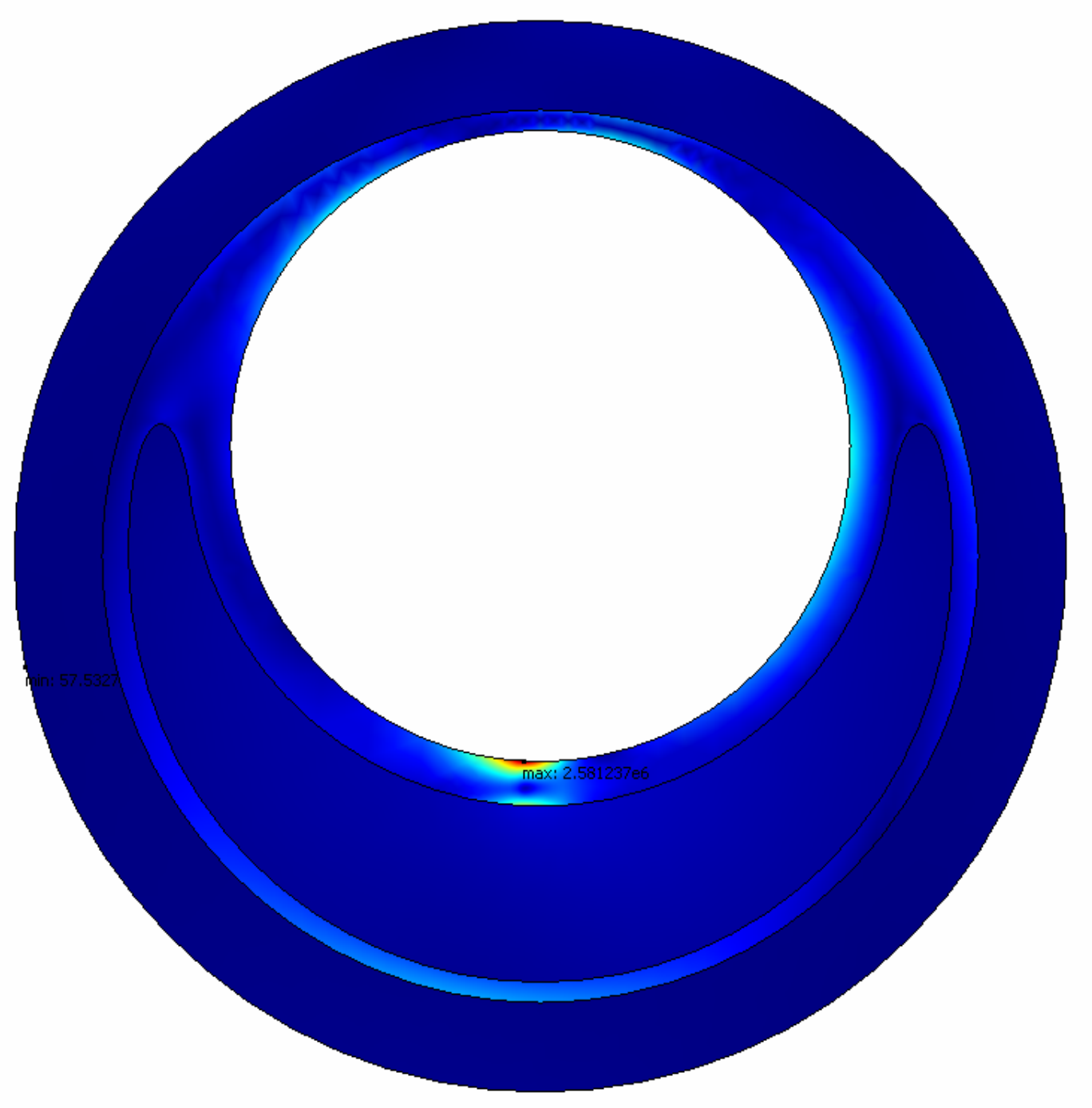


Fibrous Cap $=200 \mu \mathrm{m}$ Atheroma $=\mathbf{8 0} \%$

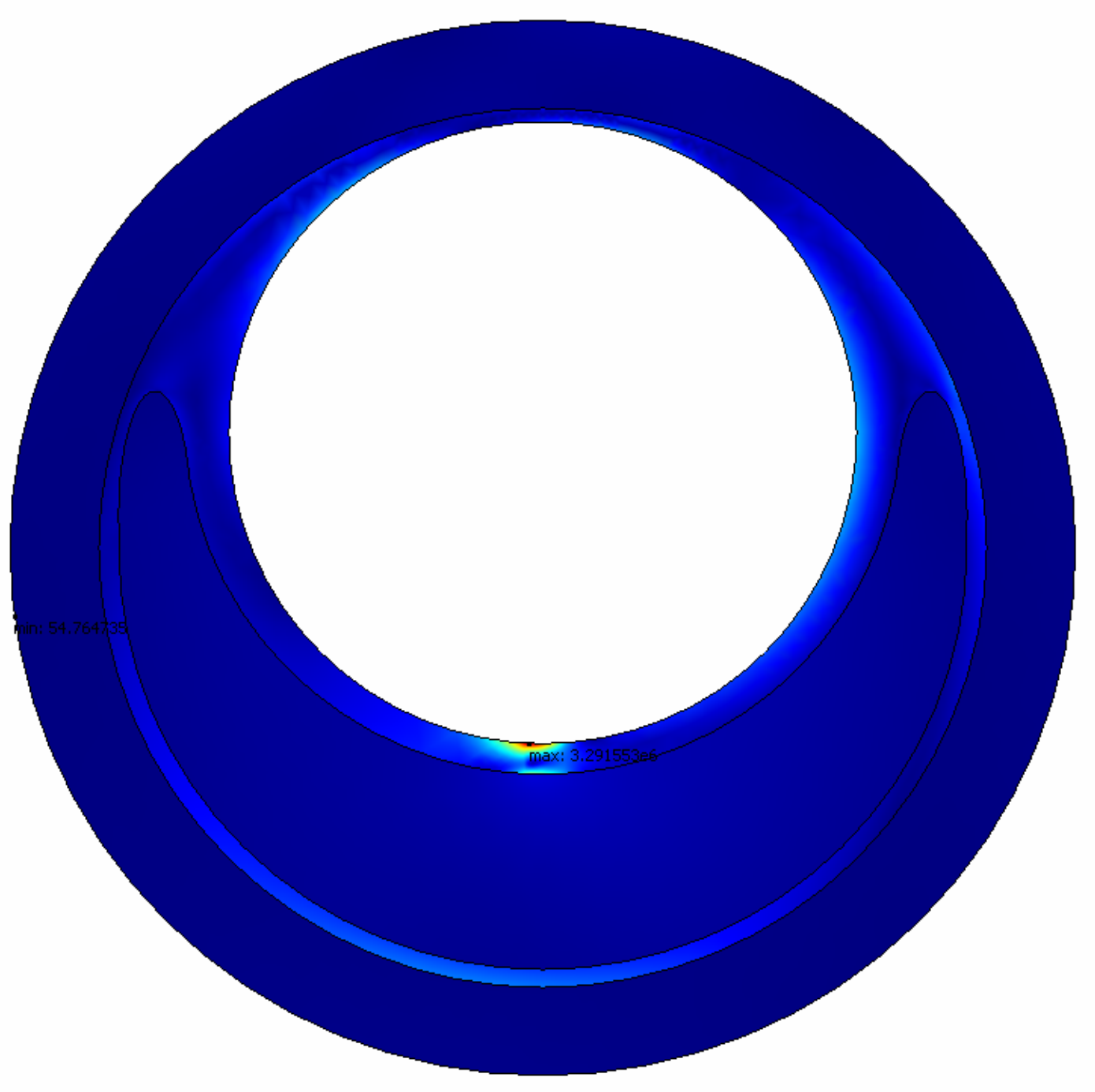


Fibrous Cap $=200 \mu \mathrm{m}$ Atheroma $=90 \%$

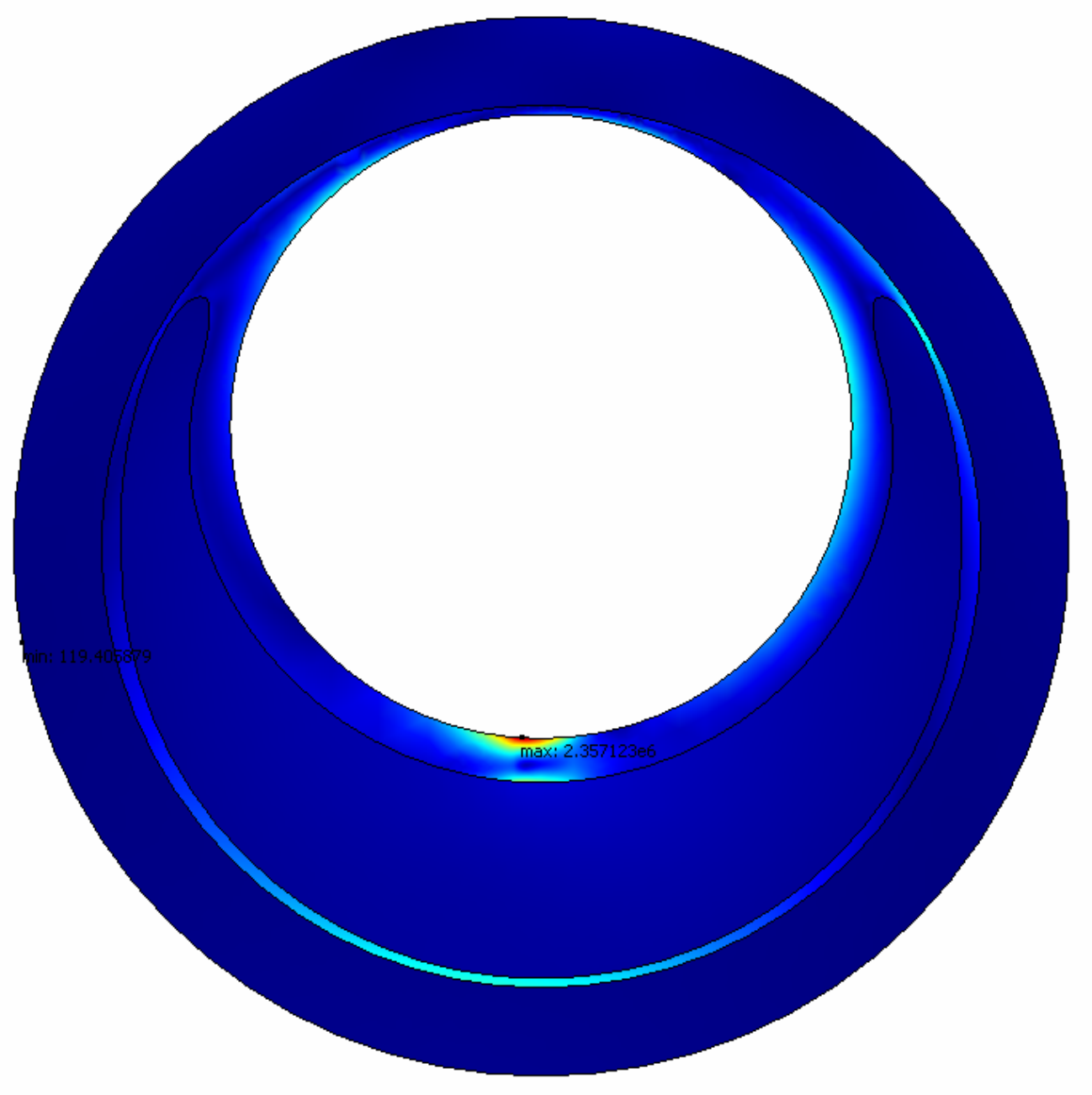




\section{REFERENCES}

1. Baldewsing, Radj A., Chris L. de Korte, Johannes A. Schaar, Frits Mastik, Antonius F. W. van Der Steen. A finite element model for performing intravascular ultrasound elastography of human atherosclerotic coronary arteries. Ultrasound in Medicine and Biology. 30.6 (2004): 803-813.

2. Baldewsing, Radj A., Johannes A. Schaar, Frits Mastik, Cees W. J. Oomens, Antonius F. W. van der Steen. Assessment of vulnerable plaque composition by matching the deformation of a parametric plaque model to measure plaque deformation. IEEE Transactions on Medical Imaging. 24.4 (2005): 514-528.

3. Baldewsing, Radj A., Chris L. de Korte, Johannes A. Schaar, Frits Mastik, Antonius F. W. van der Steen. Finite element modeling and intravascular ultrasound elastography of vulnerable plaques: parameter variation. Ultrasonics. 42 (2004): 723-729.

4. Chatzizisis, Yiannis S., Ahmet U. Coskun, Michael Jonas, Elazer R. Edelman, Peter H. Stone, Charles L. Feldman. Risk stratification of individual coronary lesions using local endothelial shear stress: a 
new paradigm for managing coronary artery disease. Current Opinion in Cardiology. 22.6 (2007): 552-564.

5. Chau, Alexandra H., Raymond C. Chan, Milen Shishkov, Brian MacNeill, Nicusor Iftimia, Guillermo J. Tearney, Roger D. Kamm, Brett E. Bouma, Mohammad R. Kaazempur-Mofrad. Mechanical analysis of atherosclerotic plaques based on optical coherence tomography. Annals of Biomedical Engineering. 32.11 (2004): 1494-1503.

6. Coronary Heart Disease. Encyclopedia Britannica. 2008. Encyclopedia Britannica Online. March 2008.

7. De Korte, Chris L., Anton F. W. van der Steen. Intravascular ultrasound elastography: an overview. Ultrasonics. 40 (2002) 859-865.

8. Diethrich, Edward B., M. Paulina Margolis, Donald B. Reid, Allen Burke, Venkatesh Ramaiah, Julio A. Rodriquez-Lopez, Grayson Wheatley, Dawn Olsen, Renu Virmani. Virtual histology intravascular ultrasound assessment of carotid artery disease: the carotid artery plaque virtual histology evaluation (CAPITAL) study. Journal of Endovascular Therapy: an Official Journal. 14.5 (2007): 676-686. 
9. Fan, Jianglin, Teruo Watanabe. Inflammatory reactions in the pathogenesis of atherosclerosis. Journal of Atherosclerosis and Thrombosis. 10.2 (2003): 63-71.

10. Finn, Aloke V., Gaku Nakazawa, Michael Joner, Frank D. Kolodgie, Erik K. Mont, Herman K. Gold, Renu Virmani. Vascular responses to drug eluting stents: importance of delayed healing. Arteriosclerosis, Thrombosis, and Vascular Biology: Journal of the American Heart Association. 27 (2007): 1500-1510.

11. Gasser, T. Christian, Gerhard A. Holzapfel. Modeling plaque fissuring and dissection during balloon angioplasty intervention. Annals of Biomedical Engineering. 35.5 (2007): 711-723.

12. Gensini, G. F., B. Dilaghi. The unstable plaque. European Heart Journal Supplements. 4 (2002): B22-B27).

13. Gourisankaran, Vijay, M. G. Sharma. The finite element analysis of stresses in atherosclerotic arteries during balloon angioplasty. Critical Reviews in Biomedical Engineering. 28.1,2 (2000): 47-51.

14. Hansson, Goran K., Peter Libby, Uwe Schonbeck, Zhong-Qun Yan. Innate and adaptive immunity in the pathogenesis of 
atherosclerosis. Circulation Research: Journal of the American Heart Association. 91 (2002): 281-291.

15. Holzapfel, Gerhard A., Michael Stadler, Christian A. J. Schulze-Bauer. A layer-specific three-dimensional model for the simulation of balloon angioplasty using magnetic resonance imaging and mechanical testing. Annals of Biomedical Engineering. 30 (2002): 753-757.

16. Huang, Hayden, Renu Virmani, Heshan Younis, Allen P. Burke, Roger D. Kamm, Richard T. Lee. The impact of calcification on the biomechanical stability of atherosclerotic plaques. Circulation Journal of the American Heart Association. 103 (2001): 1051-1056.

17. Irshad, Khalid, Samuel Millar, Raj Velu, Allan W. Reid, Edward B. Diethrich, Donald B. Reid. Virtual histology intravascular ultrasound in carotid interventions. Journal of endovascular therapy; an official journal of the international society of endovascular specialists. 14.2 (2007): 198-207.

18. Kalidindi, S. R., E. M. Tuzcu, S. J. Nicholls. Role of imaging end points in atherosclerosis trials: focus on intravascular ultrasound. International Journal of Clinical Practice. 61.6 (2007): 951-962. 
19. Kiousis, Dimitrios E., T. Christian Gasser, Gerhard A. Holzapfel. A numerical model to study the interaction of vascular stents with human atherosclerotic lesions. Annals of Biomedical Engineering. 35.11 (2007): 1857-1869.

20. Lally, C., F. Dolan, P.J. Prendergast. Cardiovascular stent design and vessel stresses: a finite element analysis. Journal of Biomechanics. 38 (2005): 1574-1581.

21. Lee, RT. AJ Grodzinsky, EH Frank, RD Kamm, FJ Schoen. Structuredependent dynamic mechanical behavior of fibrous caps from human atherosclerotic plaques. Circulation: Journal of the American Heart Association. 83 (1991): 1764-1770.

22. Lee, Richard T., Howard M. Loree, George C. Cheng, Eric H. Lieberman, Nicholas Jaramillo, Frederick J. Schoen. Computational structural analysis based on intravascular ultrasound imaging before in vitro angioplasty: prediction of plaque fracture locations. Journal of the American College of Cardiology. 21.3 (1993): 777782.

23. Li, Zhi-Yong, Simon Howarth, Rikin A. Trivedi, Jean M, U-King-Im, Martin J. Graves, Andrew Brown, Liqun Wang, Jonathan H. Gillard. 
Stress analysis of carotid plaque rupture based on in vivo high resolution MRI. Journal of Biomechanics. 39 (2006): 2611-2622.

24. Li, Zhi-Yong, Simon Howarth, Jean U-King-Im, Jonathan H. Gillard. Proceedings of the 2005 IEEE Engineering in Medicine and Biology $27^{\text {th }}$ Annual Conference. Shanghai, China. (2005): 2236-2239.

25. Libby, P. Changing concepts of atherogenesis. Journal of Internal Medicine. 247 (2000): 349-358.

26. Libby, Peter, Paul M. Ridker, Attilio Maseri. Inflammation and Atherosclerosis. Circulation: Journal of the American Heart Association. 105 (2002): 1135-1143.

27. Loree, HM, BJ Tobias, LJ Gibson, RD Kamm, DM Small, RT Lee. Mechanical properties of model atherosclerotic lesion lipid pools. Arteriosclerosis, Thrombosis, and Vascular Biology: Journal of the American Heart Association. 14 (1994): 230-234.

28. Lortie, Mireille, Rob S. B. Beanlands, Keiichiro Yoshinaga, Ran Klein, Jean N. Da Silva, Robert A. de Kemp. Quantification of myocardial blood flow with ${ }^{82} \mathrm{Rb}$ dynamic PET imaging. European Journal of Nuclear Medicine and Molecular Imaging. 34 (2007): 1765-1774. 
29. Mahmarian, John J. Combining myocardial perfusion imaging with computed tomography for diagnosis of coronary artery disease. Current Opinion in Cardiology. 22 (2007): 413-421.

30. Marcovina, S. M., F. Crea, J. Davignon, J. C. Kaski, W. Koenig, U. Landmesser, P. L. Peiri, J. Schulz-Menger, L. J. Shaw, J. Sobesky. Biochemical and bioimaging markers for risk assessment and diagnosis in major cardiovascular diseases: a road to integration of complementary diagnostic tools. Journal of Internal Medicine. 261 (2007): 214-234.

31. Maurice, Roch L., Elisabeth Brusseau, Gerard Finet, Guy Cloutier. On the potential of the Lagrangian Speckle Model estimator to characterize atherosclerotic plaques in endovascular elastography: in vitro experiments using an excised human carotid artery. Ultrasound in Medicine and Biology. 31.1 (2005): 85-91.

32. Maurice, Roch L., Elisabeth Brusseau, Gerard Finet, Guy Cloutier. On the potential of the Lagrangian estimator for endovascular ultrasound elastography: in vivo human coronary artery study. Ultrasound in Medicine and Biology. 33.8 (2007): 1199-1205. 
33. Nadkarni, Seemantini K., Mark C. Pierce, B. Hyle Park, Johannes F. de Boer, Peter Whittaker, Brett E. Bouma, Jason E. Bressner, Elkan Halpern, Stuart L. Houser, Guillermo J. Tearney. Measurement of collagen and smooth muscle cell content in atherosclerotic plaques using polarization-sensitive optical coherence tomography. Journal of the American College of Cardiology. 49.13 (2007): 1474-1481.

34. Naghavi, Morteza, Peter Libby, et al. From vulnerable plaque to vulnerable patient: a call for new definitions and risk assessment strategies: part II. Circulation: Journal of the American Heart Association. 108 (2003): 1772-1778.

35. Naghavi, Morteza, Peter Libby, et al. From vulnerable plaque to vulnerable patient: a call for new definitions and risk assessment strategies: part II. Circulation: Journal of the American Heart Association. 108 (2003): 1664-1672.

36. Ohayon, Jacques, Oliver Dubreuil, Philippe Tracqui, Simon Le Floc'h, Gilles Rioufol, Lara Chalabreysse, Francoise Thivolet, Roderic I. Pettigrew, Gerard Finet. Influence of residual stresss/strain on the biomechanical stability of vulnerable coronary plaques: potential impact for evaluating the risk of plaque rupture. American Journal 
of Physiology - Heart and Circulatory Physiology. 293 (2007):

H1987-H1996.

37. Ohayon, Jacques, Pierre Teppaz, Gerard Finet, Gilles Rioufol. In-vivo prediction of human coronary plaque rupture location using intravascular ultrasound and the finite element method. Coronary Artery Disease. 12.8 (2001): 655-663.

38. Saijo, Yoshifumi, Esmeraldo Santos Filho, Hidehiko Sasaki, Tomoyuki, Yambe, Motanao Tanaka, Naohirom Hozumi, Kazuto Kobayashi, Nagaya Okada. Ultrasonic tissue characterization of atherosclerosis by a speed-of-sound microscanning system. IEEE Transactions on Ultrasonics, Ferroelectrics, and Frequency Control. 54.8 (2007): 1571-1577.

39. Saijo, Yoshifumi, Toshiro Ohashi, Hidehiko Sasaki, Masaaki Sato, Claus S. Jorgensen, Shin-Ichi Nitta. Application of scanning acoustic microscopy for assessing stress distribution in atherosclerotic plaque. Annals of Biomedical Engineering. 29 (2001): 1048-1053.

40. Salunke, N. V. and L. D. T. Topoleski. Biomechanics of Atherosclerotic Plaque. Critical Reviews in Biomedical Engineering. 25.3 (1997): 243-285. 
41. Schaar, Johannes A., Chris L. deKorte, Frits Mastik, Chaylendra Strijder, Gerard Pasterkamp, Eric Boersma, Patrick W. Serruys, Anton F. W. van der Steen. Circulation: Journal of the American Heart Association. 108 (2003) 2636-2641.

42. Shah, Prediman K. Pathophysiology of plaque rupture and the concept of plaque stabilization. Cardiology Clinics. 14.1 (1996): 17-29.

43. Stary, Herbert C., A. Bleakley Chandler, Robert E. Dinsmore, Valentin Fuster, Seymour Glagov, William Insull, Jr., Michael E. Rosenfeld, Colin J. Schwartz, William D. Wagner, Robert W. Wissler. A definition of advanced types of atherosclerotic lesions and a histological classification of atherosclerosis. Circulation: Journal of the American Heart Association. 92 (1995): 1355-1374.

44. Tang, Dalin; Chun Yang, Jie Zheng, Jie, Pamela K. Woodard, Gragorio A. Sicard, Jeffrey E. Saffitz, Chun Yuan. 3D MRI-Based Multicomponent FSI Models for Atherosclerotic Plaques. Annals of Biomedical Engineering. 32.7 (2004): 947-960.

45. Trivedi, Rikin A., Zhi-Yong Li, Jean U-King-Im, Marin J. Graves, Peter J. Kirkpatrick, Jonathan H. Gillard. Identifying vulnerable carotid 
plaques in vivo using high resolution magnetic resonance imagingbased finite element analysis. Journal of Neurosurgery. 107.3 (2007): 536-542. 